\title{
NBSIR 80-2093
}

\section{Analysis of Computer-Simulated Thermal Performance of The Norris Cotton Federal Office Building}

William B. May, Jr.

Building Thermal Performance Division Center for Building Technology National Engineering Laboratory National Bureau of Standards U.S. Department of Commerce Washington, DC 20234

and

Lawrence G. Spielvogel, P.E.

Lawrence G. Spielvogel, Inc.

Consulting Engineers

Wyncote, PA 19095

November 1980

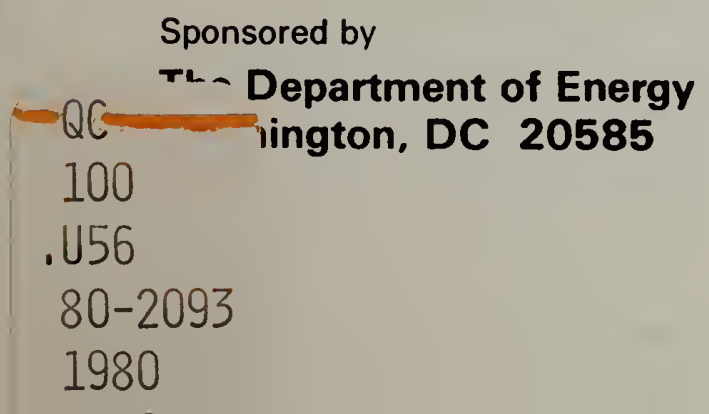



William B. May, Jr.

Building Thermal Performance Division

Center for Building Technology National Engineering Laboratory National Bureau of Standards U.S. Department of Commerce Washington, DC 20234

and

Lawrence G. Spielvogel, P.E.

Lawrence G. Spielvogel, Inc.

Consulting Engineers

Wyncote, PA 19095

November 1980

Sponsored by

The Department of Energy

Washington, DC 20585

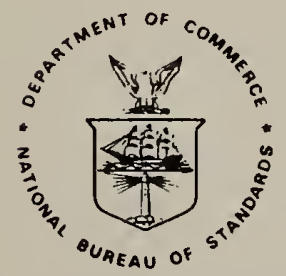

U.S. DEPARTMENT OF COMMERCE, Philip M. Klutznick, Secretary Luther H. Hodges, Jr., Deputy Secretary Jordan J. Baruch. Assistant Secretary for Productivity. Technology. and Innovation 
$-\quad \ldots+1=\ldots$

(1)

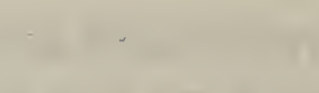

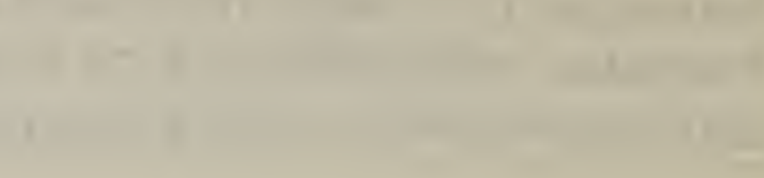

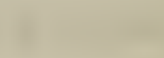

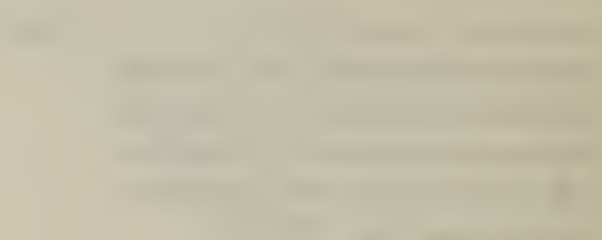

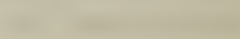
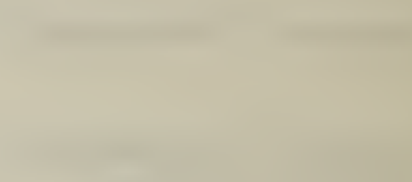

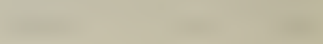

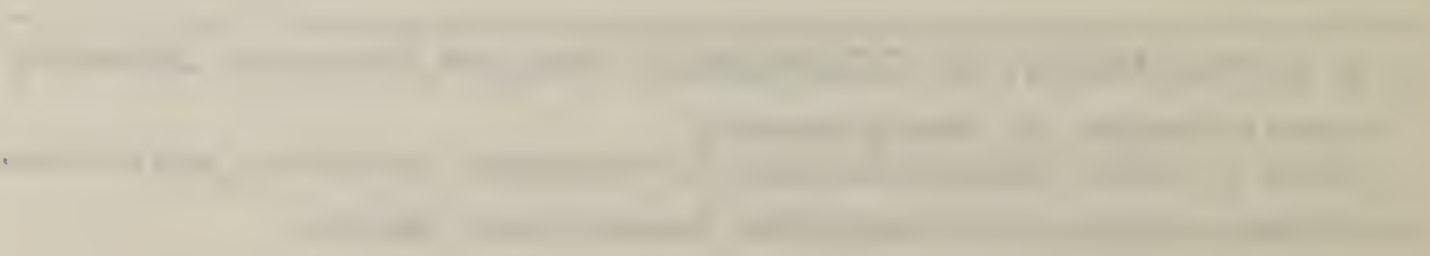




\section{ABSTRACT}

Five computer-based energy simulations of the Norris Cotton Federal office Building (NCFOB) in Manchester, New Hampshire, were performed using the Ross Meriwether Energy Systems Analysis Program. The NCFOB is a medium-size office building, occupied in September 1976, designed to serve as a demonstration of and feasibility test for energy-conserving building features. The simulations included two in accordance with the original design, with and without a solar system; a simulation of the building as actually operated; a simulation of the building with modifications to actual operation; and a simulation of an alternative building design. Results of the five simulations are compared with each other and with actual measured data at several levels of detail including total energy consumption, consumption by fuel type, and heating and cooling requirements. Good agreement between the simulation and actual data is denonstrated and consequences of design features are discussed.

Key Words: Building models; building performance data; computer simulations, building; energy conservation in commercial buildings; heat pumps; validation of computer models, buildings. 


\section{PREFACE}

This report is one of a series of reports documenting National Bureau of Standards (NBS) research and analysis efforts in developing energy and cost data in support of the Department of Energy (DoE)/NBS Building Energy Conservation Criteria Program. The work described in this report was reported by DoE/NBS Task Order No. A 008-BCS under Interagency Agreement No. EA 77 A 016010 . 
LIST OF TABLES

vi

LIST OF FIGURES

1. INTRODUCTION $\ldots \ldots \ldots \ldots \ldots \ldots \ldots \ldots \ldots \ldots \ldots \ldots \ldots \ldots \ldots \ldots \ldots \ldots \ldots \ldots$

2. DESCRIPTION OF NORRIS COTTON FEDERAL OFFICE BUILDING ........

3. DESCRIPTION OF COMPUTER SIMULATIONS $\ldots \ldots \ldots \ldots \ldots \ldots \ldots \ldots \ldots \ldots \ldots \ldots \ldots$

4. OVERALl ENERGY CONSUMPTION ......................... 10

5. HEATING AND COOLING ENERGY REQUIREMENTS .................. 14

6. COMPONENTS OF FUEL ENERGY USE AT THE NCFOB ................ 19

7. COMPONENTS OF TOTAL ENERGY USE AT THE NCFOB .............. 20

8. CONCLUSIONS $\ldots \ldots \ldots \ldots \ldots \ldots \ldots \ldots \ldots \ldots \ldots \ldots \ldots \ldots \ldots \ldots \ldots \ldots \ldots \ldots \ldots \ldots . \ldots \ldots . \ldots \ldots$

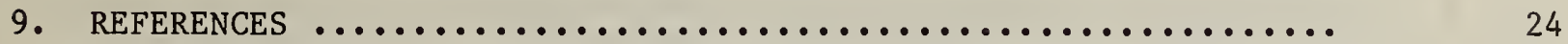


1. Important input parameters for ERE program, "as-designed"

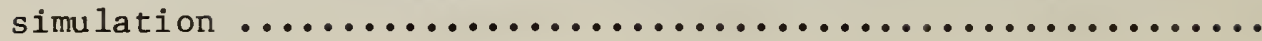

2. Selected important input parameters for ERE program, "as-

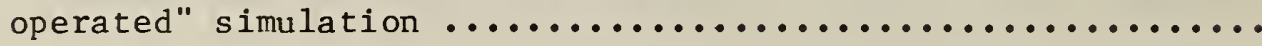

3. Selected important input parameters for ERE program,

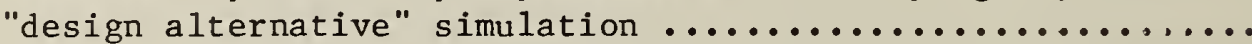

4. Norris Cotton Federal Office Building annual energy consumption

5. Summary of effects of modifications made to the "as-operated"

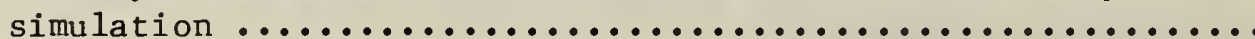

6. Fuel energy use components for the "as-designed" simulation .

7. Fuel energy use components for the "as-designed with solar" simulation

8. Fuel energy use components for the "design alternative" simulation

9. Fuel energy use components for the "as-operated" simulation .

10. Fuel energy use components for the "as-operated with modifications" simulation

11. Partial fuel energy use components from actual data ........

12. Energy use components for the "as-designed" simulation .....

13. Energy use components for the "as-designed with solar" simulation

14. Energy use components for the "as-operated" simulation ......

15. Fnergy use components for the "design alternative" simulation

16. Energy use components for the "as-operated with

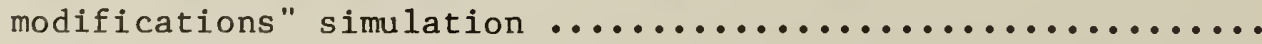

17. Energy use components from actual data ................

18. Comparison of components of annual operating energy for actual data and for "as-operated" and "design alternative"

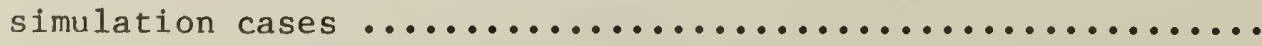


1. Schematic diagram of Norris Cotton Federal Office Building

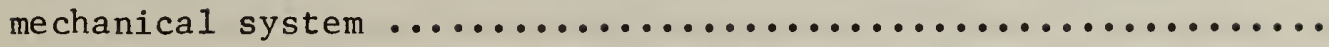

2. Total energy consumption of the NCFOB as predicted by

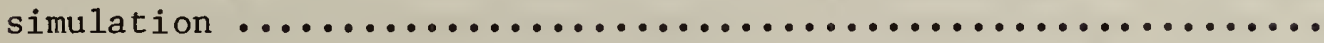

3. Electric energy consumption at the NCFOB as predicted by simu-

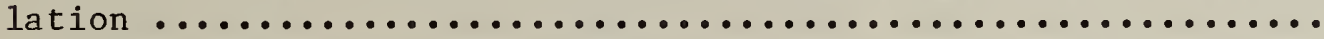

4. Natural gas consumption at the NCFOB as predicted by simulation ........................................

5. Fuel oil consumption at the NCFOB as predicted by simulation ..

6. Average monthly ambient temperatures for actual weather and 1962 weather used in the simulations

7. Tota1 energy consumption at the NCFOB as predicted by the "asoperated" simulation compared with actual consumption for three years ....................................

8. Monthly total heating requirements per unit area for the NCFOB as predicted by the "as-designed" simulation ..............

9. Monthly total cooling requirements per unit area for the NCFOB as predicted by the "as-designed" simulation ..............

10. Monthly total heating requirements per unit area for the NCFOB as predicted by the "as-operated" simulation ...............

11. Monthly total cooling requirements per unit area for the NCFOB as predicted by the "as-operated" simulation ..............

12. Monthly total heating requirements per unit area for the NCFOB as predicted by the "design alternative" simulation .........

13. Monthly total cooling requirements per unit area for the NCFOB as predicted by the "design alternative" simulation ..........

14. Monthly total heating and cooling requirements for the NCFOB as predicted by all simulations .........................

15. Comparison of heating and cooling requirement components for the $\mathrm{NCFOB}$ as predicted by simulation .................... 
16. Least squares fit of $\mathrm{NCFOB}$ heating requirements predicted by simulation versus monthly average ambient temperature ........

17. Least squares fit of $\mathrm{NCFOB}$ cooling requirements predicted by simulation versus monthly average ambient temperature ........

18. Third order least squares fit of predicted and actual NCFOB fuel use plus fan energy versus monthly average ambient temperature ....................................

19. Fuel use efficiency versus heating requirements as predicted by simulation for the NCFOB (least squares fits) .............

20. Cooling performance factor versus cooling requirements as predicted by simulations of the NCFOB (least squares fits) ....

21. Third order least squares fit of predicted and actual total energy used for HVAC at the NCFOB versus monthly average ambient temperature ...............................

22. Total heating efficiency versus heating requirements as predicted by simulations of NCFOB (least squares fits) .......

23. Total cooling factor versus cooling requirements as predicted by simulations of NCFOB (least squares fits) ........

24. Total energy for heating versus heating requirements for the central and heat pump mechanical subsystems at the NCFOB as predicted by the "as-operated" simulation .................

25. Total energy for cooling versus cooling requirements for the central and heat pump mechanical subsystems at the NCFOB as predicted by the "as-operated" simulation .................

26. Comparison of actual and predicted boiler fuel input at the NCFOB using "as-operated" simulation data .................

27. Comparison of actual and predicted heat pump and service hot water input at the NCFOB using "as-operated" simulation data ..

28. Comparison of actual and predicted energy to central chillers at the NCFOB using "as-operated" simulation data ............

29. Comparison of actual and predicted lighting-miscellaneous and operating energy at the NCFOB using "as-operated" simulation

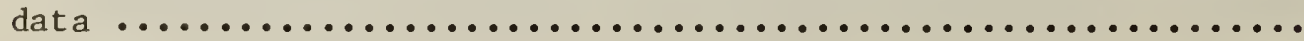

30. Energy use components and total energy use per year at the NCFOB using simulation results and measured data from September 1978 to 1979 


\section{INTRODUCTION}

The Norris Cotton Federal office Building (NCFOB) is a seven-story government office building located in Manchester, New Hampshire. This building, occupied in September of 1976, was designed to serve as a demonstration and a feasibility test for a number of energy-conserving building features. Each floor utilizes different types and arrangements of heating, ventilation, and air conditioning (HVAC) equipment and lighting systems. The equipment in the building includes heat pumps, fan coil units, variable volume air distribution systems, several heat recovery concepts, and a solar energy system. The building envelope was designed to minimize wall and roof thermal losses by making use of a cubical shape, minimum fenestration, massive construction, and external wall and roof insulation.

The original design for the building was developed by an architect/engineering firm under contract to the General Services Administration (GSA), the agency responsible for Federal Buildings [1]. The National Bureau of Standards (NBS) participated in the design stage by examining alternate design concepts with the NBSLD computer program, which was developed at NBS to predict heating and cooling loads in buildings $[2,3,4,5]$. NBS has been under contract to the Department of Energy (DoE) to collect and analyze energy consumption and performance data on the building. NBS subcontracted a consultant to simulate the thermal performance of the building using a state-of-the-art hour-by-hour computer program for the following reasons:

1. The original modeling of the building with NBSLD predicted the thermal performance of the building based on heating and cooling loads, but did not actually simulate the mechanical systems in the building. A simulation of the building using a mechanical system simulation program was felt desirable in order to verify the original design predictions for the building $\left(625 \mathrm{MJ} /\left(\mathrm{m}^{2} \cdot\right.\right.$ year $)$ $\left(55 \mathrm{kBtu} /\left(\mathrm{ft}^{2} \cdot\right.\right.$ year $\left.\left.)\right)\right)$.

2. Building energy consumption data from $98 \mathrm{kWh}$ meters, six natural gas meters, and two fuel oil meters is available for the NCFOB over three years of operation. By comparison of actual data and predicted data from a simulation of the building as it has been operated, a contribution could be made to the validation of building simulation computer programs.

3. Assuming that the results of computer modeling could be validated for the actual design, a simulation could be used to predict how this building might have performed had the design been different, with less emphasis on energy conservation and as if the building had been designed to conventional non-government criteria.

4. The model could also be used to examine possible improvements to present bullding operation and to predict their effect on building energy consumption. 
The computer-based model chosen to accomplish the above objectives was the Ross Meriwether Energy System Analysis Program*. This program was felt to represent the state of the art in building load and mechanical systems modeling. The popular public-domain programs such as DOE-2 and BLAST were not generally available at the time this analysis was begun. Because they are now available, consideration is being given to using them to replicate some of the modeling reported here. If this proves to be desirable, the results will be published later.

\section{DESCRIPTION OF NORRIS COTTON FEDERAL OFFICE BUILDING}

\subsection{BUILDING ENVELOPE}

The Norris Cotton Federal office Building has an approximately cubical shape to minimize surface area. The walls are of a massive masonry construction with insulation installed on the exterior of the masonry and covered with a granite facade. The wall has an overall heat transfer coefficient (U-value) of $\left.0.34 \mathrm{~W} /\left(\mathrm{m}^{2} \cdot{ }^{\circ} \mathrm{C}\right)\left(0.06 \mathrm{Btu} / \mathrm{h} \cdot \mathrm{ft}^{2} \cdot{ }^{\circ} \mathrm{F}\right)\right)$ and a mass of approximately $390 \mathrm{~kg} / \mathrm{m}^{2}$ $\left(80 \mathrm{lb} / \mathrm{ft}^{2}\right)$ of surface area. This wall design was intended to minimize thermal transmission losses in the winter and thermal gains in the summer. To further assist in minimizing winter transmission losses and summer solar gains, the window area averages only 6 percent of the total wall area and the north building wall is completely windowless. The south, east and west walls have approximately the same window area. Each window is double-glazed and contains a set of adjustable louvers between the panes of glass. Overhangs and fins surround the windows to maximize winter solar gain and minimize summer solar gain.

\subsection{MECHANICAL SYSTEMS}

Due to the experimental nature of the NCFOB, the mechanical systems are more complex and include more redundant equipment than would be found in a typical energy-conserving building. The mechanical systems at the NCFOB can be divided into two major parts which supply different areas of the building. The first three floors are served by a unitary water loop heat pump system consisting of 57 water-to-air heat pumps in various ceiling and floor mounted configurations having a combined capacity of $350 \mathrm{~kW}(1200 \mathrm{kBtu} / \mathrm{h})$ for heating and $280 \mathrm{~kW}$ (79 tons) for cooling. A closed water loop supplies all of the heat pumps with thermal energy for heating and acts as a heat sink for cooling. The upper four floors are served by several types of central systems. These upper floors are heated by a hot water heating system which uses fin tube perimeter radiation on the fourth floor and various types of ceiling or floor mounted fan coil units on floors 5, 6 and 7 . Cooling is provided on the upper four floors by central chillers used to produce chilled water which is pumped to the fan coil units or to a cooling coil in the variable air volume (VAV) air handling unit for the core area. Untreated ventilation air is provided

* Identification of a proprietary computer program in no case implies a recommendation or endorsement by the National Bureau of Standards. 
for two below-grade parking levels and a mechanical equipment penthouse is heated and ventilated. The NCFOB has two separate systems for handling outside air. One system, the heat pump air system, supplies ventilation air to the lower three floors by bringing outside air down from the penthouse mechanical room where the supply fan, return fan, and outside air and return dampers are located. Cooling and heating of the air is accomplished by having the air pass in parallel through six floor-mounted heat pumps before reaching interior areas of the lower three floors. This air system is a variable air volume type.

The upper four floors are supplied with ventilation air through a second air handling system also located in the penthouse. This system, which is also a variable air volume system, is configured much like the heat pump air system except that the only heating and cooling equipment in the air stream is a chilled water coil in the air handling unit. A heat pipe heat recovery system is used to preheat the outside air using energy recaptured from the exhaust air.

The NCFOB has a number of energy conversion devices utilizing natural gas, fuel oil, and electricity to provide heated and chilled water for the building water loops. Figure 1 is a schematic of the energy conversion and supply equipment. Four $55 \mathrm{~kW}(187 \mathrm{kBtu} / \mathrm{h})$ natural gas modular boilers and two $108 \mathrm{~kW}$ $(370 \mathrm{kBtu} / \mathrm{h}$ ) number 2 fuel oil modular boilers (not shown in figure 1) can supply heating energy to the heat pump and hot water loops. A $211 \mathrm{~kW}$ (60 ton) electric reciprocating chiller and an $88 \mathrm{~kW}$ (25 ton) hot water driven absorption chiller provide chilled water. Electric power for the reciprocating chiller can be purchased or supplied by a $150 \mathrm{kVA}$ natural gas fueled enginegenerator set in the penthouse. Thermal energy for the absorption chiller is supplied by the oil boilers or by recovery of waste heat from the engine generator.

A solar energy system is installed on the NCFOB and includes $353 \mathrm{~m}^{2}$ (3800 $\mathrm{ft}^{2}$ ) of liquid-type flat-plate collectors mounted on the roof of the building and which may be tilted at angles of from 20 to 60 degrees. In the winter, the system is operated with an ethlyene-glycol/water solution as the collector fluid and a heat exchanger is used between collector loop and the building solar storage loop. For summer operation, water is used as the collector fluid and the heat exchanger is bypassed. Energy collected in the solar array can be stored in one of three 37,850 liter (10,000 gallon) storage tanks located in the basement. Solar heated water was intended to fire the absorption chiller, to be used in the heating water system, and potentially could be used in the heat pump system (the control system which existed during the first three years of operation prevented this from happening). The solar system can also supply energy to the domestic hot water system. If no solar energy is available, the domestic hot water is heated by a natural gas-fired storage water heater. In the summer, one tank is available as a chilled water storage tank.

In addition to engine-generator heat recovery, two other energy recovery options were designed into the mechanical systems. One was to utilize condenser water from the chillers in the heating water system by means of a double-bundle condenser. The other scheme was to operate the electric chiller as a heat pump to produce hot water for the heating water system from low temperature water 
stored in the tanks (false loading). These options have not proven to be feasible in the operation of the building because heating water system temperatures have been elevated above maximum condenser operating temperatures $\left(41^{\circ} \mathrm{C}\right)\left(105^{\circ} \mathrm{F}\right)$ during mid-winter to ensure occupant comfort [6]. During mild weather, when the heating water system temperature is lowered, the solar system can supply energy to meet the heating requirements.

\subsection{CONTROLS}

The NCFOB has two distinct control systems for the mechanical equipment. A pneumatic system provides basic control functions and device actuation. Tied to the pneumatic system is a minicomputer. The minicomputer was designed to provide some overall control functions such as solar system mode selection, nighttime thermostat setback, and maintenance management. In addition, the computer monitors over 900 binary and analog sensors allowing the building operators to watch critical equipment and set up alarm signals for changes of state.

\section{DESCRIPTION OF COMPUTER SIMULATIONS}

\subsection{DESCRIPTION OF COMPUTER PROGRAM USED FOR SIMULATION}

The Ross Meriwether Energy System Analysis program basically consists of a number of computer programs run in sequence, the output data generated by one program being used as input to the next. The building is divided into a number of zones, the number and size of the zones depending on the load resolution required, hours of operation, and the number of air-side HVAC and control systems in the building. Hourly heating, cooling, and electrical loads for each zone are calculated by the Energy Requirements Estimate program (ERE). The ERE program uses as input an hourly weather tape and design point data describing the building envelope, the zone occupancy, zone base electric loads, and the types of air-side HVAC and control systems in the zone. Hourly loads calculated for individual zones by the ERE program are combined by the Total Coincident Requirements program (TCR) to determine total and peak simultaneous loads for an entire mechanical subsystem. Using the ERE and TCR calculated loads and data describing the characteristics of the mechanical systems, the Equipment Energy Consumption program (EEC) simulates the performance of the mechanical system components as they respond to loads imposed on them by the building air-side systems, and determines the monthly input of all energy forms to the building systems. The EEC program also computes operating and full-load hours for each piece of equipment, heat recovery utilization, and an energy use breakdown by categories.

For simulation of a solar energy system or solar heat gain, a program is used which generates an ASHRAE solar table for the specific location and orientation of any surfaces collecting solar energy [7]. This table gives the energy striking a unit surface area after taking into account cosine effects and optical losses. The EEC program can be used to model an actual solar array by simulating a room with an "imaginary" chiller. Any net solar gain into the room, which represents the collector array, is pumped into the building by the chiller. 
Five different simulation runs were made. The characteristics of the building simulated by each run will be described in the next sections, followed by a presentation of the simulation results.

\subsection{AS-DESIGNED SIMULATION}

An "as-designed" simulation was intended to represent the NCFOB as it was originally designed, using the design plans and specifications for the building as input to the program. A solar energy system was not originally included in the design and was therefore excluded from the "as-designed" simulation.

The complete building was divided into two sub-buildings for this simulation in order to represent the two main mechanical subsystems, the heat pump system and the combined central systems. Each of the sub-buildings was further sub-divided into major zones, each of which required a separate ERE program execution. The heat pump system sub-building consisted of the first three floors of the building and was divided into a core zone and perimeter zone, each zone spanning three floors. The central system sub-building was divided into four major zones: the fourth floor, the fifth floor, the sixth and seventh floor core, and the six and seventh floor perimeter. In the real building, each major zone utilizes a different type of air-side HVAC and control system and thus each zone had to be simulated differently by the ERE program. As mentioned previously the fourth floor uses a standard variable air volume system with finned tube radiation to offset transmission losses. The fifth floor uses a variable air volume system with a separate single-duct system to offset transmission losses. The sixth and seventh floors both have variable air volume systems for the core and four-pipe fan coil units for perimeter heating and cooling. Each of the zones was simulated with a design thermostat setting of $20^{\circ} \mathrm{C}\left(68^{\circ} \mathrm{F}\right)$ for heating and $26^{\circ} \mathrm{C}\left(78^{\circ} \mathrm{F}\right)$ for cooling with a winter setback to $16^{\circ} \mathrm{C}\left(60^{\circ} \mathrm{F}\right)$ from $6 \mathrm{pm}$ to 5 am during the week and all day on weekends and holidays. Table 1 lists some important input parameters used by the ERE program. Other parameters used as input data but not described here included base electric load for lights, miscellaneous and fans, supply fan temperature rise, supply air flow, hourly percentage variation profiles for base electric and internal loads, maximum outside air flow, primary supply air temperature and humidity, air system economizer temperatures, outside air-exhaust air heat recovery efficiency, and minimum variable volume air flow.

The TCR program was run to sum the loads calculated for individual major zones by the ERE program into total hourly loads for the two sub-buildings, the heat pump and central. The EEC program was used to predict the performance of the mechanical equipment as it supplied the load for the two main types of air-side systems over a year. All of the equipment was described in the EEC program input data by a full-load input and output rating together with a part-load profile. The part-load profile allows the program to determine equipment energy consumption when the equipment is not delivering the full rated load. The mechanical equipment simulated included four gas-fired modular boilers used to provide hot water to the heat pump or central systems. Central chilled water was assumed to be supplied by the electric chiller, 
always driven by the engine-generator, as called for in the original design. Waste heat from the engine generator was assumed to be used to drive the absorption chiller in parallel with the electric chiller. Energy storage was available to store excess heat from the engine-generator and this storage could supply energy for heating or for the absorption chiller if no other sources were available.

\subsection{AS-DESIGNED WITH SOLAR SIMULATION}

A second simulation was run using the final building design which included a solar energy system added to the original design. This simulation used the same ERE program inputs as the "as-designed" simulation. Besides the addition of a solar system, the EEC (equipment) program inputs for this case were similar to the "as-designed" inputs with the exception that the central electric chiller was assumed to always run on purchased power rather than power produced by the engine-generator. The "with solar" design called for the solar system to provide thermal energy to run the absorption chiller. With the solar system, the engine-generator was designed to be operated and the recovered heat to be used only if the solar system did not have sufficient output to operate the absorption chiller (on cloudy days, for example). Simulation of this complex control scheme was not possible with the program and therefore engine-generator use was not simulated for this case.

At the time the simulations were run, the Ross Meriwether program had no provision for direct solar system simulation. The operation of the solar system in the building was approximated by a room with south-facing windows simulated by the ERE program. This room had no space heating capabilities and cooling was provided by an "imaginary" chiller which acted as a "heat" pump to remove solar gain from the room and pump it to storage. This chiller differed from a real chiller in that it required no compressor power. The thermostat setting for removing heat from the room was $88^{\circ} \mathrm{C}\left(190^{\circ} \mathrm{F}\right)$ during the summer and $37^{\circ} \mathrm{C}$ $\left(99^{\circ} \mathrm{F}\right)$ during the winter to simulate collector temperatures. These settings insured that the simulated collector array would operate at a minimum output temperature for the loads it was required to supply. The design of the solar system called for a storage tank to be heated with solar energy to a specified temperature level before solar energy could be used. Due to limitations in the simulation program, it was assumed that energy from the solar system could be used directly. The use of this assumption yielded a slightly higher solar system performance than might be expected from the actual design.

Prediction of the amount of solar energy entering the room was accomplished by using a separate program to generate a table of solar heat gain values for each hour of the day throughout the year. The regular function of this program is to predict solar gain through windows using as input a series of absorptance and transmittance constants. For a solar system, these constants can be given values so that the program simulates the energy arriving at the absorber plate of a solar collector. This gives the same result as applying a transmittance-absorptance product and an incident angle modifier to the energy incident upon the solar panel. Energy loss from the solar collectors by heat transfer to the environment was approximated by the transmission 
loss through the walls of the solar room simulated by the ERE program. Original design specifications for collector performance were used for the collector simulation.

\subsection{AS-OPERATED SIMULATION}

Following building start-up in September 1976, differences between the design predictions for the building and the actual operational performance became apparent. The major problems with the building have been described in a previous paper [6]. In many cases, problems with the controls forced building operators to resort to manual operation of systems. Because of the differences between the actual operation of the building and what was assumed during the design phase, a simulation was felt to be required that would predict the energy consumption of the building "as-operated". The most important differences between the assumptions made at the time of design and what has occurred with the actual building were incorporated in the "as-operated" simulation and are as follows:

1. Different air infiltration rates were used. In the simulations, infiltration is considered to be air leakage to or from outside the building and is separate from mechanical ventilation. For the "as-designed" simulation, 0.5 air changes per hour were used. However, average rates of 0.75 air changes per hour were measured initially after occupancy of the building [8]. After recaulking of the building exterior, lower rates were measured $(0.75$ air changes per hour on the first three floors and 0.39 on the upper four floors or an average of 0.54 air changes per hour for the building). The lower rates were used in the "as-operated" simulation. Table 2 lists ERE program inputs for the "as-operated" case. In the "as-designed" case, infiltration was assumed to be constant on the first three floors and exist only on the upper floors when the fans were off (a pressurized building). The air exchange measurements showed that there is constant infiltration throughout the building even when the fans are operating. Consequently the infiltration rate for the "as-operated" case was not only higher but was input as constant in all zones.

2. Two manually controlled oil-fired boilers were added. Originally, these boilers were only intended as back-up equipment in the event of an interruption of natural gas but have been used routinely during winter operation in sequence with the gas boilers to meet higher than expected heating loads. The oil-fired boilers have also been used in the summer as the source of hot water for the absorption chiller. Gas is not used to heat water for the chiller because retrofit piping was only added between the chiller and the oil boilers to avoid modifications to gas boiler controls.

3. For the "as-operated" simulation, the operation of the gas-fired boilers was limited to the months of October through April for heating and the operation of the chillers was limited to the months of May through September. 
4. The building operators increased the heating water system temperature from the design value of $41^{\circ} \mathrm{C}\left(105^{\circ} \mathrm{F}\right)$ to $60^{\circ} \mathrm{C}\left(140^{\circ} \mathrm{F}\right)$ during mid-winter to improve comfort conditions and meet peak heating loads in the building.

5. Recovered heat from the engine-generator has never successfully driven the absorption chiller. When the engine-generator is operated at maximum jacket water temperatures, water in the heat recovery loop, after having passed through the jacket water heat exchanger, seven stories of piping, and an oversized storage tank, is at too low a temperature to drive the absorption chiller. The electric chiller is always driven by purchased power since the waste heat produced by the engine-generator cannot be put to any use. The absorption chiller is driven by water heated in the oilfired boilers. Also, the two other heat recovery options for the electric chiller (double-bundle condenser and false loading) have never been used successfully. No heat recovery from the enginegenerator or electric chiller was simulated in the "as-operated" case.

6. In the actual building, the solar array output is used only during the spring and fall to provide energy for the heating water system. During mid-winter, the heating water system temperature is raised to $60^{\circ} \mathrm{C}\left(140^{\circ} \mathrm{F}\right)$ and at this temperature the efficiency of of the existing solar array is too low for any usable energy to be collected. In the summer, the solar array has been unable to produce usable energy at $104^{\circ} \mathrm{C}\left(220^{\circ} \mathrm{F}\right)$, the temperature required by the absorption chiller. Although the solar array can easily produce energy at temperatures usable in the heat pump water loop, problems with the valves and controls specified in the original design have prevented solar-heated water from being used in the heat pump system [6]. To simulate this situation, the "as-operated" simulation allowed the solar array to provide energy for the heating water system only during the months of April, May, September, and October (when heating water temperatures are lowered). The only other system in which solar energy was assumed used in the simulation was the service hot water system (used all year).

7. Thermostat settings were changed to $18^{\circ} \mathrm{C}\left(65^{\circ} \mathrm{F}\right)$ for occupied heating and to $13^{\circ} \mathrm{C}\left(55^{\circ} \mathrm{F}\right)$ for unoccupied setback near the end of the third operating year.

8. In the "as-operated" simulation the lighting loads were raised slightly and redistributed to more accurately reflect the electric energy requirements of the various agency tenants occupying different floors.

\subsection{SIMULATION OF MODIFICATIONS TO EXISTING OPERATION}

A simulation of the NCFOB was made to predict what the effect would be of several easily implemented changes to the current operation of the building. 
The "as-operated" simulation was taken as a baseline and several changes were made to the input data. The changes for this "as-operated with modifications" case consisted of the following:

1. The heat pump fans were cycled by room thermostats with the heating or cooling load. As presently operated, the heat pump fans operate continuously during occupied hours.

2. The variable air volume air handling unit cooling coil discharge temperature was raised from $13^{\circ} \mathrm{C}\left(55^{\circ} \mathrm{F}\right)$ to $16^{\circ} \mathrm{C}\left(60^{\circ} \mathrm{F}\right)$.

3. The water loop temperature for the heat pump system was operated at the maximum temperature consistent with the safety of the heat pump units.

4. The temperature of the central chiller condenser water was lowered to the minimum consistent with chiller safety and cooling tower capability. [The use of $41^{\circ} \mathrm{C}\left(105^{\circ} \mathrm{F}\right)$ condenser water was required only to allow heat recovery and has reduced chiller efficiency.] Also in the simulation, the absorption chiller was sequenced to run after the electric chiller was at full load rather than in parallel.

\subsection{DESIGN ALTERNATIVE SIMULATION}

The final simulation run was intended to be a prediction of how a design alternative to the $N C F O B$ might have performed, had it been built instead of the existing building. The design of the alternative chosen did not stress energy conservation as much as the actual building and represented what was felt to be typical design practice for a commercial building used for rental of office space during the early 1970's. This type of building might have been used if office space for government agencies had been rented in a commercially owned building. Basically, the "design alternative" had the same configuration as the "as-designed" building, with the same shape, occupancy, layout and floor area. The differences were in the thermal quality of the building envelope and the types of mechanical systems used. In addition, the alternative building had none of the demonstration character of the existing building. Table 3 describes ERE program input data. The major differences between the "as-designed" and the "design alternative" building were as follows:

1. The alternative used more electricity for lighting per unit of floor area and had higher internal gains.

2. The alternative had no solar system or heat recovery systems.

3. The overall wall U-value including the effect of windows was changed from 0.57 to $1.59 \mathrm{~W} /\left(\mathrm{m}^{2} \cdot{ }^{\circ} \mathrm{C}\right)\left(0.10\right.$ to $\left.0.28 \mathrm{Btu} /\left(\mathrm{h} \cdot \mathrm{ft}^{2} \cdot{ }^{\circ} \mathrm{F}\right)\right)$.

4. The window area was changed from 6 percent to 29 percent of the total wall area and windows were used on the north wall. The "design alternative" simulation input data included a reference solar gain 
since the window area was increased beyond the area in the original design and no outside window shading "fins" were assumed (solar gains were considered negligible in the "as-designed" case). A shading coefficient of 0.5 was used to calculate solar gain for the alternative.

5. The wall and roof U-value was changed from 0.34 to $0.85 \mathrm{~W} /\left(\mathrm{m}^{2} \cdot{ }^{\circ} \mathrm{C}\right)$ $\left(0.06\right.$ to $\left.0.15 \mathrm{Btu} /\left(\mathrm{h} \cdot \mathrm{ft}^{2} \cdot{ }^{\circ} \mathrm{F}\right)\right)$.

6. The design alternative used a hot water system for heating with a central boiler and hot water coils on the perimeter. The capacity per unit area was higher than for the "as-designed" building.

7. The design alternative used through-the-wall air conditioning units on the perimeter and packaged air conditioning units in the core for cooling.

8. A pressurized building was assumed and infiltration rates were those with fans off.

\section{OVERALL ENERGY CONSUMPTION}

Each of the simulation runs resulted in a prediction of the consumption of various fuels and the overall building energy consumption, on a monthly and annual basis. The following sections will describe the simulation results.

\subsection{TOTAL ENERGY CONSUMPTION}

Total energy consumption predicted in each of the five simulation runs is shown in Figure 2 for each month of the year. The total consumption is the sum of the maximum energy contents of electricity and all forms of fuel as they pass through the building boundary. It is important to keep in mind that while different buildings may use the same amounts of energy at the building boundary, the cost of the energy will differ between buildings using different fuels and having different demand characteristics. In figure 2 the basic shape of the energy consumption curves is the same for all runs and shows that for an office building in this climatic region, the predominant energy use is for heating rather than for cooling. Differences between the individual curves are the result of a number of factors. The "asdesigned with solar" consumption is slightly lower than in the "as-designed" case since some of the solar energy collected replaces purchased energy. The energy consumption for the "as-operated" case is higher in winter than for the "as-designed" case due to factors such as higher heating loads. The effect of the modifications to the building in the "as-operated with modifications" case is a slight overall decrease in the energy consumption. A surprising result is that in the "design alternative" case, energy consumption levels are predicted to be similar to those in the "as-operated" case. The reasons for this result will be examined in later sections. 


\subsection{ELECTRIC ENERGY CONSUMPTION}

The electric energy consumption per month predicted for the NCFOB is shown in Figure 3. For the "as-designed" case, electric energy is used for lights, receptacles, the mini-computer, miscellaneous, pumps, fans, and for heat pumps all year. The greater electrical use in winter can be attributed to the heat pump system, which must meet the heating load for the first three floors. The addition of the solar system has little effect on the electric energy consumption compared to the "as-designed" case except in the summer months. The increase in the summer is the result of running the electric chiller on purchased power and never with the engine-generator. The electric energy consumption for the "as-operated" case is significantly higher than for the "asdesigned" case due to higher heating and cooling loads, greater energy use by pumps, fans, controls, for lighting, and the operation of the electric chiller solely on purchased power. The slight reduction in electric consumption for the "as-operated with modifications" case is due to savings in fan energy and heat pump electric consumption and more efficient electric chiller operation. A noticable difference exists between the electrical consumption for the "design alternative" and the other cases. The "design alternative" does not use heat pumps for heating, but does utilize electricity for cooling. Therefore this results in a lower curve during the winter and a higher one in the summer.

\subsection{NATURAL GAS CONSUMPTION}

Predicted natural gas consumption is shown in Figure 4. The "as-designed" curve shows a large winter usage of gas (used in boilers for heating) and a smaller but significant use of gas in summer (to operate the engine-generator to drive the electric chiller). The "as-designed with solar" gas consumption is lower all year reflecting the replacement of boiler-generated thermal energy with solar thermal energy. Some gas consumption exists in the summer, even though this simulation case did not allow use of the engine-generator, because gas was used to heat water to fire the absorption chiller when the solar system could not supply all of the absorption chiller requirements. In the original design with solar, the engine-generator was supposed to be used when solar energy was not available and therefore the gas boilers were not to be permitted to fire the absorption chiller. Thus, the summer gas use in Figure 4 approximates gas use in the engine-generator as called for in the original design with solar.

In the "as-operated" case, the engine-generator is never used and the electric chiller operates on purchased power while the absorption chiller is fired by water heated in the oil boilers. Thus there is no natural gas use in the summer for this case. The winter natural gas consumption is higher than for the "as-designed" case because of higher heating loads. The modifications to the "as-operated" case are not of the type which would save boiler energy and therefore there is no change in the gas consumption for the "with modifications" case. The gas consumption for the "design alternative" case is significantly higher than for the other cases but it must be kept in mind that the "design alternative" does not use heat pumps and all of the energy for heating is supplied by natural gas boilers. 
No fuel-oil-fired equipment was included in the original design and therefore no oil consumption was predicted by the first two simulation cases. Fuel oil boilers were added to the actual building as supplementary boilers and in the "as-operated" case and the "as-operated with modifications" case oil boiler capacity was present. In the winter, the oil boilers have been used when the demand on the boiler system exceeded the gas boiler capacity. In simulating the complex control scheme of the building in the "as-operated" cases, more gas boiler capacity had to be included in the simulation than the building actually has. The "as-operated" simulations predicted that the extra gas boiler capacity was used, indicating that the actual gas boiler capacity was exceeded and that fuel oil would have been used in the winter. This agrees with the actual operation of the building where the fuel oil boilers were used during the winter.

Figure 5 depicts use of fuel oil in the summer predicted by the simulation cases. Piping was added to the original building so that the oil boilers could be used to heat water to fire the absorption chiller. Figure 5 shows a large use of oil for the absorption chiller for the "as-operated" case and a reduced usage for the "as-operated with modifications" case. The lower usage after the "modifications" results from a reduction in absorption chiller operating hours due to use of the absorption machine in sequence with the electric chiller rather than in parallel with it.

\subsection{ACTUAL ENERGY CONSUMPTION COMPARED WITH PREDICTED CONSUMPTION}

The simulation runs were all made using weather data for Concord, New Hampshire (which is $24 \mathrm{~km}$ ( 15 miles) away) for the calendar year 1962. The monthly average dry-bulb temperatures for this particular year were found to be very close to the thirty year norm values. In comparing actual energy consumption data with the results of the simulations, it is important to consider that the actual weather has been different from the 1962 weather assumed in the simulations. Although it would have been desirable to use input weather tapes from the period during which the actual building has been operating, detailed hourly tapes were not obtainable. Figure 6 is a plot of the average monthly ambient drybulb temperature in Concord for 1962 and for the three years that the NCFOB has been in operation. The plot is based on the operating year which is defined as being from September to August (the building was occupied in September 1976). It is obvious that the ambient temperatures for all years are similar although there is an $8^{\circ} \mathrm{C}\left(15^{\circ} \mathrm{F}\right)$ variation in January average temperature among the years.

A comparison of the overall building energy consumption for the "as-operated" case and the actual consumption for the three years of building operation is shown in Figure 7. The energy consumption for the first two years of operation was quite variable and much higher than predicted by the simulation. The first two years represent the long period required to "debug" the building as operators attempted to make the mechanical systems perform as called for in the original design. During the third year of operation, the building was finally operated in the best way possible given the shortcomings of the 
installed systems and equipment. The agreement between the actual energy consumption and the "as-operated" simulation results is fairly close for the third year.

\subsection{ANNUAL TOTAL ENERGY CONSUMPTION PER UNIT AREA}

The expression of overall building energy consumption on a per unit area basis has been used to make comparisons between buildings and to establish energy consumption design goals. In making comparisons, it is important that all buildings involved in the comparison have their areas calculated in a consistent manner and that all references to a single building use the same area. The GSA Public Buildings Service (PBS) uses two methods of computing floor area. The "equivalent gross floor area" (EGFA) method of calculating building area is used as a basis for energy consumption goals [9]. This method identifies three types of building area: office space, mechanical equipment space, and garage areas. Since garage and mechanical areas use energy for lighting, elevator service, and ventilation, GSA/PBS felt that it was important to include such areas in the total but not "weight" them as fully as conditioned office areas. Equivalent gross floor area as defined by GSA/PBS is one quarter of the mechanical and garage areas plus the total office area. A different area, the "total gross floor area", is used for reporting of building performance. This area includes all areas of the building.

In order to be consistent with the GSA/PBS conventions, an EGFA of $10,900 \mathrm{~m}^{2}$ $\left(117,334 \mathrm{ft}^{2}\right)$ is used here. This includes $9072 \mathrm{~m}^{2}\left(97,648 \mathrm{ft}^{2}\right)$ of office space, $643 \mathrm{~m}^{2}\left(6925 \mathrm{ft}^{2}\right)$ of mechanical space, and $6672 \mathrm{~m}^{2}\left(71,818 \mathrm{ft}^{2}\right)$ of garage. The total area of the NCFOB is $16,387 \mathrm{~m}^{2}\left(176,394 \mathrm{ft}^{2}\right)$. During the design stage GSA established an energy consumption goal of $625 \mathrm{MJ} /\left(\mathrm{m}^{2}\right.$-year) (55 kBtu/( $\mathrm{ft}^{2}$-year)) (using EGFA) for the NCFOB and as a provisional goal for other energy conserving buildings to follow.

Table 4 lists the annual energy consumption per equivalent gross floor area predicted for the $\mathrm{NCFOB}$ as a result of the five computer simulations. Also listed are the values of actual energy consumption of the building since occupancy in September 1976. The "as-designed" simulation prediction exceeds the GSA goal by 9 percent. However, when the solar system is added, the simulation prediction is 2 percent less than the goal. The "as-operated" simulation prediction is 12 percent higher than the goal. The "design alternative" simulation results in a value which is 8 percent above the GSA goal. The reasons why the alternative building does not use much more energy than the original design will be discussed in the following sections.

The actual operating data show that the annual energy consumption of the NCFOB has been falling since the building was first occupied. Consumption for the third year of operation (September 1978 to August 1979) was only 2 percent above the GSA goal and the consumption for the third calendar year (ending December 1979) was 1 percent below the goal.

The "as-operated" simulation was intended to represent the actual operation of the building during the recent past. At the time that the simulations were performed, the operation of the building during the third calendar 
year (1979) was used as a basis for selecting "as-operated" simulation inputs. It is important to remember that the "as-operated" simulation could not exactly simulate the actual building operation because some manual control has been used by the operator during the three years of operation, and various operational schemes have been used for time periods shorter than a year. It is impossible to accurately simulate a mechanical system when human judgement has been used to control the operation of the equipment. Including these qualifications and the use of different weather data, the simulation predicts a total energy consumption 14 percent greater than the third calendar year consumption.

The modifications to the "as-operated" simulation resulted in an annual reduction in energy consumption of about 6 percent. A summary of the major modifications causing the energy reduction are given in Table 5.

\section{HEATING AND COOLING ENERGY REQUIREMENTS}

\subsection{ZONE HEATING AND COOLING ENERGY REQUIREMENTS}

The monthly heating and cooling energy requirements, or the energy delivered to or removed from the air side of the mechanical systems, were available from the simulation output. Heating requirements predicted for the "asdesigned" case are shown in Figure 8 per unit floor area for the major zones for each month of the year. In the figure, the results for the core and perimeter zones have been combined. The most apparent characteristic of this plot is that the requirement for the first three floors is much larger than the requirements for the other floors. This is due to the constant infiltration component assumed on the lower three floors rather than the infiltration occuring only with fans of $f$ on the upper floors. Since the thermal design of the building facade is of high quality, loads due to infiltration tend to dominate. Also the heating capacity of the heat pump system on the lower three floors is higher than for the central system on the other floors. Higher capacity results in less time in which the air-side system cannot satisfy the load. Since in the simulation it was found that the air-side systems were not able to meet the load on many occasions (confirming actual experience in the building), the lower capacity of equipment on the upper four floors results in less energy delivered to the upper four floors by the air-side system than if all loads had been satisfied.

Figure 9 shows the cooling requirements for the same case. The cooling requirements for the lower three floors are less than the requirements for the upper floors and this is again due to the difference in the assumptions concerning air infiltration. Higher infiltration rates flush more heat out of the building during moderate weather thus reducing cooling requirements. The figure also shows the prediction of small cooling requirements in the winter months.

Heating energy requirements per unit area for the "as-operated" case are shown in Figure 10. Extra runs of the ERE program were made for the perimeter and core of the first three floors. These extra runs were made using a value for the air infiltration rate which had been measured in tests made before the 
building facade was caulked. The figure shows the effect of the increase in air infiltration rate from 0.75 to 1.0 air changes per hour. The dotted line representing the requirements for the higher air change rate is approximately 25 percent higher than for the lower air change rate (solid line).

In the "as-operated" case, as was noted for the "as-designed" case, the lower three floors have higher energy requirements than the upper floors. The greater requirements are not due to a difference between constant and fansoff infiltration rates but result from a higher rate of constant infiltration (see Table 2). Basically the heating requirements are similar for the two cases, with the "as-operated" requirements being slightly higher.

The effect of infiltration rate on the cooling energy requirements for the "as-operated" case can be observed in Figure 11. For the lower floor zones, the increase in infiltration rate lowers the cooling requirements. In this figure, the fifth floor stands above the other floors. This is a result of the redistribution of the lighting loads to reflect the tenant requirements. The fifth floor in the simulation has a higher internal gain from lighting than the fourth floor, which is otherwise similar.

The heating and cooling energy requirements per unit area for the "asoperated with modifications" case are not shown since they are very similar to the "as-operated" requirements. The cooling requirements for the "modifications" case are lowered slightly due to the supply air temperature reset on the upper four floors.

Heating and cooling energy requirements for the "design alternative" case are shown in Figures 12 and 13. In this case there are only three major zones. One zone represents an area on the first floor occupied 24 hours per day as a guard office. The requirements follow a pattern similar to the other cases. The heating requirements are slightly higher and the cooling requirements are definitely higher than in the other cases. The higher cooling requirements result from greater internal gains and from solar gain. The high cooling requirements in the perimeter zone relative to the core zone result from solar gains.

For comparison, the total monthly heating and cooling energy requirements for all cases are shown in Figure 14.

\subsection{LOAD COMPONENTS}

One type of output data available from the ERE program is a summation of load components such as transmission losses and internal gains. The information is output as a yearly total. This means that the summation of, for example, transmission losses includes losses during the summer as well as the winter. This limits the value of the data but it is still possible to gain insight into the building performance by looking at these components. Figure 15 shows the components for all cases in bar chart form. Infiltration and transmission gains are not shown since these are very small relative to the corresponding type of losses. The figure shows that the heating energy requirements for all cases are very similar although the cooling energy requirements differ. 
All of the simulation cases result in approximately the same infiltration losses. The internal gains differ somewhat, the gains being higher in the "design alternative" case and lower in the "as-designed" case. However, the most striking difference is for transmission loss where the "design alternative" value is much larger than for other cases. It might seem that this would cause the "design alternative" to have higher heating energy requrements. However, examination of the solar gain data shows a much higher solar gain in the "design alternative" than in the other cases (where gain is zero because of the very small window area). This solar gain, together with the higher internal gains, is the cause of the higher cooling requirements in the "design alternative" case. However, the higher solar and internal gains offset the larger transmission losses in the "design alternative" so that for all the cases, the heating requirements are approximately the same. The conclusion is that smaller window areas in the actual building do decrease transmission losses but also reduce beneficial winter solar gain. In general, the solar gain, transmission loss, and internal gains should be carefully balanced in any design to minimize energy usage or cost.

\subsection{HEATING AND COOLING ENERGY REQUIREMENTS VS AMBIENT TEMPERATURE}

Figure 16 illustrates the result when the total monthly heating energy requirement is plotted against the average ambient temperature for the month. The curves in this figure are second order (quadratic) least squares fits of the simulation output data and are nearly straight lines. The symbols on the lines are identifiers and do not represent the actual points. The closeness of the fitted line to the individual points can be described by a residual standard deviation which is the standard deviation between values predicted by the fitted curve and the original points. In figure 16 residual standard deviations are less than $22 \mathrm{GJ}\left(23 \times 10^{6} \mathrm{Btu}\right)$ for all curves. The value of figure 16 is that it divorces the energy requirements data from the climate to some extent and allows comparisons to be made between buildings in different climatic regions. The slope of the curve represents an overall heating requirement factor. The curves from all simulation cases lie fairly close together and approach zero between 13 and $18^{\circ} \mathrm{C}\left(55\right.$ and $65^{\circ} \mathrm{F}$ ).

If the cooling energy requirements are plotted versus ambient temperature, the result is Figure 17. Again, the curves in this plot are second order least squares fits of the simulation output data. The curves are less significant than for heating since there are less months of cooling and thus less data points. Residual standard deviations are less than $15 \mathrm{GJ}$ (15 x $10^{6}$ Btu). The results differ between the cases, the "design alternative" data lying well above the others as observed previously. Cooling requirements tend to appear at ambient temperatures lower than $18^{\circ} \mathrm{C}\left(65^{\circ} \mathrm{F}\right)$ since during spring and fall there may be times when heating and cooling energy requirements appear on the same day.

\subsection{FUEL USE VERSUS AMBIENT TEMPERATURE}

In order to meet heating and cooling energy requirements, fuel must be used. Besides oil and gas, fuel is also considered to include the electric energy used by compressors in the heat pumps and chillers. Total fuel use can be 
plotted versus the ambient temperature. The value of such a plot is that actual fuel consumption data are available for the NCFOB and a comparison with the simulation results can be made. For the actual data, fan energy cannot be separated from the fuel use. Figure 18 shows the fuel plus fan energy versus monthly average ambient temperature for all the simulation cases and actual data. The lines shown represent a third order (cubic) fit of the data. Residual standard deviations for the simulation data range from 16 to $21 \mathrm{GJ}$ ( 15 to $20 \times 10^{6} \mathrm{Btu}$ ) and for the actual data the residual standard deviation is $51 \mathrm{GJ}\left(48 \times 10^{6} \mathrm{Btu}\right)$. The fit is approximately a "U" shaped curve with the minimum at an ambient temperature of approximately $16^{\circ} \mathrm{C}\left(60^{\circ} \mathrm{F}\right)$. Energy use to the left of the minimum is predominantly for heating; to the right is predominantly for cooling. The actual data compare well with simulation data although the actual data are somewhat lower than the "as-operated" simulation data. This figure also shows that fuel use for heating is higher for the "design alternative" case than for the other simulation cases.

\subsection{FUEL USE EFFICIENCY VERSUS HEATING AND COOLING ENERGY REQUIREMENTS}

The figures presented to this point have described overall building performance. The performance of the mechanical equipment can be represented by the ratio of heating or cooling requirements to the fuel (plus fan) energy consumed for each month. For heating, such a ratio may be termed the fuel use efficiency. Least squares fits of the monthly calculated fuel use efficiency for heating are plotted versus heating requirements in figure 19. The curves are of the form:

$$
e=R /(A R+B)
$$

where $A$ and $B$ are constants, $R$ is heating (or cooling) requirements and $e$ is efficiency. Residual standard deviations for the fits are less than 9 percentage points of efficiency. In general the efficiency decreases with decreasing load on the mechanical equipment and approaches a full load efficiency at high loads. The "as-designed", "as-operated", and "as-operated with modifications" curves approach efficiencies of 79 percent. At low requirements the "as-operated with modifications" curve is higher because fan energy is reduced in this case. The "design alternative" curve is lower than the other curves, approaching only 66 percent efficiency.

For cooling the ratio of cooling requirements to fuel plus fan energy may be termed the cooling performance factor. Figure 20 shows least squares fits of cooling performance factor versus requirements. Residual standard deviations range from 1 to 15 percentage points. The "as-operated with modifications" case shows the highest performance factors and the "as-designed" case the lowest. The low "as-designed" curve is due to the use of natural gas as the primary cooling fuel for the central system.

\subsection{TOTAL HVAC ENERGY VS AMBIENT TEMPERATURE}

Figures 18 through 20 used fuel consumption as the major dependent variable. In any building, equipment is used to heat and cool the building space and to 
supply required ventilation. Such equipment, which includes pumps, controls, and fans, requires energy to operate. Such energy usage may be termed energy distribution energy or operating energy. It is important to consider both the operating energy and the fuel energy use in designing and analyzing the performance of large buildings. Figure 21 is similar to Figure 18 except that total HVAC energy (fuel and operating energy) is plotted versus the ambient temperature. This plot is also a third order fit of the data and residual standard deviations are 18 to $22 \mathrm{GJ}$ (17 to $21 \times 10^{6} \mathrm{Btu}$ ) for the simulation and the actual measured data.

The curves in Figure 21 lie closer together than the curves in Figure 18 and the actual data curve is in better agreement with the "as-operated" simulation data curve than in Figure 18. There is a distinct difference between the simulation and the actual data curves for cooling, the actual being lower than the predicted. This discrepancy is due to differences in the operation of the building cooling systems in actual practice compared to what was assumed in the simulation. For example, the strategy of flushing the building with the outside air in the early morning by manual control was used during the third year of operation but was not simulated in any of the cases.

In Figure 21, the position of the "design alternative" curve relative to the other curves in the figure is different than the corresponding position in Figure 18. In Figure 21, the "design alternative" curve is in roughly the same position for heating as the other curves. In the plot of Figure 18, the "design alternative" curve is distinctly above the other curves. This indicates that the operating energy is lower for the "design alternative" compared to the other cases.

\subsection{HVAC ENERGY USE EFFICIENCY VERSUS HEATING AND COOLING ENERGY REQUIREMENTS}

A total heating efficiency may be defined as the heating requirements divided by the total energy for heating (fuel plus operating energy). Figure 22 is a plot of least squares fitted curves of total heating efficiency versus heating requirements. Residual standard deviations are all low, less than 2 percentage points. At high loads all curves approach 64 percent efficiency. The "design alternative" curve is in the same region of the plot as the other curves while in the fuel use efficiency plot, figure 19, it was lower. This is due to the addition of the operating energy to fuel energy.

Least squares fits of calculated total cooling factors (cooling requirements divided by the sum of operating and fuel energy for cooling) are plotted in figure 23. Residual standard deviations are less than 14 percentage points. Due to the inclusion of operating energy in the total cooling factor the "design alternative" cooling factors are higher than for the other simulation cases.

\subsection{COMPARISON OF SIMULATED SUBSYSTEMS - CENTRAL VERSUS HEAT PUMP}

Plotting HVAC energy versus energy requirements from the various simulation cases allows a comparison to be made of the two major subsystems in this bullding, the heat pump and central system. A plot of the total heating 
energy (fuel and operating) versus the heating requirement is shown in Figure 24 with a different symbol for each of the two subsystems. It appears that the central system uses a slightly larger amount to meet a given load than does the heat pump system, but there are not enough points for a strong preference for either of the subsystems. Data for the cooling season are shown in Figure 25 and again the central system appears to use a slight amount more energy than the heat pump system. A complete comparison of the systems should use a life cycle cost analysis including effects of fuel and equipment costs.

\section{COMPONENTS OF FUEL ENERGY USE AT THE NCFOB}

The output data from the EEC program allow the amounts of energy being used by the major pieces of equipment such as the boilers, chillers, heat pumps and engine-generator, as well as the amount of energy delivered to areas with heating loads and extracted from areas with cooling loads, to be determined. This fuel energy does not include auxiliary energy to operate the major pieces of equipment and to operate pumps, fans, controls, and other devices used to transport heat transfer fluids throughout the building. The components of fuel energy use for the five simulation cases described here are compiled in tables 6 through 10 .

A limited amount of actual measured energy data collected at the NCFOB is available for comparison with the simulation fuel energy components data. The actual data is presented in Table 11 and consists of fuel input to boilers, fuel input to the domestic hot water heater, electric input to heat pumps, fuel input to the boilers used to heat water for the absorption chiller, and electric chiller input. No actual energy requirements or load data are available and therefore nothing can be said about the actual energy conversion efficiency of the equipment. It is possible to compare the actual fuel energy data with the analogous simulation data and this is done in Figures 26, 27, and 28. The Figures show that at this level there are some differences between the "as-operated" simulation data and the actual data.

Figure 26 compares measured boiler input (gas and oil) and simulation predicted boiler input. The actual input to the boilers is lower than the simulated input at low ambient temperatures. Figure 27 shows the comparison for heat pump electric input and service hot water heating (purchased energy only). The actual data for the heat pumps include fans in the heat pump units, while the simulated data are for compressor input only (total heat pump system $\mathrm{fan}$ input in the simulation is on the order of $22 \mathrm{GJ} / \mathrm{month}(20 \mathrm{x}$ $\left.\left.10^{6} \mathrm{Btu} / \mathrm{month}\right)\right)$. The actual electric input to the heat pumps in winter is lower than in the simulation, especially when fan energy is added to the simulation data. However, the actual summer heat pump electric consumption is slightly higher even when fan energy is added to the simulation data. The simulated and actual service hot water heater inputs are similar although in the actual case all requirements for service water heating are met by solar energy during summer months. A comparison of actual and simulation data for the chillers is given in Figure 28. Actual input to the electric chiller is slightly lower than predicted. Figure 28 also shows that the pattern of use for the absorption chiller that is simulated is very different 
from the actual use pattern. The simulation is based on parallel operation of the chillers. In actuality, the absorption chiller can be used independently of the electric chiller via manual control.

\section{COMPONENTS OF TOTAL ENERGY USE AT THE NCFOB}

Total energy use can be divided into two broad categories: lightingmiscellaneous and HVAC. HVAC energy is used to provide all heating, cooling, control functions, ventilation, and service hot water. Lighting-miscellaneous energy is used to provide power to lights, elevators, and electric receptacles for operating typewriters, copiers, and other equipment. HVAC energy can be divided into fuel and operating energy. Operating energy can be subdivided into energy to operate fans and energy to operate pumps, controls, and miscellaneous HVAC equipment. Table 12 contains energy use component data on a monthly basis for the "as-designed" simulation results. At the bottom of the table are annual totals and the percentage of the total for each category. The table shows that lighting-miscellaneous energy accounts for 36 percent of the total usage. Fuel energy makes up 44 percent while operating energy consumes a suprisingly large fraction of the total, 20 percent.

Tables 13 through 16 show the components of total energy use as predicted for the various building simulation cases. Actual measured data from the NCFOB for the period from November 1978 to October 1979 is given in Table 17 and is broken down into categories similar to those used in the tables for the simulation results. Actual and simulated total energy components are compared in Figure 29. In order to compare the results on an annual basis for the simulations and the actual data, Figure 30 has been prepared in bar chart form with the quantity of energy for each end use shown as different regions of the bars. For the actual data, the fuel energy and energy to operate fans cannot be separated due to the fact that the heat pump units do not have separate meters for the compressors and the integral fans. Thus, for the actual data, fan and fuel energy have been combined in Figure 30 .

\subsection{PREDICTED CONPONENTS OF TOTAL ENERGY USE}

When the solar system is added to the "as-designed" case the effect on the energy use is to decrease the fuel used; all other energy usages remain the same. This has the effect of increasing the percentage of energy used for lighting-miscellaneous and for operating energy.

For the "as-operated" case, while the energy used for lights and miscellaneous remains the same relative to the "as-designed" case, the fuel use decreases and the operating energy goes up to approximately 26 percent of the total. The operating energy increases because several pumps in the actual building operate around the clock but were assumed to operate only when heating or cooling loads existed in the "as-designed" case. Also, some equipment was added to the building after the original design, most notably an air conditioner for the elevator machine room to cool the solid state controls. 
The "as-operated with modifications" case shows a reduction in HVAC energy, both in the fuel and the operating energy categories. Operating energy for this case is approximately 25 percent of the total and HVAC energy makes up 63 percent. The energy use components for the "design alternative" look very different from the use components for the other cases. The lightingmiscellaneous increases to almost 41 percent of the total and fuel use increases to 51 percent of the total. However, the operating energy is much less than in the other cases, accounting for only 8 percent of the total energy usage. The energy to operate fans is about 4 to 6 percent of the total in all cases. If the fan energy is subtracted from the operating energy for the "design alternative" the remainder is 2 percent for pumps, controls and other HVAC equipment compared to 16 to 21 percent of the total in the other simulation cases. Much of the equipment used in the "design alternative" is more distributed throughout the building and less efficient than the equipment in the actual building but requires less supporting equipment and less operating energy. The fact that the NCFOB is an experimental building also has an effect on operating energy. The multiple systems in the building require much more operating energy than if a single type of mechanical system were used.

\subsection{ACTUAL ENERGY USE COMPONENTS VERSUS PREDICTED USE COMPONENTS}

In Figure 30, the "as-operated" case shows an operating energy use 9 percent greater than for the actual building, a lighting-miscellaneous which is 9 percent greater than actual, and a fuel plus fan energy use which is 12 percent greater than the actual. Fuel plus fan energy for the simulation and measured data were compared on a monthly basis in Figure 18. After plotting the fuel data versus ambient temperature, the "as-operated" curve fitted through the data was higher than the measured data curve. Some of the discrepancy may be due to weather differences. The lighting-miscellaneous energy and operating energy may be compared on a monthly basis in Figure 29. The lighting-miscellaneous energy is higher for the simulation than for the measured data and the difference is approximately constant through the year. However, the difference between predicted and measured operating energy varies as a function of the month. The actual operating energy dips to lower values during spring and fall compared to the "as-operated" simulation results.

Table 18 contains a comparison of the components of operating energy for the "as-operated" case, the "design alternative" case, and the actual data. The "as-operated" simulation overpredicts usage for various categories of equipment in some cases and underpredicts in others. This type of energy consumption is the most difficult to predict since estimated values for hourly consumption of auxiliary equipment must be input on an item by item basis for equipment which may operate under varying load and control conditions.

The "design alternative" does not contain as much mechanical equipment as in the "as-operated" case and this explains much of the higher operating energy consumption for the "as-operated" case. When the pieces of equipment exist in both cases, the usage is similar. 


\section{CONCLUSIONS}

\subsection{VALIDATION OF SIMULATION}

1. Actual total energy consumption per year measured at the NCFOB for calendar year 1979 was within 14 percent of the predicted value using the Ross Meriwether Energy System Analysis computer program for 1962 weather.

2. The simulation of the NCFOB in the "as-designed with solar" case with the computer program resulted in a prediction of total energy consumption per year which was within 2 percent of the original design goal of $625 \mathrm{MJ} /\left(\mathrm{m}^{2}\right.$. year) $\left(55 \mathrm{kBtu} /\left(\mathrm{ft}^{2} \cdot\right.\right.$ year $\left.)\right)$.

3. Actual energy consumption for lights and non-HVAC purposes at the NCFOB for the third year of operation was within 8 percent of the predicted value from the "as-operated" simulation case.

4. Actual energy consumption for fuel and fan energy at the NCFOB for the third year of operation was within 12 percent of the predicted value from the "as operated" simulation case using 1962 weather data.

5. Actual energy consumption for operating energy at the NCFOB for the third year of operation was within 9 percent of the predicted value from the "as-operated" simulation case using 1962 weather data.

\subsection{BUILDING DESIGN CONCLUSIONS}

1. As a result of modeling the mechanical systems in the NCFOB, a maximum efficiency of approximately 64 percent was predicted for meeting the heating loads in the building when heating requirements approached a maximum of 470 $\mathrm{GJ} /$ month $\left(500 \times 10^{6} \mathrm{Btu} / \mathrm{month}\right)$. For cooling, an overall coefficient of performance for the building was predicted to approach 0.75 as cooling requirements approached a maximum of $285 \mathrm{GJ} /$ month $\left(300 \times 10^{6} \mathrm{Btu} / \mathrm{month}\right)$ for the "as-operated" case. These values include the operating energy for the mechanical system as well as fuel consumption.

2. Based on a comparison of the performance predicted by the simulation of the two major mechanical subsystems in the NCFOB, the heat pump system on floors $1-3$ and the central system on floors 4-7 were found to use approximately the same amount of energy to meet a given load for the range of heating and cooling loads occurring in the building.

3. A "design alternative" was simulated which had approximately twice the lighting per unit floor area, five times more window area, one-third the insulation value in the roof and walls, and a much simpler mechanical system than the NCFOB. The yearly heating energy requirement was predicted to be similar to that of the NCFOB. The additional transmission losses in the "design alternative" were offset by increased solar gains and higher internal loads. However, cooling requirements were higher than for the NCFOB due to solar and internal gains. 
4. When the simulation results for the "design alternative" to the NCFOB were compared to the results for the other simulation cases, the predicted operating energy for the "design alternative" with its less complex and less efficient mechanical systems was approximately 2 percent of the total energy consumption of the building. This is in comparison to the 26 to 21 percent for the "actual design" cases. The large operating energy was partially due to the experimental nature of the building.

5. Selected modifications to the NCFOB as currently operated were predicted by simulation to reduce total energy consumption by 6 percent if implemented. A 2.5 percent reduction was due to lowering central chiller condenser water temperature and minimizing use of the absorption chiller fired by fuel oil. 


\section{REFERENCES}

1. Isaak, N., and Isaak, A., "Designing An Energy Efficient Building," General Services Administration/Public Buildings Service, GSA DC 76-3360 (September, 1975).

2. Hill, J. E., and Kusuda, T., "Manchester's New Federal Building: An Energy Conservation Project," ASHRAE Journal, (August, 1975).

3. Kusuda, T., Hill, J. E., Liu, S. T., Barnett, J. P., and Bean, J. W., "Pre-Design Analysis of Energy Conservation Options for a Multi-Story Demonstration Office Bulding, "Nat. Bur. Stand. (U.S.), Bldg. Sci. Ser. 78, (November, 1975).

4. Kusuda, T., Liu, S. T., Bean, J. W., and Barnett, J. P., "Analysis of the Solar Energy System for the GSA Demonstration Office Building in Manchester, New Hampshire," Nat. Bur. Stand. (U. S.) Report NBSIR 76-1056, (March, 1976).

5. Kusuda, T., "NBSLD, the Computer Program for Heating and Cooling Loads in Buildings," Nat. Bur. Stand. (U. S.), Bldg. Sci. Ser.69, (July, 1976).

6. Richtmyer, T. E., May, W. B., Hunt, C. M., Hill, J. E., "Thermal Performance of the Norris Cotton Federal Office Building in Manchester, New Hampshire," DoE/ASHRAE Conference on Thermal Performance of Exterior Envelopes of Buildings, Orlando, FL, (December, 1979).

7. ASHRAE Fundamentals Handbook, ASHRAE, New York, NY, (1977).

8. Hunt, C. M., "Ventilation Measurements in the Norris Cotton Federal Office Building in Manchester, New Hampshire," ASHRAE Transactions, Vol. 85, Part 1, (1979).

9. General Services Administration/Public Buildings Service, "Energy Conservation Design Guidelines for New Office Buildings," 2nd ed. (1977). 


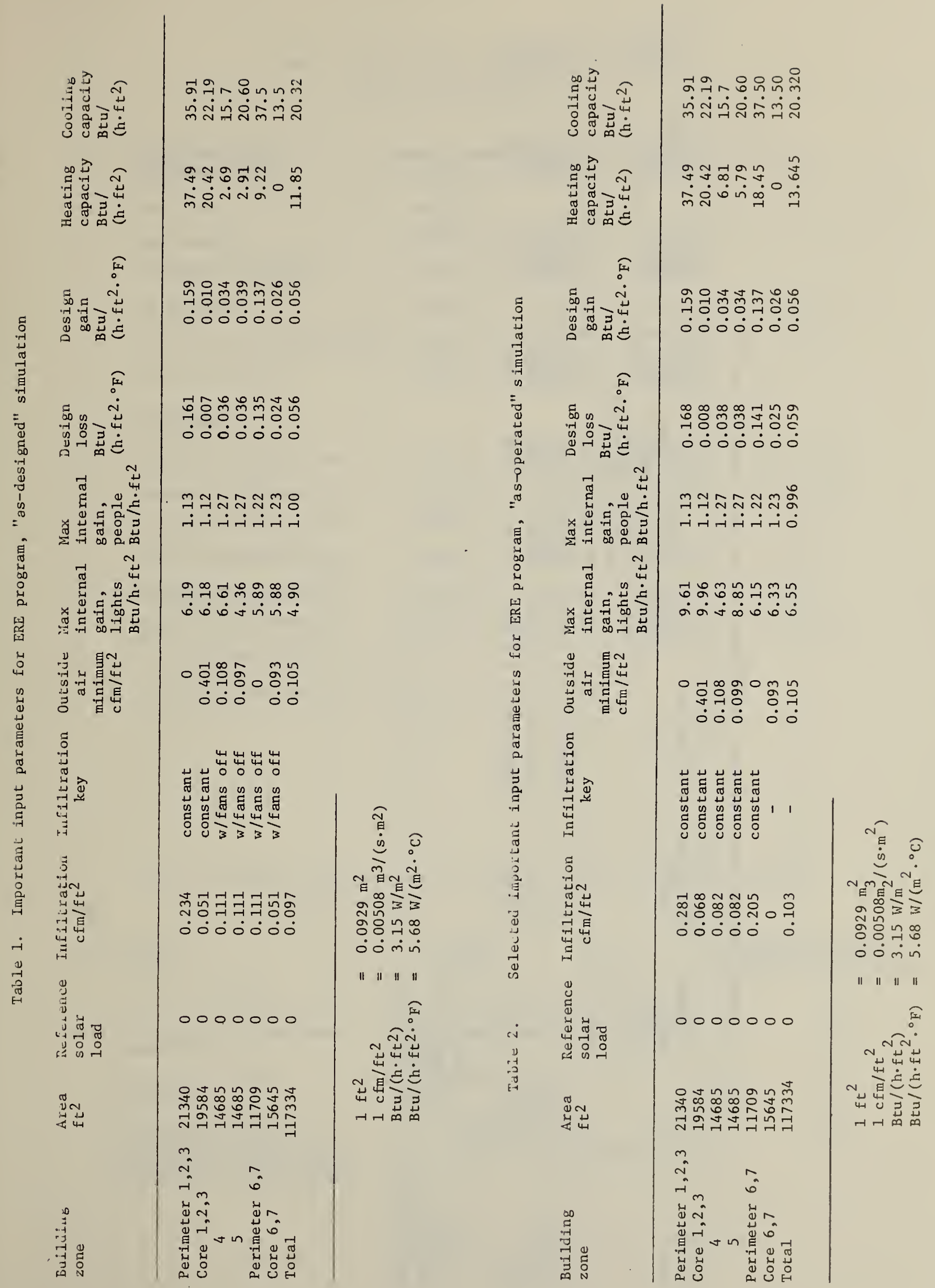




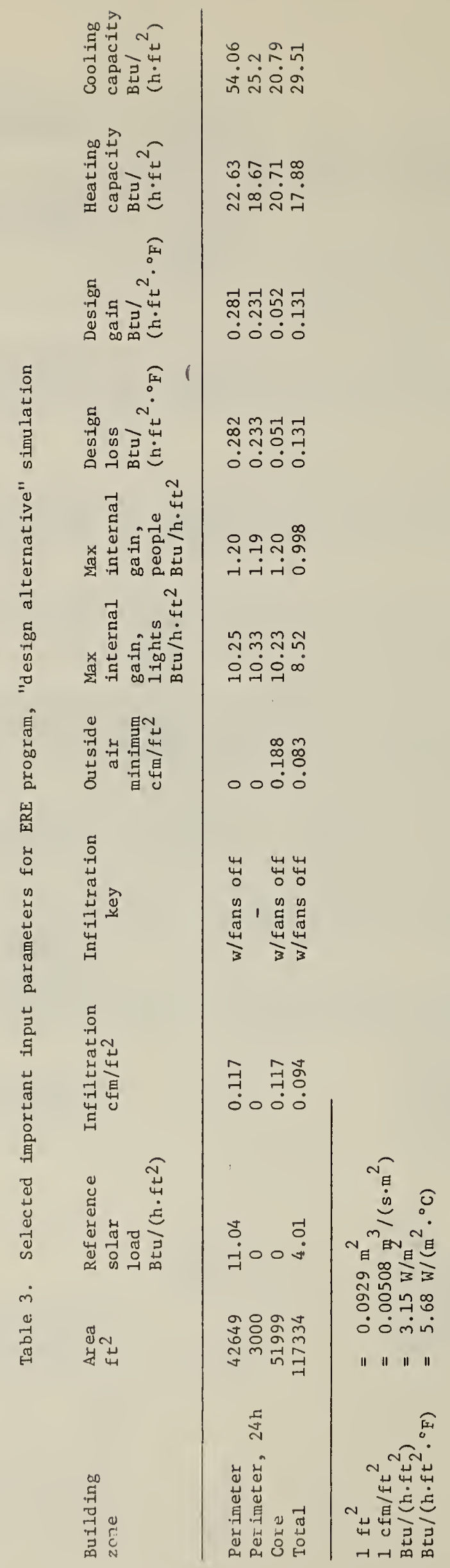


Table 4: Norris Cotton Federal office Building annual energy consumption

\begin{tabular}{|c|c|c|c|c|}
\hline \multirow{2}{*}{$\frac{\text { SIMULATION CASES }}{(1962 \text { weather data) }}$} & \multicolumn{4}{|c|}{ Energy consumption in $\mathrm{MJ} /\left(\mathrm{m}^{2 *} \cdot \mathrm{yr}\right)\left(\mathrm{kBtu} /\left(\mathrm{ft}^{2 *} \cdot \mathrm{yr}\right)\right)$} \\
\hline & Total & Gas & Electric & $\underline{011}$ \\
\hline Design Goal & $625(55.0)$ & --- & --- & -- \\
\hline "As-designed" & $686(60.2)$ & $251(22.0)$ & $436(38.2)$ & --- \\
\hline "As-designed with solar" & $616(54.0)$ & $174(15.3)$ & $441(38.7)$ & --- \\
\hline "As-operated" & $705(61.8)$ & $197(17.2)$ & $442(38.8)$ & $24(2.1)$ \\
\hline "As-operated with modifications" & $662(58.1)$ & $194(17.0)$ & $468(41.0)$ & $1(0.1)$ \\
\hline "Design alternative" & $676(59.3)$ & $303(26.5)$ & $373(32.8)$ & --- \\
\hline \multicolumn{5}{|l|}{ ACTUAL DATA } \\
\hline September 1976-August 1977 & $919(80.6)$ & $280(24.6)$ & $563(49.4)$ & $76(6.6)$ \\
\hline January 1977-December 1977 & $813(71.3)$ & $237(20.9)$ & $514(45.1)$ & $61(5.3)$ \\
\hline September 1977-August 1978 & $758(66.5)$ & $225(19.7)$ & $498(43.7)$ & $35(3.1)$ \\
\hline January 1978-December 1978 & $730(64.0)$ & $208(18.3)$ & $495(43.4)$ & $27(2.3)$ \\
\hline September 1978-August 1979 & $641(56.2)$ & $153(13.4)$ & $459(40.3)$ & $28(2.5)$ \\
\hline January 1979-December 1979 & $619(54.3)$ & $141(12.3)$ & $459(40.3)$ & $19(1.7)$ \\
\hline
\end{tabular}

*equivalent gross floor area $=10,900 \mathrm{~m}^{2}\left(117334 \mathrm{ft}^{2}\right)$

Table 5. Summary of effects of modifications made to the "as-operated" simulation

\section{MODIFICATIONS}

1. Cycle heat pump fans

2. Raise cooling coil discharge temperature of VAV

3. Raise heat pump loop temperature

4. Lower central chiller condenser water temperature and sequence chillers, electric chiller first, absorption last

\section{EFFECT}

Saves $45000 \mathrm{kWh}$ for fans

Reduce cooling requirements $18 \%$

Save $5000 \mathrm{kWh}$

Save $54415 \mathrm{kWh}$

absorption chiller seldom used
PERCENT REDUCTION IN TOTAL ENERGY CONSUMPTION
$1.3 \%$
$1.2 \%$
$0.3 \%$
$2.5 \%$ 


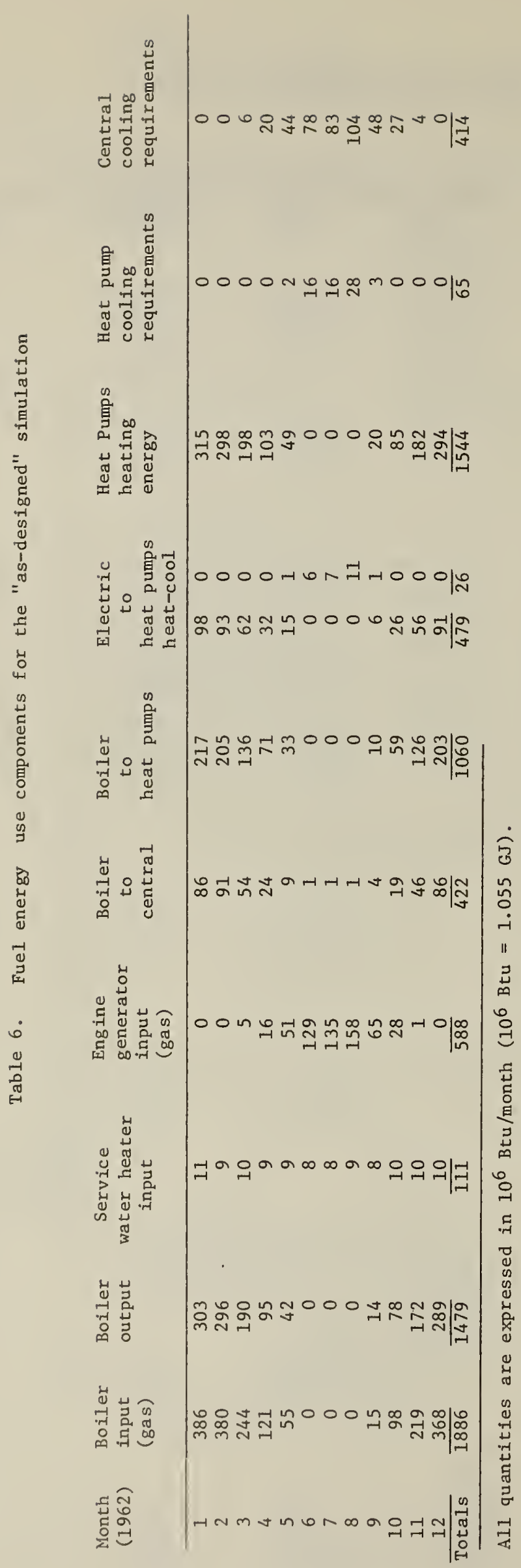


Table 7. Fuel energy use components for the "as-designed with solar" simulation

\begin{tabular}{|c|c|c|c|c|c|c|c|c|c|}
\hline $\begin{array}{l}\text { Month } \\
(1962)\end{array}$ & $\begin{array}{l}\text { Boiler } \\
\text { input } \\
\text { (gas) }\end{array}$ & $\begin{array}{l}\text { Boiler } \\
\text { output }\end{array}$ & $\begin{array}{l}\text { Service } \\
\text { water } \\
\text { input }\end{array}$ & $\begin{array}{l}\text { Boiler } \\
\text { to } \\
\text { central }\end{array}$ & $\begin{array}{l}\text { Boiler } \\
\text { to } \\
\text { heat pumps }\end{array}$ & $\begin{array}{l}\text { Elect } \\
\text { heat } \\
\text { heat }\end{array}$ & $\begin{array}{l}\text { ric } \\
\text { pumps } \\
\text { cool }\end{array}$ & $\begin{array}{l}\text { Heat } \\
\text { syst } \\
\text { requ } \\
\text { heat }\end{array}$ & $\begin{array}{l}\text { mp } \\
\text { ments } \\
\text { cool }\end{array}$ \\
\hline 1 & 330 & 260 & 11 & 43 & 217 & 98 & 0 & 315 & 0 \\
\hline 2 & 329 & 257 & 9 & 52 & 205 & 93 & 0 & 298 & 0 \\
\hline 3 & 195 & 153 & 10 & 15 & 136 & 62 & 0 & 198 & 0 \\
\hline 4 & 93 & 73 & 9 & 0 & 71 & 32 & 0 & 103 & 0 \\
\hline 5 & 44 & 34 & 9 & 0 & 33 & 15 & 1 & 42 & 2 \\
\hline 6 & 28 & 21 & 8 & 0 & 0 & 0 & 6 & 0 & 16 \\
\hline 7 & 27 & 21 & 8 & 0 & 0 & 0 & 7 & 0 & 16 \\
\hline 8 & 35 & 27 & 10 & 0 & 0 & 0 & 11 & 0 & 28 \\
\hline 9 & 21 & 5 & 8 & 0 & 10 & 6 & 1 & 20 & 3 \\
\hline 10 & 77 & 60 & 10 & 0 & 59 & 26 & 0 & 85 & 0 \\
\hline 11 & 176 & 139 & 10 & 13 & 126 & 56 & 0 & 182 & 0 \\
\hline 12 & 321 & 253 & 10 & 50 & 203 & 91 & 0 & 294 & 0 \\
\hline Totals & $\overline{1676}$ & $\overline{1303}$ & $\overline{112}$ & $\overline{173}$ & 1060 & $\overline{479}$ & $\overline{26}$ & $\overline{1537}$ & $\overline{62}$ \\
\hline
\end{tabular}

\begin{tabular}{|c|c|c|c|c|c|c|c|}
\hline $\begin{array}{l}\text { Month } \\
(1962)\end{array}$ & $\begin{array}{l}\text { Solar } \\
\text { to } \\
\text { heat pumps }\end{array}$ & $\begin{array}{l}\text { Solar } \\
\text { to } \\
\text { central }\end{array}$ & $\begin{array}{l}\text { Solar } \\
\text { to } \\
\text { absorption } \\
\text { chiller }\end{array}$ & $\begin{array}{l}\text { Auxiliary } \\
\text { to } \\
\text { absorption } \\
\text { chiller }\end{array}$ & $\begin{array}{l}\text { Electric } \\
\text { chiller } \\
\text { input }\end{array}$ & $\begin{array}{l}\text { Central } \\
\text { cooling } \\
\text { requirements }\end{array}$ & $\begin{array}{l}\text { Solar } \\
\text { energy } \\
\text { used }\end{array}$ \\
\hline 1 & 0 & 43 & 0 & 0 & $\dot{0}$ & 0 & 43 \\
\hline 2 & 0 & 39 & 0 & 0 & 0 & 0 & 39 \\
\hline 3 & 0 & 39 & 0 & 2 & 0 & 6 & 39 \\
\hline 4 & 0 & 24 & 4 & 2 & 1 & 20 & 28 \\
\hline 5 & 0 & 9 & 16 & 1 & 5 & 44 & 25 \\
\hline 6 & 0 & 1 & 22 & 21 & 13 & 78 & 23 \\
\hline 7 & 0 & 1 & 24 & 21 & 14 & 83 & 25 \\
\hline 8 & 0 & 1 & 27 & 27 & 18 & 104 & 28 \\
\hline 9 & 0 & 4 & 16 & 5 & 6 & 48 & 20 \\
\hline 10 & 0 & 19 & 8 & 1 & 2 & 27 & 27 \\
\hline 11 & 0 & 33 & 0 & 0 & 0 & 4 & 33 \\
\hline 12 & 0 & 36 & 0 & 0 & 0 & 0 & 36 \\
\hline$\overline{\text { Totals }}$ & $\overline{0}$ & $\overline{249}$ & $\overline{117}$ & $\overline{80}$ & $\overline{59}$ & $\overline{414}$ & $\overline{366}$ \\
\hline
\end{tabular}

Al1 quantities are expressed in $10^{6} \mathrm{Btu} / \mathrm{month}\left(10^{6} \mathrm{Btu}=1.055 \mathrm{GJ}\right)$. 
Table 8. Fuel energy use components for the "design alternative" simulation

\begin{tabular}{|c|c|c|c|c|c|c|c|}
\hline $\begin{array}{l}\text { Month } \\
(1962)\end{array}$ & $\begin{array}{l}\text { Boiler } \\
\text { input } \\
\text { (gas) }\end{array}$ & $\begin{array}{l}\text { Boiler } \\
\text { to } \\
\text { heating }\end{array}$ & $\begin{array}{l}\text { Service } \\
\text { water heater } \\
\text { input }\end{array}$ & air & $\begin{array}{l}\text { electric } \\
\text { to } \\
\text { thru-wall } \\
\text { conditioners }\end{array}$ & $\begin{array}{l}\text { electric } \\
\text { to } \\
\text { packaged } \\
\text { units }\end{array}$ & $\begin{array}{l}\text { cooling } \\
\text { load }\end{array}$ \\
\hline 1 & 626 & 447 & 5 & & 0 & 0 & 0 \\
\hline 2 & 617 & 444 & 4 & & 0 & 0 & 0 \\
\hline 3 & 375 & 249 & 4 & & 4 & 0 & 9 \\
\hline 4 & 173 & 110 & 4 & & 10 & 0 & 25 \\
\hline 5 & 74 & 46 & 4 & & 31 & 7 & 96 \\
\hline 6 & 0 & 0 & 3 & & 67 & 27 & 243 \\
\hline 7 & 0 & 0 & 3 & & 69 & 30 & 250 \\
\hline 8 & 0 & 0 & 4 & & 78 & 39 & 295 \\
\hline 9 & 32 & 18 & 3 & & 32 & 8 & 103 \\
\hline 10 & 160 & 98 & 4 & & 12 & 0 & 30 \\
\hline 11 & 365 & 140 & 5 & & 1 & 0 & 2 \\
\hline 12 & 608 & 430 & 5 & & 0 & 0 & 0 \\
\hline Totals & 3030 & 1982 & $\overline{48}$ & & $\overline{304}$ & $\overline{111}$ & $\overline{1053}$ \\
\hline
\end{tabular}

Al1 quantities are expressed in $10^{6} \mathrm{Btu} /$ month $\left(10^{6} \mathrm{Btu}=1.055 \mathrm{GJ}\right)$. 
Table 9. Fuel energy use components for the "as-operated" simulation

\begin{tabular}{|c|c|c|c|c|c|c|c|c|}
\hline $\begin{array}{l}\text { Month } \\
\text { (1962) }\end{array}$ & $\begin{array}{l}\text { Boiler } \\
\text { input } \\
\text { (gas \& } \\
\text { oil) } \\
\end{array}$ & $\begin{array}{l}\text { Boiler } \\
\text { output }\end{array}$ & $\begin{array}{l}\text { Service } \\
\text { water } \\
\text { input }\end{array}$ & $\begin{array}{l}\text { Boiler } \\
\text { to } \\
\text { central }\end{array}$ & $\begin{array}{l}\text { Boiler } \\
\text { to } \\
\text { heat pumps }\end{array}$ & $\begin{array}{l}\text { Electric } \\
\text { to } \\
\text { heat pumps } \\
\text { heat cool }\end{array}$ & \multicolumn{2}{|c|}{$\begin{array}{l}\text { Heat pump } \\
\text { system } \\
\text { requirements }\end{array}$} \\
\hline 1 & 447 & 344 & 11 & 120 & 224 & 101 & 325 & 0 \\
\hline 2 & 434 & 334 & 9 & 122 & 212 & 95 & 307 & 0 \\
\hline 3 & 261 & 202 & 10 & 72 & 130 & 58 & 188 & 0 \\
\hline 4 & 81 & 61 & 10 & 8 & 53 & 24 & 77 & 0 \\
\hline 5 & 40 & 26 & 10 & 0 & 19 & 8 & 27 & 9 \\
\hline 6 & 55 & 46 & 8 & 1 & 0 & 18 & 0 & 45 \\
\hline 7 & 59 & 47 & 8 & 1 & 0 & 19 & 0 & 47 \\
\hline 8 & 74 & 58 & 10 & 11 & 0 & 27 & 0 & 68 \\
\hline 9 & 14 & 10 & 9 & 0 & 8 & 5 & 12 & 13 \\
\hline 10 & 63 & 47 & 10 & 5 & 42 & 19 & 61 & 0 \\
\hline 11 & 236 & 179 & 10 & 64 & 115 & 52 & 167 & 0 \\
\hline 12 & 420 & 323 & 11 & 113 & 210 & 94 & 304 & 0 \\
\hline \multirow[t]{15}{*}{ Totals } & $\overline{2184}$ & $\overline{1677}$ & $\overline{116}$ & 507 & $\overline{1013}$ & $\overline{455}$ & $\overline{1468}$ & $\overline{182}$ \\
\hline & $\begin{array}{l}\text { Month } \\
(1962)\end{array}$ & $\begin{array}{l}\text { Solar } \\
\text { to } \\
\text { central }\end{array}$ & $\begin{array}{l}\text { Solar } \\
\text { to } \\
\text { absorption } \\
\text { chiller }\end{array}$ & $\begin{array}{l}\text { Auxiliary } \\
\text { to } \\
\text { absorption } \\
\text { chiller }\end{array}$ & $\begin{array}{l}\text { Electric } \\
\text { chiller } \\
\text { input }\end{array}$ & $\begin{array}{l}\text { central } \\
\text { cooling } \\
\text { requirement }\end{array}$ & $\begin{array}{l}\text { Solar } \\
\text { used }\end{array}$ & \\
\hline & 1 & 0 & 0 & 0 & 0 & 0 & 4 & \\
\hline & 2 & 0 & 0 & 0 & 0 & 0 & 3 & \\
\hline & 3 & 0 & 0 & 0 & 0 & 3 & 5 & \\
\hline & 4 & 25 & 0 & 0 & 0 & 9 & 28 & \\
\hline & 5 & 14 & 12 & 17 & 5 & 27 & 29 & \\
\hline & 6 & 0 & 0 & 45 & 14 & 72 & 7 & \\
\hline & 7 & 0 & 0 & 47 & 15 & 77 & 6 & \\
\hline & 8 & 0 & 0 & 58 & 20 & 103 & 6 & \\
\hline & 9 & 5 & 21 & 2 & 6 & 34 & 29 & \\
\hline & 10 & 21 & 0 & 0 & 0 & 14 & 24 & \\
\hline & 11 & 0 & 0 & 0 & 0 & 1 & 3 & \\
\hline & 12 & $\underline{0}$ & $\underline{0}$ & 0 & $\underline{0}$ & 0 & 3 & \\
\hline & Totals & $\overline{65}$ & $\overline{33}$ & $\overline{169}$ & $\overline{60}$ & $\overline{340}$ & $\overline{147}$ & \\
\hline
\end{tabular}

Al1 quantities are expressed in $10^{6} \mathrm{Btu} /$ month $\left(10^{6} \mathrm{Btu}=1.055 \mathrm{GJ}\right)$. 
Table 10. Fuel energy use components for the "as-operated with modifications" simulation

\begin{tabular}{|c|c|c|c|c|c|c|c|c|c|}
\hline \multirow[t]{2}{*}{$\begin{array}{l}\text { Month } \\
\text { (1962) }\end{array}$} & \multirow{2}{*}{$\begin{array}{l}\text { Boiler } \\
\text { input } \\
\text { (gas \& oil) }\end{array}$} & \multirow[t]{2}{*}{$\begin{array}{l}\text { Boiler } \\
\text { output }\end{array}$} & \multirow{2}{*}{$\begin{array}{c}\text { Service } \\
\text { water-heater } \\
\text { input }\end{array}$} & \multirow{2}{*}{$\begin{array}{l}\text { Boiler } \\
\text { to } \\
\text { central }\end{array}$} & \multirow[t]{2}{*}{$\begin{array}{l}\text { Boiler to } \\
\text { heat pumps }\end{array}$} & \multicolumn{2}{|c|}{$\begin{array}{l}\text { Electric to } \\
\text { heat pumps }\end{array}$} & \multicolumn{2}{|c|}{$\begin{array}{l}\text { Heat pump system } \\
\text { requirements }\end{array}$} \\
\hline & & & & & & heat & cool & heat & \\
\hline 1 & 444 & 348 & 11 & 119 & 229 & 96 & 0 & 325 & 0 \\
\hline 2 & 432 & 339 & 9 & 122 & 217 & 90 & 0 & 307 & 0 \\
\hline 3 & 257 & 202 & 10 & 69 & 133 & 55 & 0 & 188 & 0 \\
\hline 4 & 77 & 59 & 10 & 5 & 54 & 23 & 0 & 77 & 0 \\
\hline 5 & 5 & 4 & 10 & 4 & 0 & 8 & 4 & 27 & 9 \\
\hline 6 & 0 & 0 & 8 & 0 & 0 & 0 & 19 & 0 & 45 \\
\hline 7 & 0 & 0 & 8 & 0 & 0 & 0 & 20 & 0 & 47 \\
\hline 8 & 0 & 0 & 10 & 0 & 0 & 0 & 29 & 0 & 68 \\
\hline 9 & 1 & 1 & 9 & 1 & 0 & 3 & 6 & 11 & 13 \\
\hline 10 & 61 & 43 & 10 & 0 & 43 & 18 & 0 & 61 & 0 \\
\hline 11 & 231 & 179 & 10 & 61 & 118 & 49 & 0 & 167 & 0 \\
\hline 12 & 416 & 326 & 11 & 111 & 215 & 89 & 0 & 304 & 0 \\
\hline Totals & $\overline{1924}$ & $\overline{1501}$ & $\overline{116}$ & $\overline{492}$ & $\overline{1009}$ & $\overline{431}$ & $\overline{78}$ & $\overline{1467}$ & $\overline{182}$ \\
\hline
\end{tabular}

$\begin{array}{cccccc}\text { Month } & \text { Solar } & \text { Absorption } \\ \text { (1962) } & \text { Electric chiller } & \text { Central cooling } \\ \text { central } & \text { input } & \text { input } & \text { Solar used }\end{array}$

\begin{tabular}{|c|c|c|c|c|c|}
\hline 1 & 0 & 0 & 0 & 0 & 4 \\
\hline 2 & 0 & 0 & 0 & 0 & 4 \\
\hline 3 & 0 & 0 & 0 & 2 & 5 \\
\hline 4 & 26 & 0 & 0 & 5 & 29 \\
\hline 5 & 9 & 0 & 5 & 21 & 12 \\
\hline 6 & 0 & 0 & 14 & 61 & 3 \\
\hline 7 & 0 & 0 & 16 & 66 & 3 \\
\hline 8 & 0 & 1 & 21 & 89 & 5 \\
\hline 9 & 4 & 0 & 6 & 26 & 7 \\
\hline 10 & 25 & 0 & 0 & 8 & 25 \\
\hline 11 & 0 & 0 & 0 & 0 & 4 \\
\hline 12 & 0 & 0 & 0 & 0 & 4 \\
\hline Totals & $\overline{64}$ & $\frac{\overline{1}}{1}$ & $\overline{62}$ & $\overline{278}$ & $\overline{105}$ \\
\hline
\end{tabular}

All quantities are expressed in $10^{6} \mathrm{Btu} /$ month $\left(10^{6} \mathrm{Btu}=1.055 \mathrm{GJ}\right)$. 
Table 11 Partial fuel energy use components from actual data

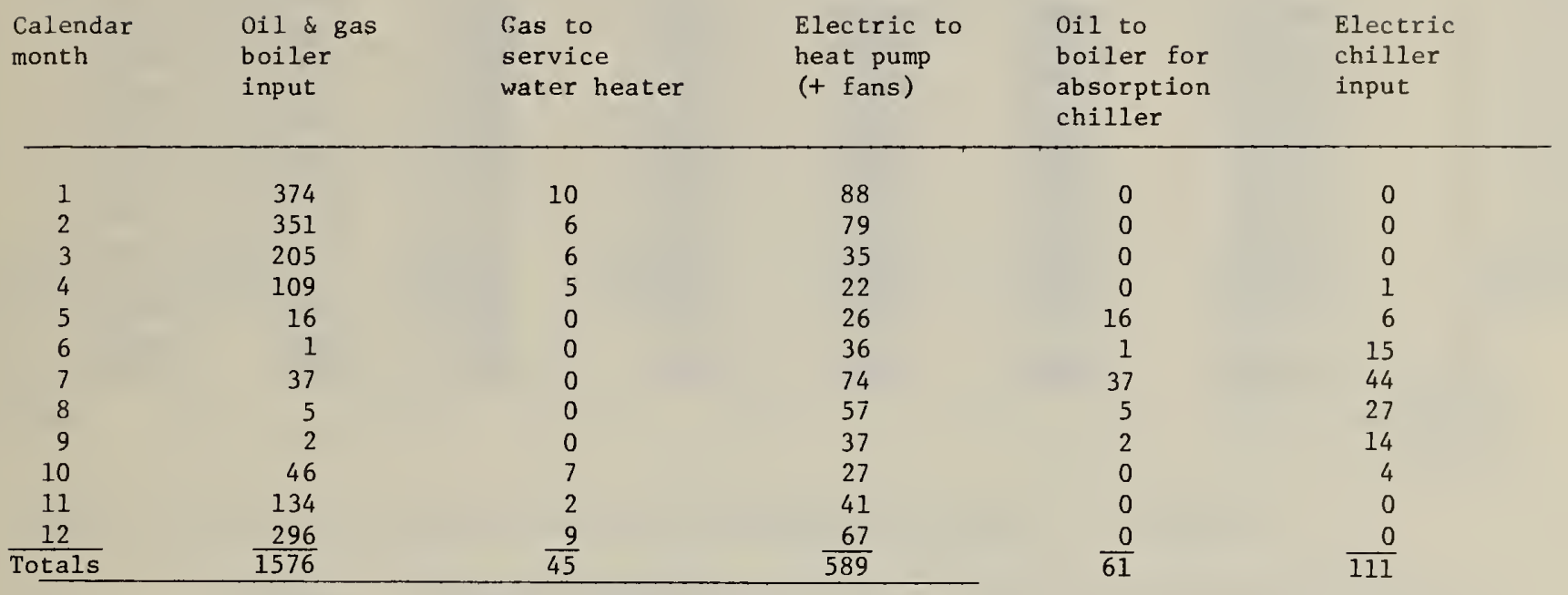

All quantities are expressed in $10^{6} \mathrm{Btu} / \mathrm{month}\left(10^{6} \mathrm{Btu}=1.055 \mathrm{GJ}\right)$.

Data are from the period from November 1978 to October 1979. 
Table 12. Energy use components for the "as-designed" simulation

\begin{tabular}{|c|c|c|c|c|c|c|c|}
\hline $\begin{array}{l}\text { Month } \\
(1962)\end{array}$ & $\begin{array}{l}\text { Lights } \\
+ \text { misc. } \\
\text { kWh }\end{array}$ & $\begin{array}{l}\text { HVAC } \\
\mathrm{kWh}\end{array}$ & $\begin{array}{l}\text { Direct } \\
\text { fuel } \\
\text { kWh }\end{array}$ & $\begin{array}{l}\text { Operating } \\
\text { energy } \\
\text { kWh }\end{array}$ & $\begin{array}{l}\text { Fans } \\
\mathrm{kWh}\end{array}$ & $\begin{array}{l}\text { Pumps, } \\
\text { controls } \\
+ \text { misc. } \\
\mathrm{kWh} \\
\end{array}$ & Total \\
\hline 1 & 64138 & 188841 & 144700 & 44140 & 10415 & 33725 & 252979 \\
\hline 2 & 56585 & 183987 & 140863 & 43124 & 10261 & 32862 & 240572 \\
\hline 3 & 62593 & 133413 & 93959 & 39453 & 9193 & 30260 & 196006 \\
\hline 4 & 61620 & 82630 & 52154 & 30475 & 6648 & 23827 & 144250 \\
\hline 5 & 64138 & 68125 & 38381 & 29744 & 6360 & 23384 & 132263 \\
\hline 6 & 61620 & 72489 & 41998 & 30491 & 6068 & 24423 & 134109 \\
\hline 7 & 62593 & 75326 & 43866 & 31460 & 6069 & 25391 & 137919 \\
\hline 8 & 65683 & 85278 & 52233 & 33045 & 6685 & 26360 & 150961 \\
\hline 9 & 58530 & 56031 & 28051 & 27980 & 5557 & 22423 & 114561 \\
\hline 10 & 64138 & 79144 & 47605 & 31539 & 6863 & 24676 & 143282 \\
\hline 11 & 61620 & 119146 & 83964 & 35182 & 8177 & 27005 & 180766 \\
\hline 12 & 61047 & 182671 & 137509 & 45162 & 10602 & 34560 & 243718 \\
\hline$\overline{\text { Annual }}$ & 744305 & 1327081 & 905576 & 421795 & 92898 & 328896 & 2071386 \\
\hline$\%$ of total & & & & & & & \\
\hline energy & 36 & 64 & 44 & 20 & 4 & 16 & \\
\hline
\end{tabular}

Table 13. Energy use components for the "as designed with solar" simulation

\begin{tabular}{|c|c|c|c|c|c|c|c|}
\hline $\begin{array}{l}\text { Month } \\
(1962)\end{array}$ & $\begin{array}{l}\text { Lights } \\
+ \text { misc. } \\
\text { kWh }\end{array}$ & $\begin{array}{l}\text { HVAC } \\
\mathrm{kWh}\end{array}$ & $\begin{array}{l}\text { Direct } \\
\text { fuel } \\
\mathrm{kWh}\end{array}$ & $\begin{array}{l}\text { Operating } \\
\text { energy } \\
\text { kWh }\end{array}$ & $\begin{array}{l}\text { Fans } \\
\mathrm{kWh}\end{array}$ & $\begin{array}{l}\text { Pumps, } \\
\text { controls } \\
+ \text { misc. } \\
\quad \text { kWh }\end{array}$ & Tota 1 \\
\hline 1 & 64138 & 172663 & 128581 & 44082 & 10415 & 33667 & 236801 \\
\hline 2 & 56585 & 169080 & 126210 & 42870 & 10261 & 32609 & 225665 \\
\hline 3 & 62593 & 117646 & 78244 & 39402 & 9193 & 30209 & 180239 \\
\hline 4 & 61620 & 69969 & 39598 & 30371 & 6648 & 23723 & 131589 \\
\hline 5 & 64138 & 51332 & 21546 & 29786 & 6360 & 23426 & 115470 \\
\hline 6 & 61620 & 46816 & 16250 & 30566 & 6068 & 24498 & 108436 \\
\hline 7 & 62593 & 48188 & 16575 & 31613 & 6069 & 25544 & 110781 \\
\hline 8 & 65683 & 55062 & 21806 & 33256 & 6685 & 26571 & 120745 \\
\hline 9 & 58530 & 40528 & 12448 & 28080 & 5557 & 22523 & 99058 \\
\hline 10 & 64138 & 65399 & 33853 & 31546 & 6863 & 24683 & 129537 \\
\hline 11 & 61620 & 106017 & 71096 & 34921 & 8127 & 26794 & 167637 \\
\hline 12 & 61047 & 168721 & 123735 & 44986 & 10602 & 34384 & 229768 \\
\hline $\begin{array}{l}\overline{\text { Annual }} \\
\% \text { of tota } 1\end{array}$ & $\overline{774305}$ & $\overline{1111421}$ & $\overline{689942}$ & $\overline{421479}$ & $\overline{92898}$ & $\overline{328581}$ & $\overline{1185726}$ \\
\hline energy & 40 & 60 & 37 & 23 & 5 & 18 & \\
\hline
\end{tabular}


Table 14 Energy use components for the "as-operated" simulation

\begin{tabular}{|c|c|c|c|c|c|c|c|}
\hline $\begin{array}{l}\text { Month } \\
\text { (1962) }\end{array}$ & $\begin{array}{l}\text { Lights }+ \\
\text { misc. } \mathrm{kWh}\end{array}$ & $\begin{array}{l}\text { IIVAC } \\
\mathrm{kWh}\end{array}$ & $\begin{array}{l}\text { Direct } \\
\text { fuel } \\
\text { kWh }\end{array}$ & $\begin{array}{l}\text { Operating } \\
\text { energy } \\
\text { kWh }\end{array}$ & $\begin{array}{l}\text { Fans } \\
\mathrm{kWh}\end{array}$ & $\begin{array}{c}\text { Pumps, controls } \\
+\quad \text { misc. } \\
\text { kWh }\end{array}$ & Total \\
\hline 1 & 64138 & 213986 & 162945 & 51041 & 11676 & 39365 & 278124 \\
\hline 2 & 56585 & 203955 & 156895 & 47060 & 10749 & 36311 & 260540 \\
\hline 3 & 62592 & 143437 & 95618 & 47819 & 10924 & 36895 & 206029 \\
\hline 4 & 61620 & 76416 & 32489 & 43927 & 9597 & 34330 & 138036 \\
\hline 5 & 64138 & 59245 & 18753 & 40492 & 9886 & 30606 & 123383 \\
\hline 6 & 61620 & 70555 & 27562 & 42993 & 10186 & 32807 & 132175 \\
\hline 7 & 62592 & 73100 & 28992 & 44108 & 10414 & 33694 & 135692 \\
\hline 8 & 65685 & 84367 & 37656 & 46712 & 10856 & 35856 & 150052 \\
\hline 9 & 58530 & 49320 & 10263 & 39057 & 9205 & 29852 & 107850 \\
\hline 10 & 64138 & 71847 & 26328 & 45519 & 9864 & 35655 & 135985 \\
\hline 11 & 61620 & 131514 & 86413 & 45101 & 10157 & 34944 & 193134 \\
\hline 12 & 61046 & 203890 & 152804 & 51086 & 11610 & 39476 & 264936 \\
\hline$\overline{\text { Annual }}$ & 744308 & 1381632 & 836718 & 544915 & 125124 & 419791 & 2125940 \\
\hline $\begin{array}{l}\% \text { of } \\
\text { total } \\
\text { energy }\end{array}$ & 35 & 65 & 39 & 26 & 6 & 20 & \\
\hline
\end{tabular}

Table 15. Energy use components for the "design alternative" simulation

\begin{tabular}{|c|c|c|c|c|c|c|c|}
\hline $\begin{array}{l}\text { Month } \\
(1962)\end{array}$ & $\begin{array}{l}\text { Lights }+ \\
\text { misc. kWh }\end{array}$ & $\begin{array}{c}\text { HVAC } \\
\mathrm{kWh}\end{array}$ & $\begin{array}{l}\text { Direct } \\
\text { fuel } \\
\mathrm{kWh}\end{array}$ & $\begin{array}{l}\text { Operating } \\
\text { energy } \\
\text { kWh }\end{array}$ & $\begin{array}{l}\text { Fans } \\
\mathrm{kWh}\end{array}$ & $\begin{array}{l}\text { Pumps, controls } \\
+ \text { misc. } \\
\text { kWh }\end{array}$ & Total \\
\hline 1 & 72271 & 203802 & 186100 & 17702 & 14255 & 3447 & 276073 \\
\hline 2 & 63279 & 199606 & 182876 & 16729 & 13096 & 3633 & 262885 \\
\hline 3 & 69976 & 126968 & 112981 & 13987 & 11262 & 2725 & 196944 \\
\hline 4 & 69274 & 67004 & 55646 & 11358 & 9623 & 1735 & 136278 \\
\hline 5 & 72271 & 47888 & 35049 & 12839 & 10073 & 2766 & 120159 \\
\hline 6 & 69274 & 43265 & 29920 & 13345 & 9623 & 3722 & 112539 \\
\hline 7 & 69976 & 44029 & 30511 & 13517 & 9643 & 3874 & 114005 \\
\hline 8 & 74565 & 52042 & 36282 & 15759 & 10504 & 5255 & 126607 \\
\hline 9 & 64685 & 34959 & 22935 & 12024 & 8762 & 3262 & 99644 \\
\hline 10 & 72271 & 65472 & 52691 & 12781 & 10073 & 2708 & 137743 \\
\hline 11 & 69274 & 122688 & 109531 & 13157 & 10501 & 2656 & 191962 \\
\hline 12 & 67683 & 197546 & 180239 & 17308 & 14218 & 3090 & 265229 \\
\hline$\overline{\text { Annual }}$ & $\overline{834802}$ & $\overline{1205269}$ & $\overline{1034761}$ & $\overline{170506}$ & $\overline{131633}$ & $\overline{38873}$ & 2040071 \\
\hline $\begin{array}{l}\% \text { of } \\
\text { total } \\
\text { energy }\end{array}$ & 41 & 59 & 51 & 8 & 6 & 2 & \\
\hline
\end{tabular}




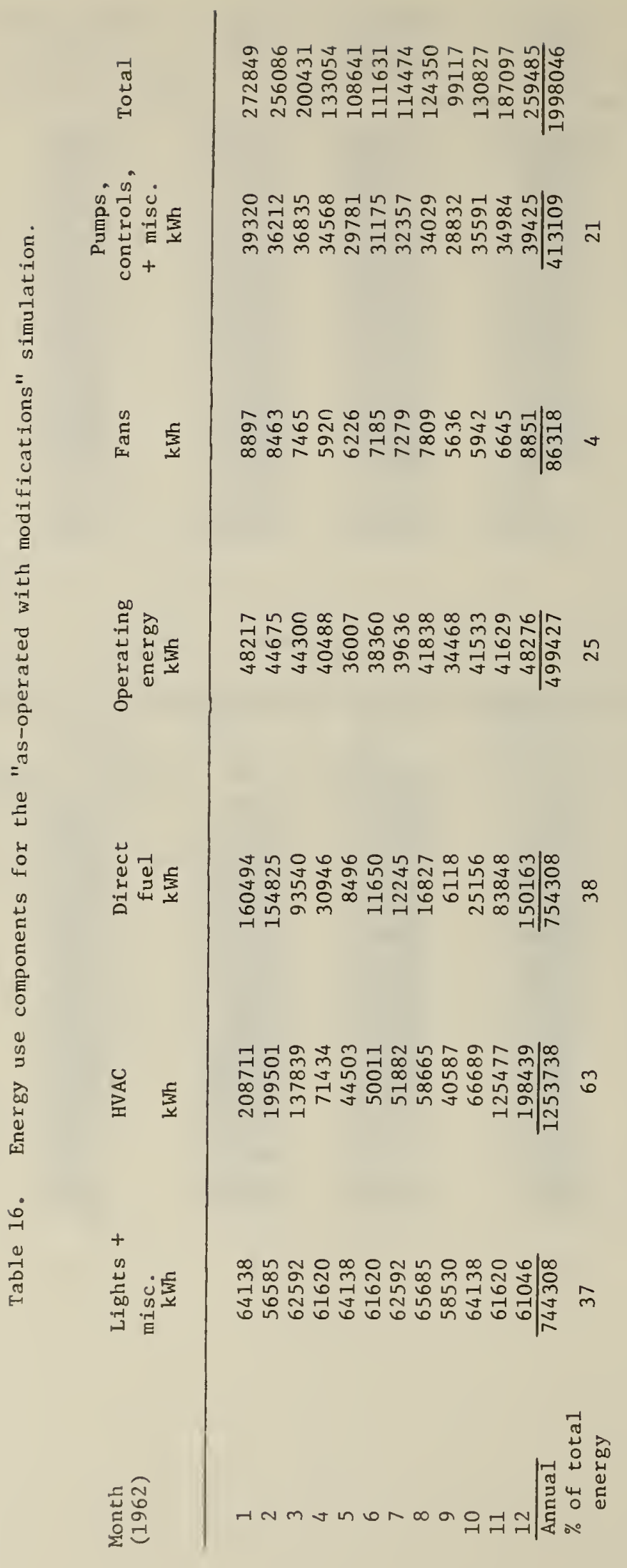


Table 17. Energy use components from actual data

\begin{tabular}{|c|c|c|c|c|c|}
\hline $\begin{array}{c}\text { Month } \\
(1978-79)\end{array}$ & $\begin{array}{l}\text { Total } \\
\text { energy } \\
\text { kWh }\end{array}$ & $\begin{array}{l}\text { Lights + } \\
\text { misc. } \\
\text { kWh }\end{array}$ & $\begin{array}{l}\text { HVAC } \\
\mathrm{kWh}\end{array}$ & $\begin{array}{l}\text { Direct fuel } \\
\text { and f ans } \\
\mathrm{kWh}\end{array}$ & $\begin{array}{c}\text { Pumps, controls } \\
+ \text { misc. } \\
\text { kWh }\end{array}$ \\
\hline 1 & 262943 & 60149 & 202794 & 162002 & 40793 \\
\hline 2 & 256124 & 53576 & 202548 & 169060 & 33488 \\
\hline 3 & 172472 & 62367 & 110105 & 82476 & 27630 \\
\hline 4 & 135282 & 57227 & 78055 & 51995 & 26060 \\
\hline 5 & 108612 & 55405 & 53207 & 23454 & 29753 \\
\hline 6 & 113981 & 5.5450 & 58531 & 25543 & 32988 \\
\hline 7 & 151981 & 58840 & 93141 & 58684 & 34457 \\
\hline 8 & 135853 & 60074 & 75779 & 36374 & 39405 \\
\hline 9 & 108498 & 56012 & 52486 & 26305 & 26181 \\
\hline 10 & 120062 & 59150 & 60912 & 33670 & 27242 \\
\hline 11 & 142696 & 53981 & 88715 & 60884 & 27831 \\
\hline 12 & 212201 & 53197 & 159004 & 120383 & 38621 \\
\hline$\overline{\text { Annual }}$ & 1920705 & 685428 & $\overline{1235277}$ & 850828 & $\overline{384449}$ \\
\hline $\begin{array}{l}\% \text { of } \\
\text { total } \\
\text { energy }\end{array}$ & 100 & 36 & 64 & 44 & 20 \\
\hline
\end{tabular}

Table 18. Comparison of components of annual operating energy for actual data and for "as-operated" and "design alternative" simulation cases

\begin{tabular}{|c|c|c|c|c|c|c|}
\hline & $\begin{array}{l}\text { Actual } \\
\text { data } \\
\text { kWh }\end{array}$ & $\begin{array}{l}\%^{2} \text { of } \\
\text { operating } \\
\text { energy }\end{array}$ & $\begin{array}{l}\text { As-operated } \\
\text { simulation } \\
\text { data } \\
\text { kWh }\end{array}$ & $\begin{array}{l}\%^{2} \text { of } \\
\text { operating } \\
\text { energy }\end{array}$ & $\begin{array}{l}\text { Design } \\
\text { alternative } \\
\text { data } \\
\text { kWh }\end{array}$ & $\begin{array}{l}\%^{2} \text { of } \\
\text { operating } \\
\text { energy }\end{array}$ \\
\hline Operating energy -fans & 384449 & 100 & 419791 & 100 & 38873 & 100 \\
\hline Abs. chill accessories & 303 & $<1$ & 2055 & $<1$ & - & - \\
\hline Elec. chill accessories & 4216 & 1 & 13974 & 3 & 3070 & 8 \\
\hline Solar pumps & 3531 & 1 & 7788 & 2 & - & - \\
\hline Elev. rm. air conditioner & 18411 & 5 & 21453 & 5 & 21203 & 55 \\
\hline Boiler accessories & 11480 & 3 & 6709 & 2 & 4518 & 12 \\
\hline Cooling towers & 30499 & 8 & 9597 & 2 & 412 & 1 \\
\hline HWS pump & 12353 & 3 & 60768 & 14 & 9792 & 25 \\
\hline CHWS pump & 3607 & 1 & 6960 & 2 & - & - \\
\hline HPS pump & 57524 & 15 & 65700 & 16 & - & - \\
\hline Snow melt ing & 28371 & 7 & 75520 & 18 & - & - \\
\hline Other misc. & 214154 & 56 & 148920 & 35 & 0 & 0 \\
\hline
\end{tabular}

Components of other misc.

$\begin{array}{lrr}\text { Telephone power } & 19051 & 5 \\ \text { Controls } & 38968 & 10 \\ \text { Computer \& emergency } & 71646 & 19 \\ \text { Misc. pumps \& motors } & 20135 & 5 \\ \text { Other misc. } & 64354 & 17\end{array}$

1 Data are from the period from November 1978 through October 1979.

2 Does not add up to $100 \%$ due to rounding. 


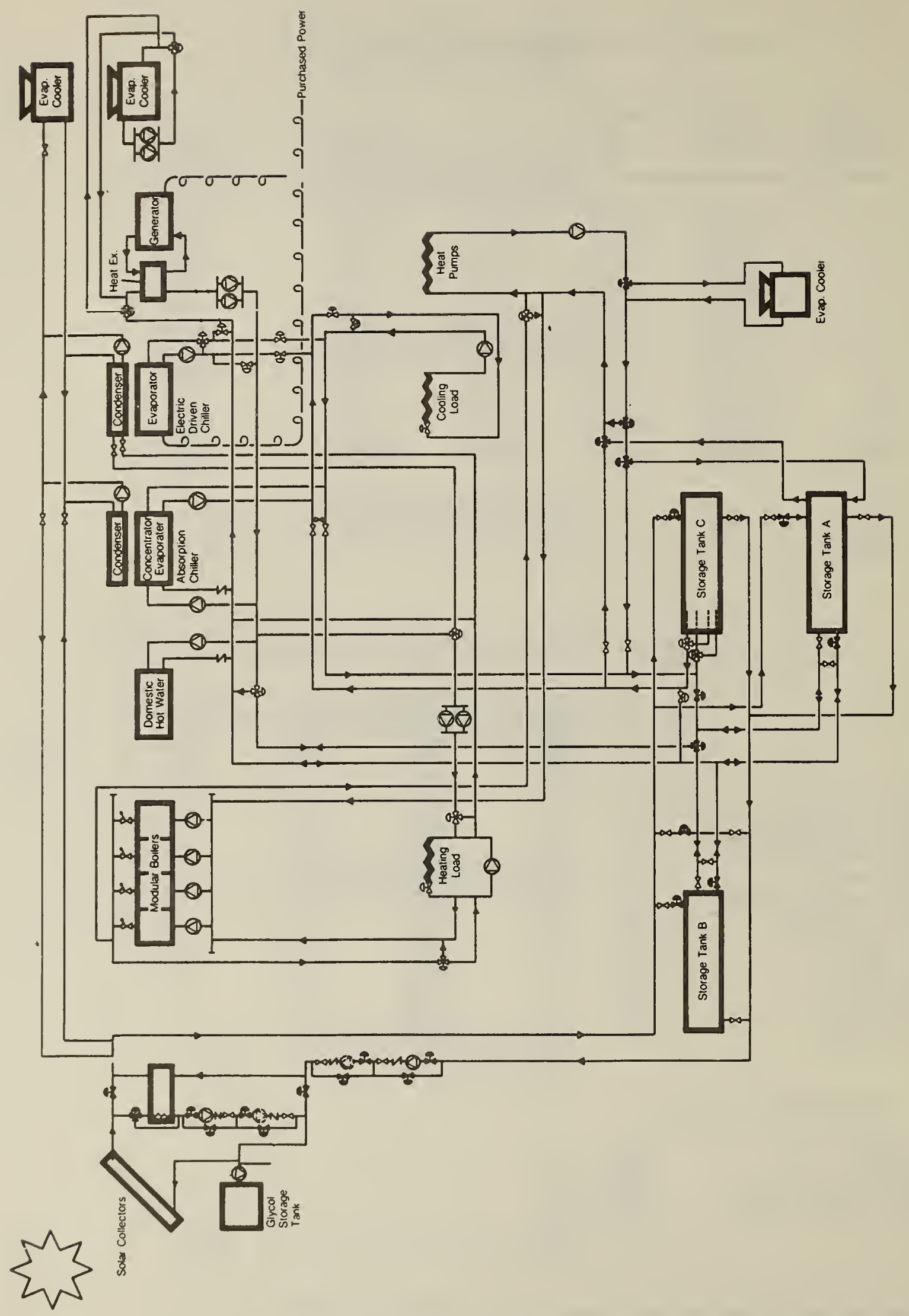

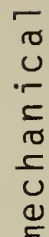

0
5
5
7
5
5
0

0
0
4
4
0

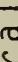

$\frac{1}{0}$

a

5

0
2
2
2
2
2

4

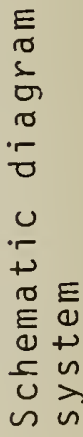

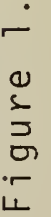




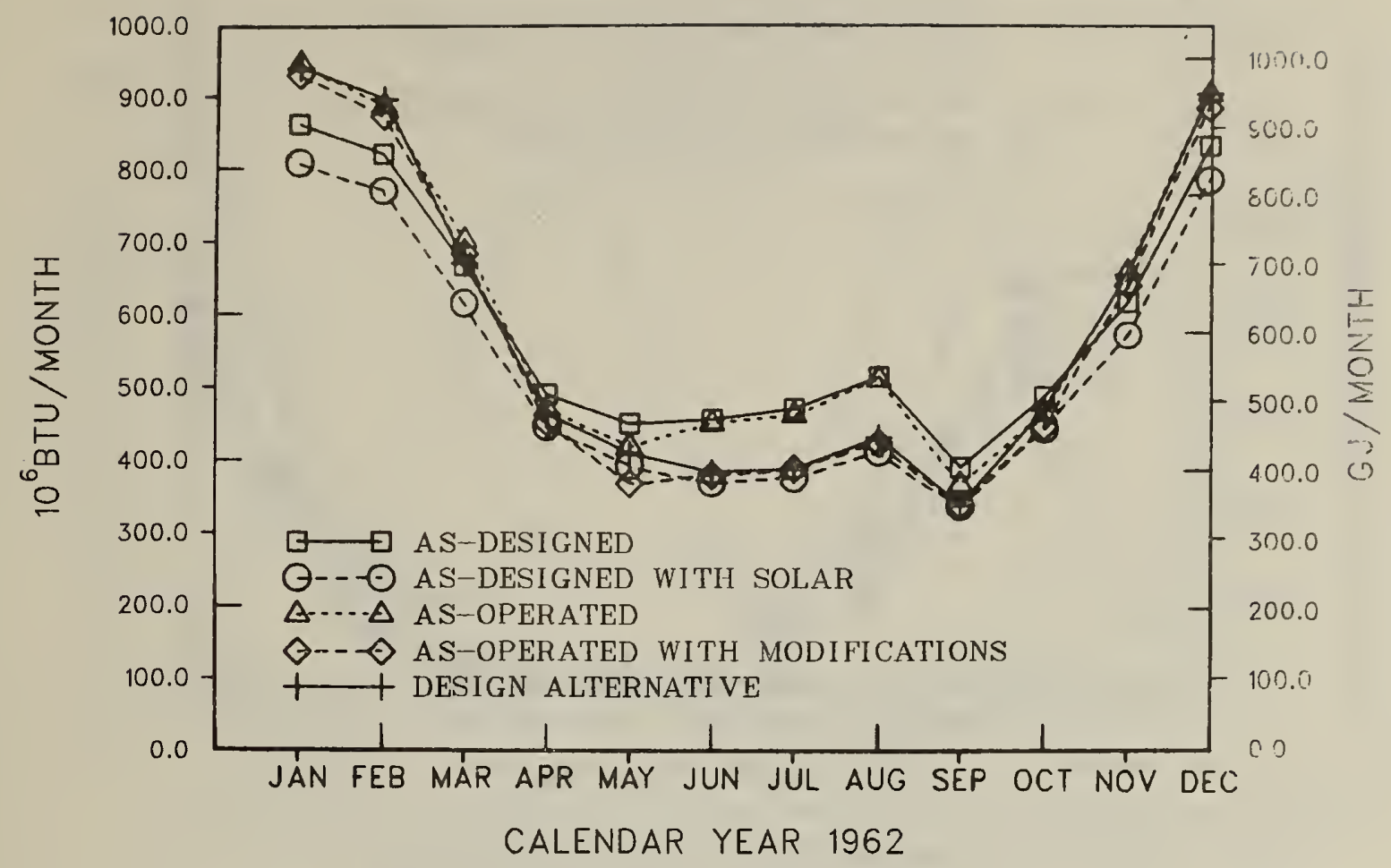

Figure 2. Total energy consumption of the NCFOB as predicted by simulation

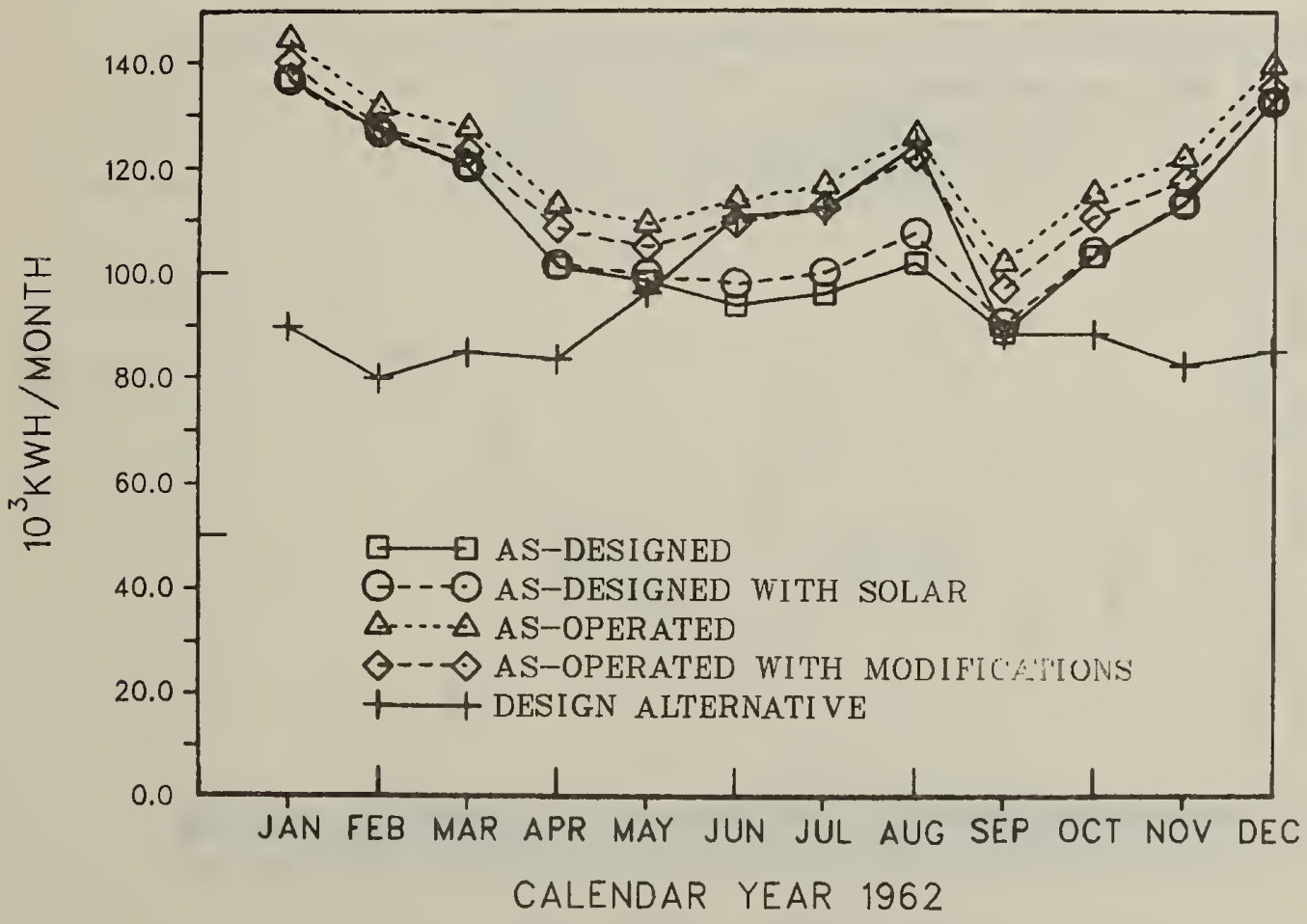

Figure 3. Electric energy consumption at the NCFOB as predicted by simu-
lation 


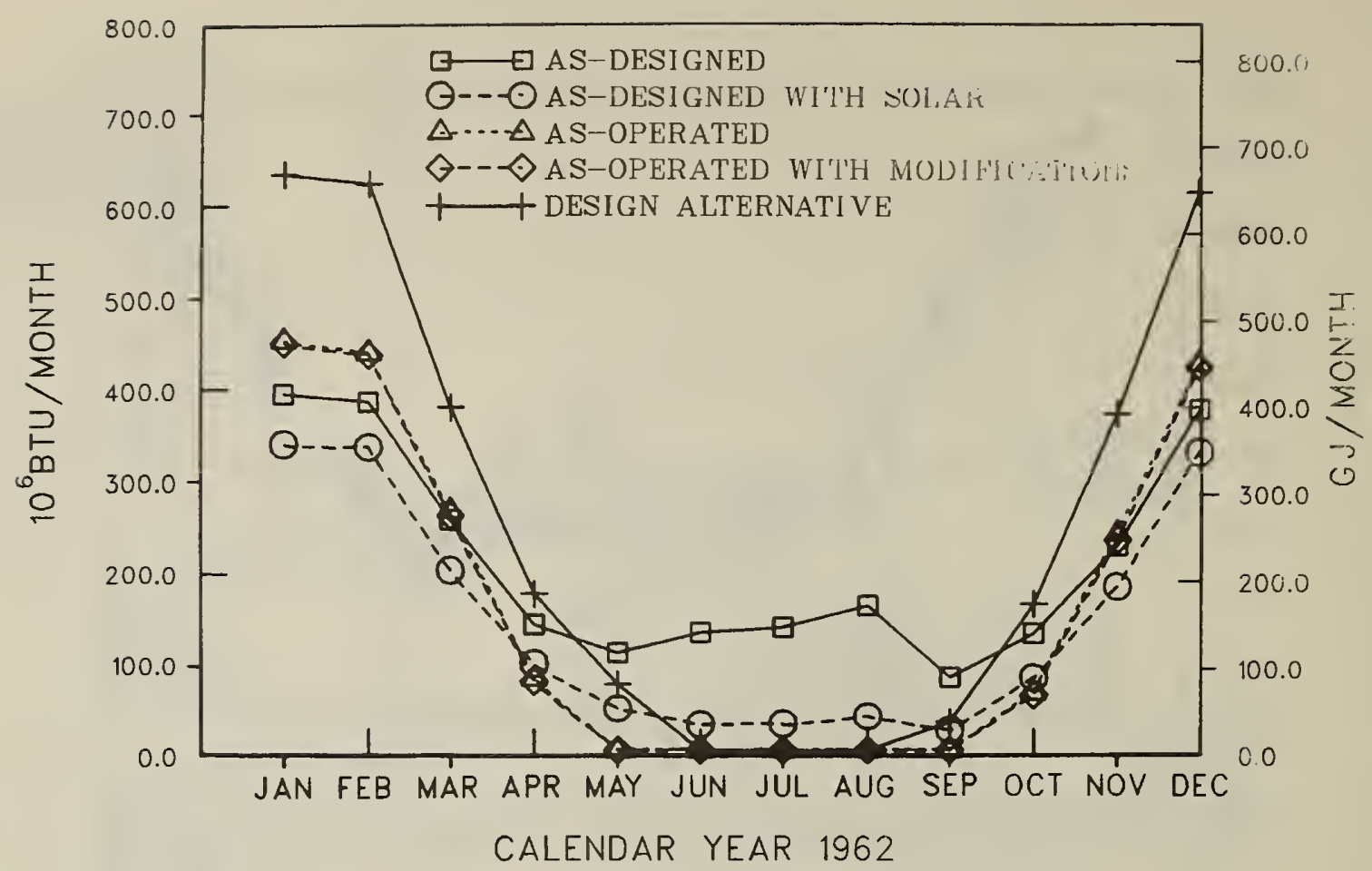

Figure 4. Natural gas consumption at the NCFOB as predicted by simulation

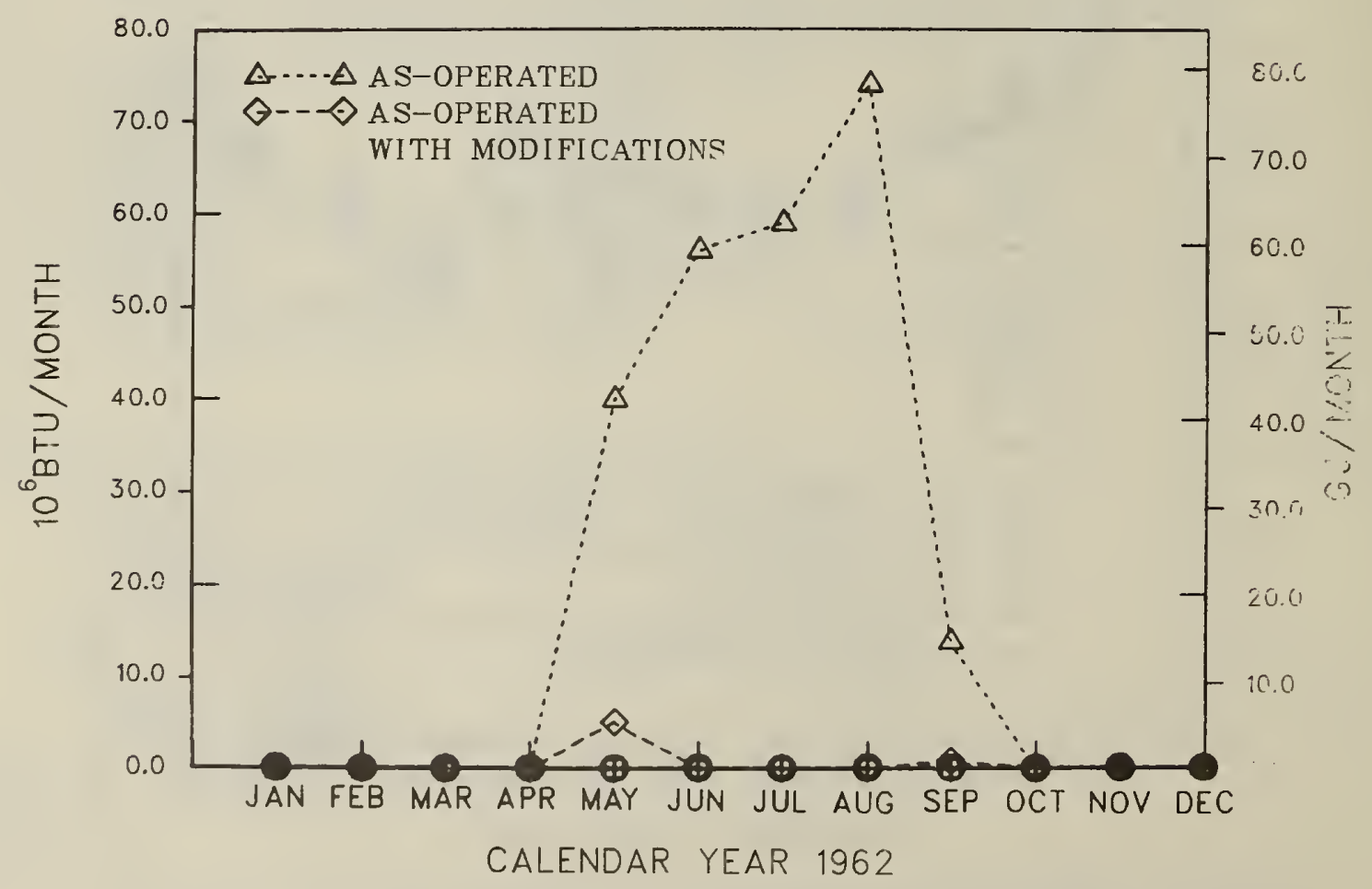

Figure 5. Fuel oil consumption at the NCFOB as predicted by simulation 


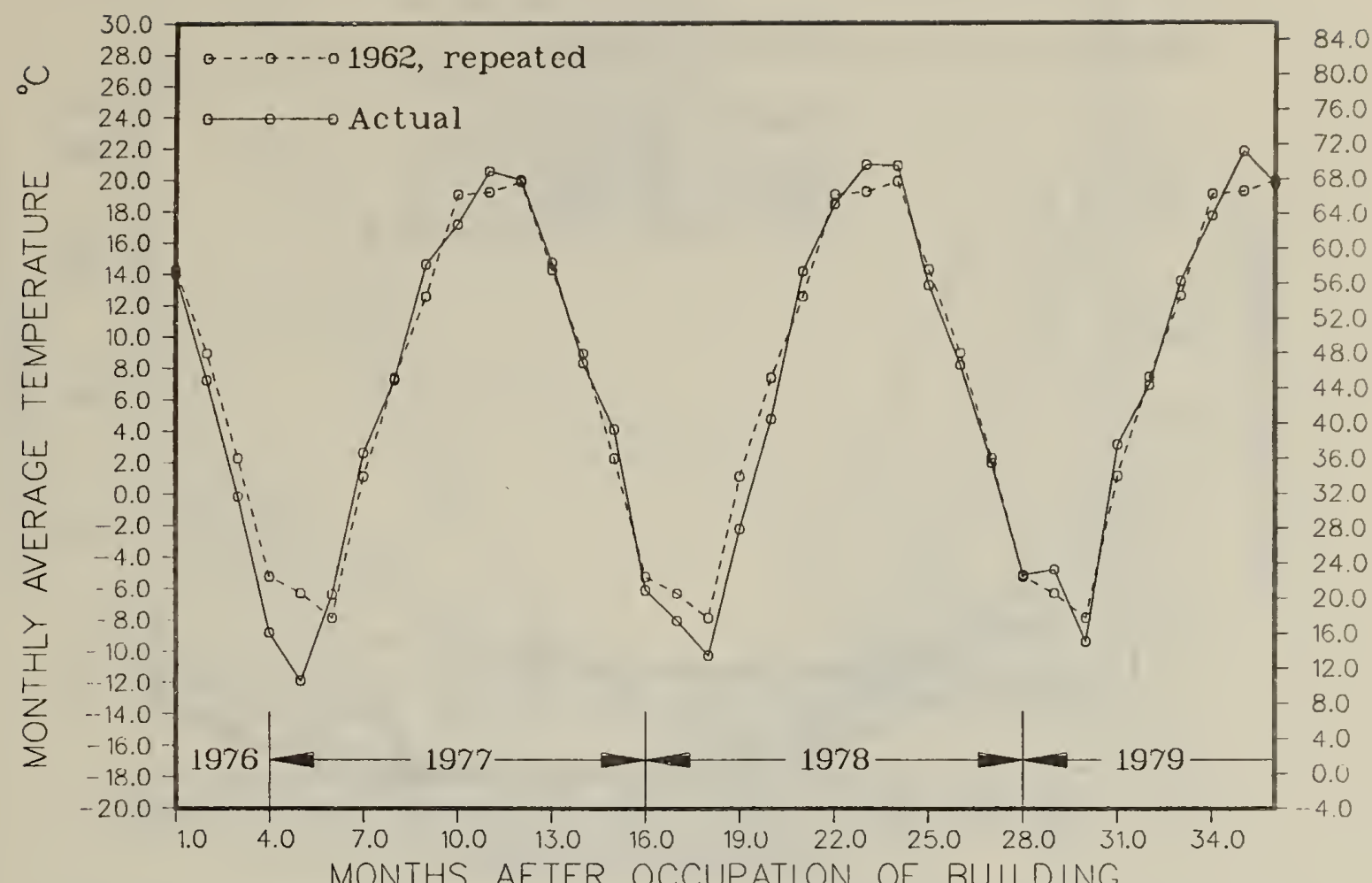

Figure 6. Average monthly ambient temperatures for actual weather and 1962 weather used in the simulations

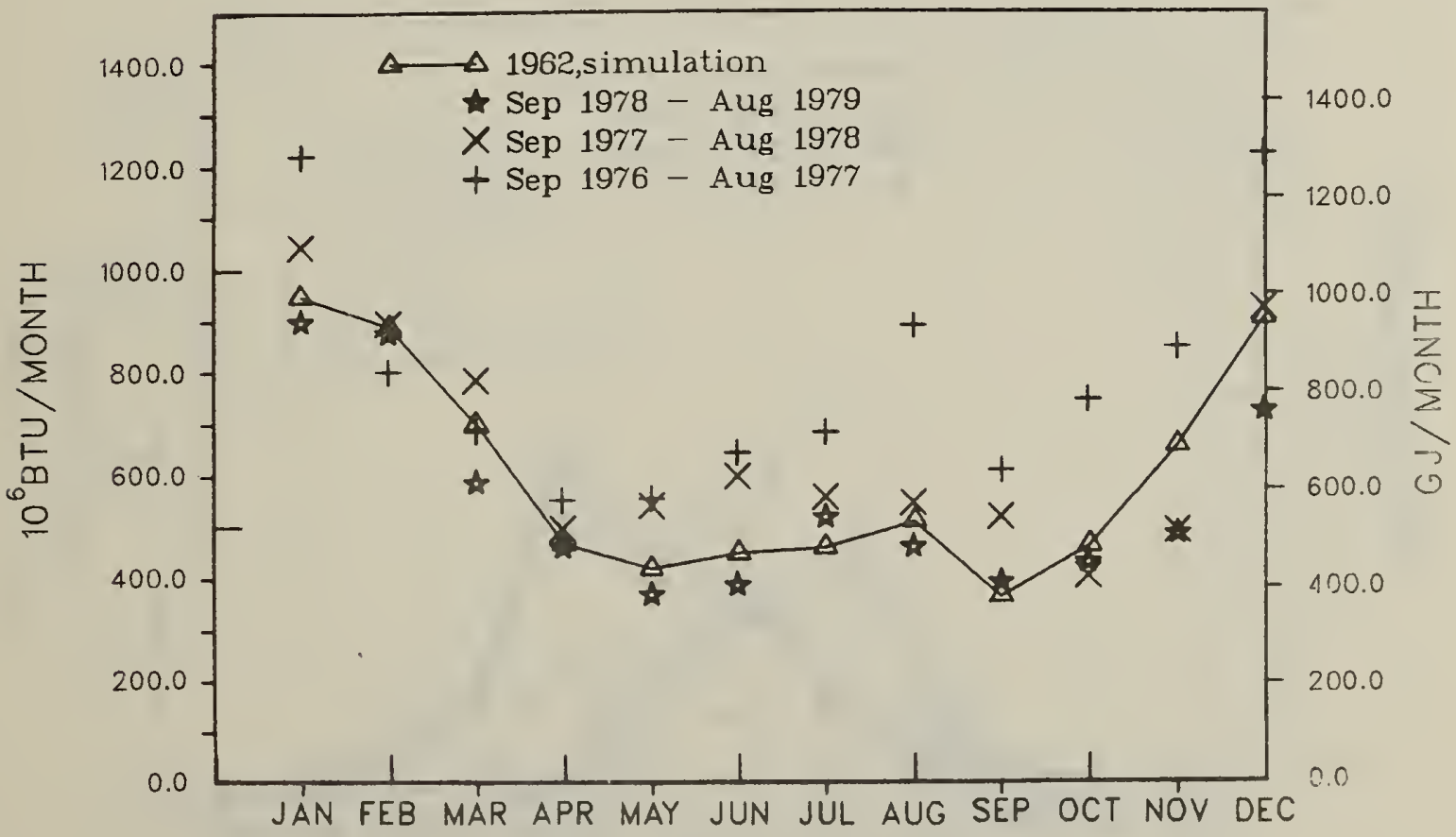

Figure 7. Total eneray consumption at the NCFOB as predicted by the "asoperated" simulation compared with actual consumption for three years 


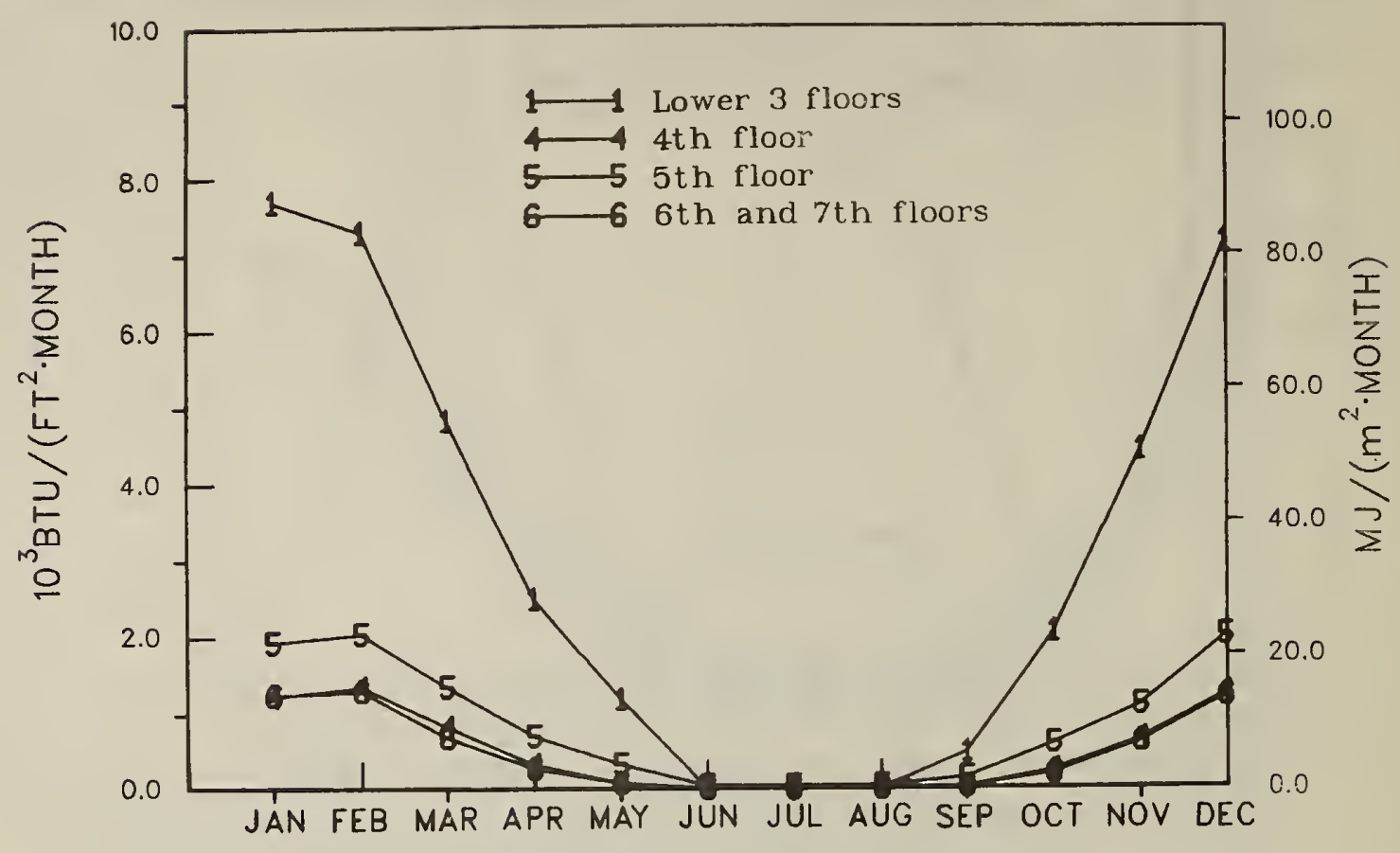

CALENDAR YEAR 1962

Figure 8 . Monthly total heating requirements per unit area for the NCFOB as predicted by the "as-designed" simulation

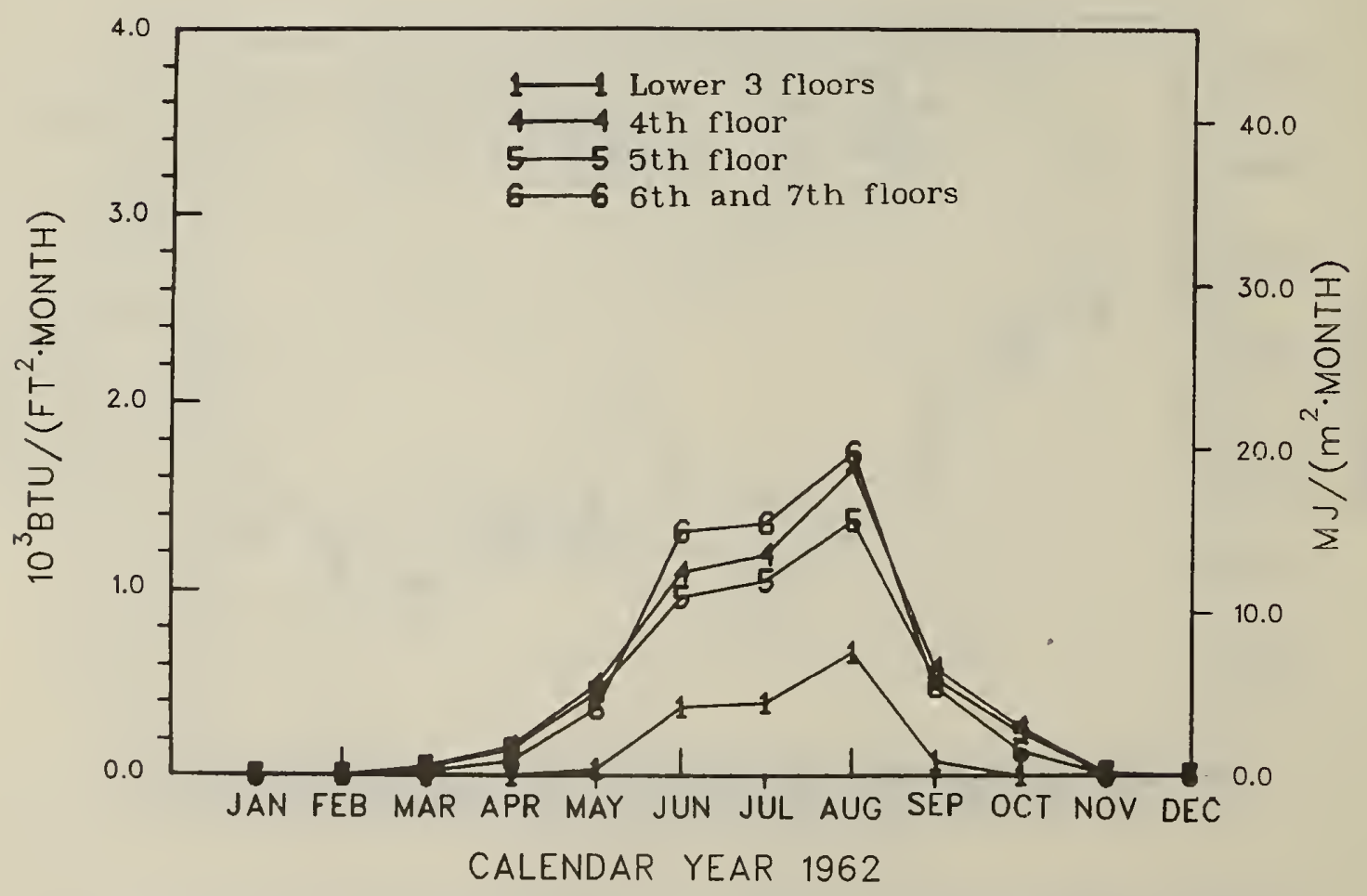

Figure 9. Monthly total cooling requirements per unit area for the NCFOB as predicted by the "as-designed" simulation 


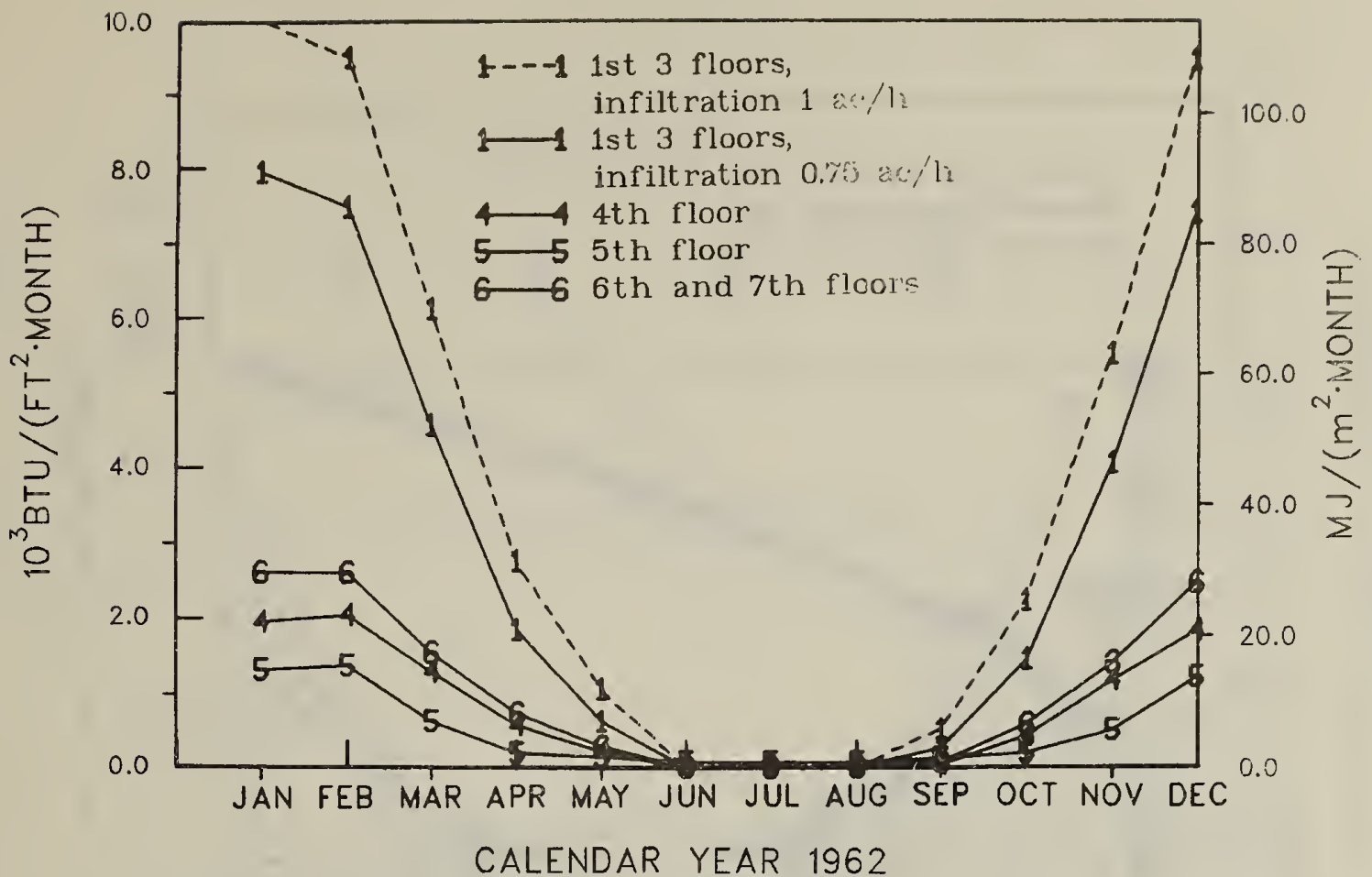

Figure 10. Monthly total heating requirements per unit area for the NCFOB as predicted by the "as-operated" simulation

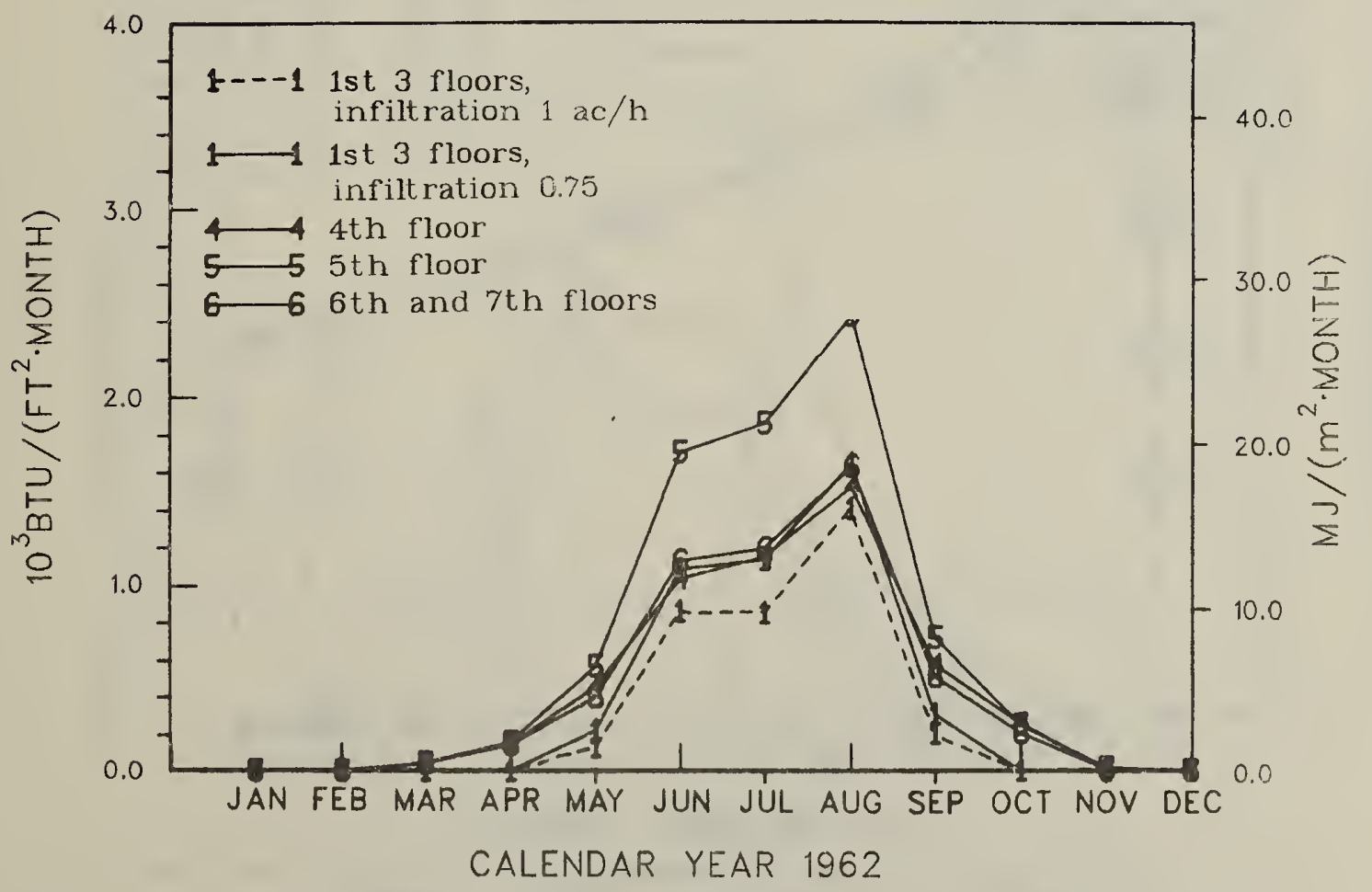

Figure 11. Monthly total cooling requirements per unit area for the NCFOB as predicted by the "as-operated" simulation 


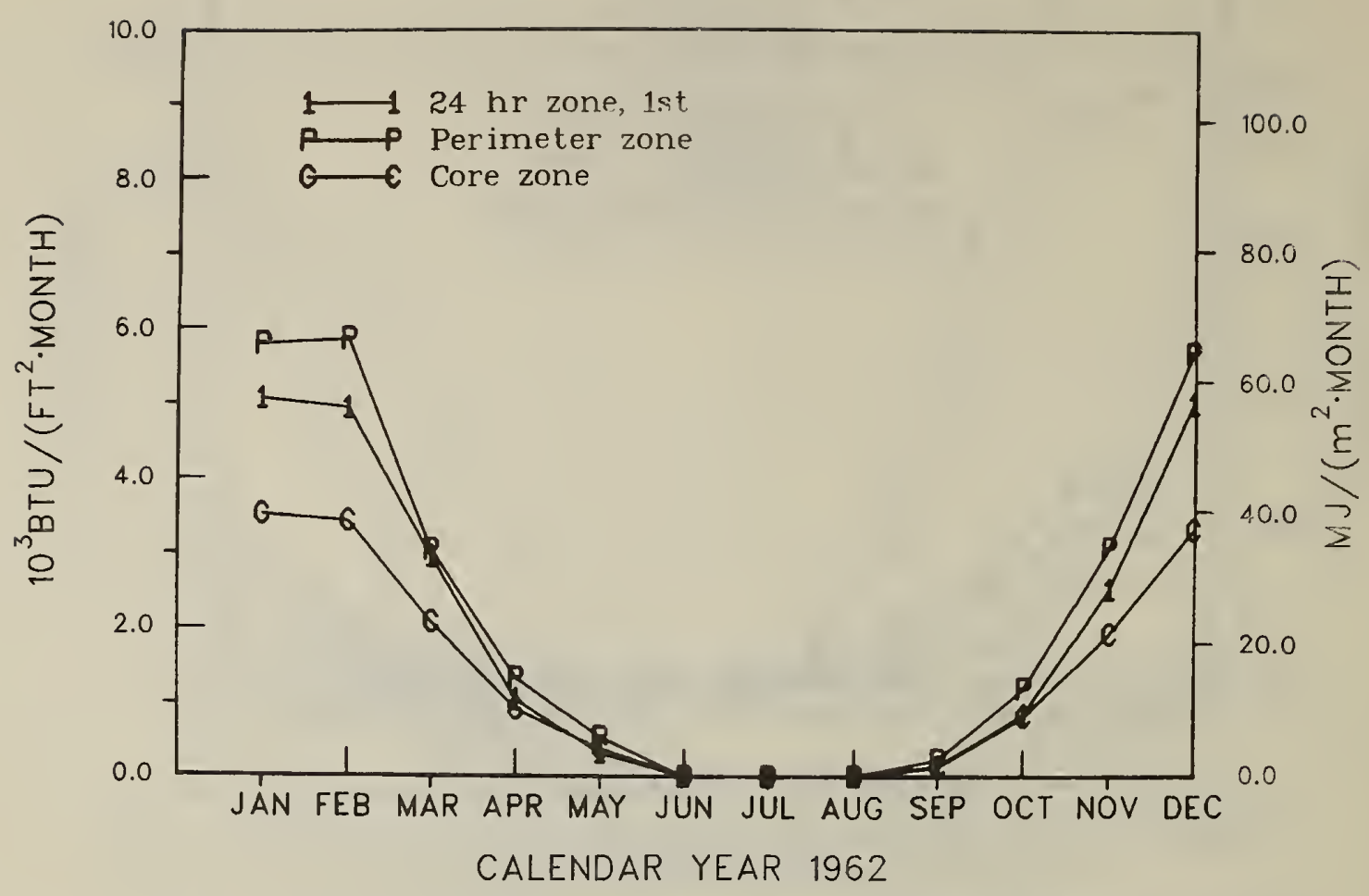

Figure 12. Monthly total heating requirements per unit area for the NCFOB as predicted by the "design alternative" simulation

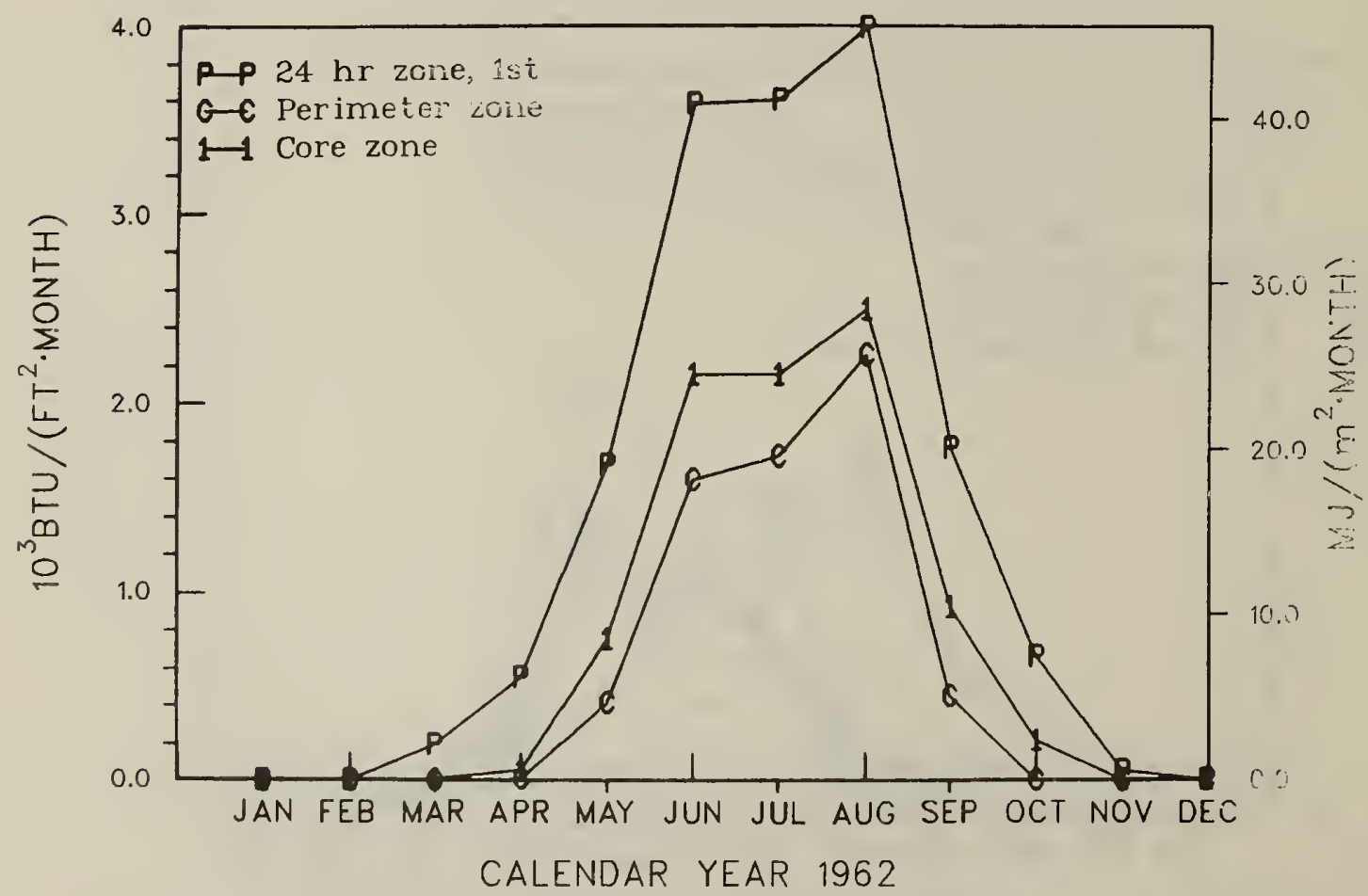

Figure 13. Monthly total cooling requirements per unit area for the NCFOB as predicted by the "design alternative" simulation 


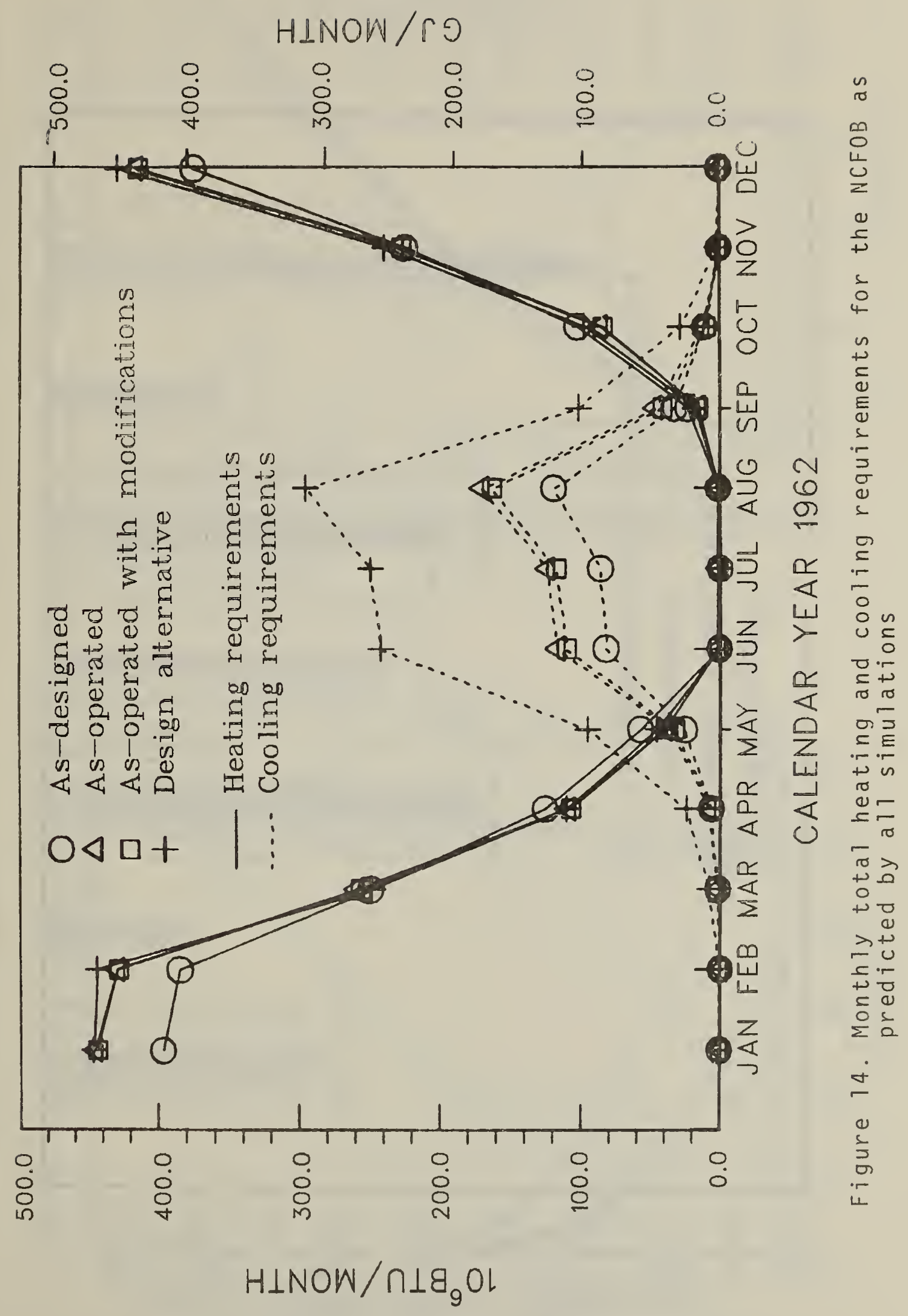


$\left(\forall \forall \exists \lambda_{2} m\right) / \Gamma W$

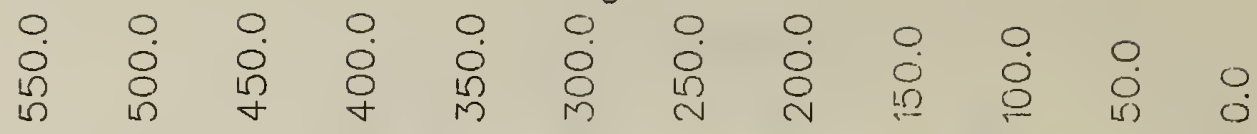

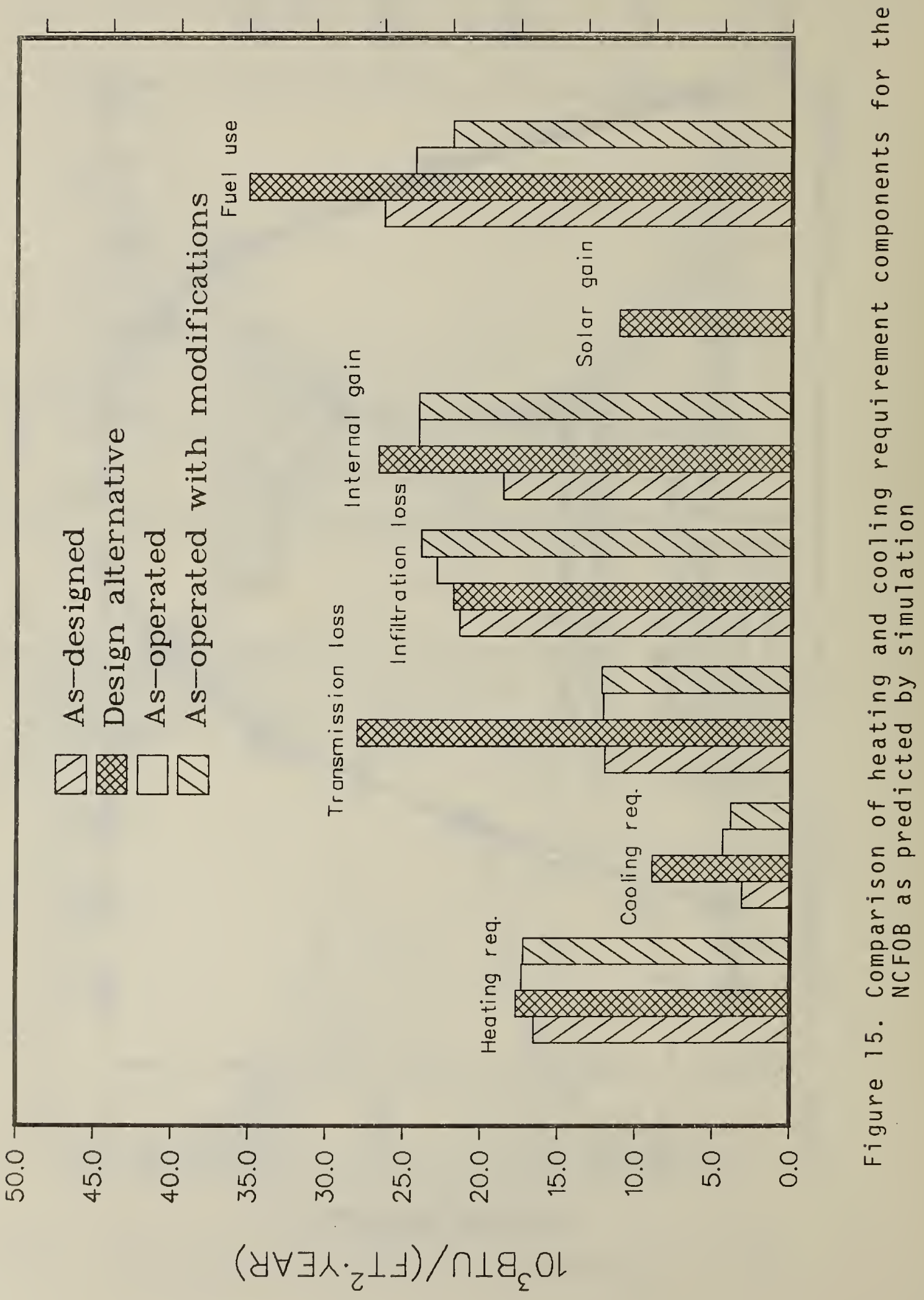




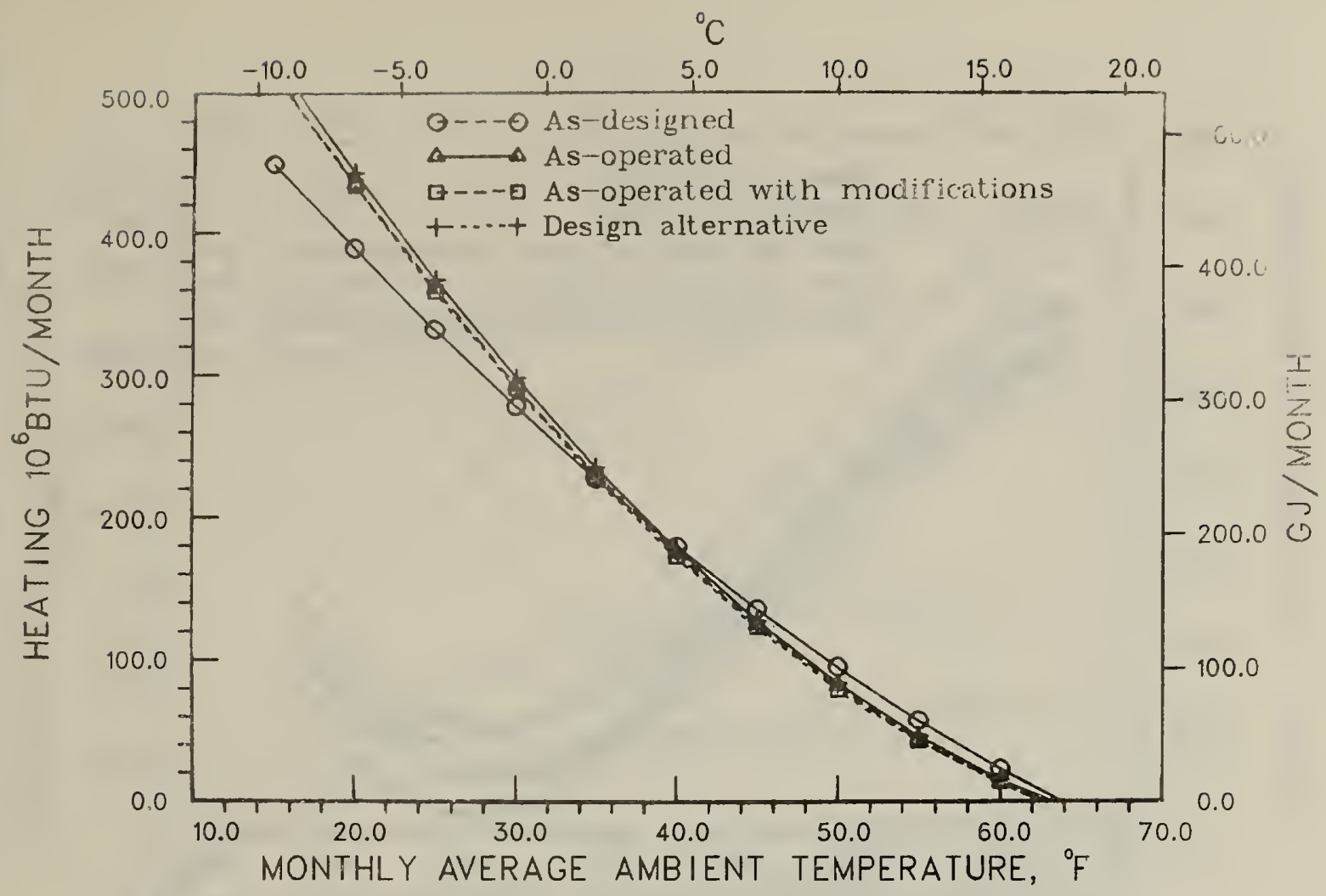

Figure 16. Least squares fit of $N C F O B$ heating requirements predicted by simulation versus monthiy average ambient temperature

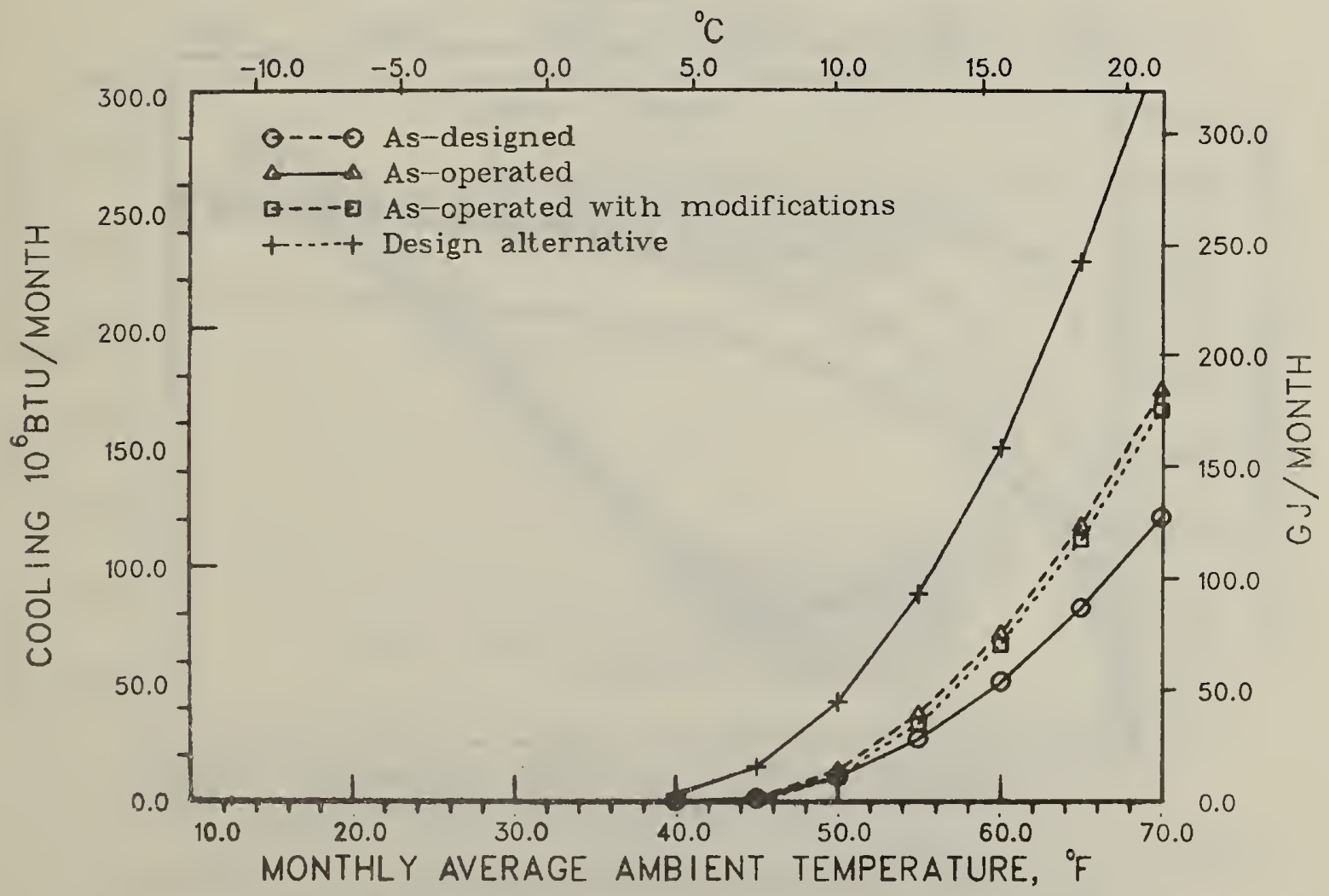

Figure 17. Least squares fit of NCFOB cooling requirements predicted by simulation versus monthly average ambient temperature 

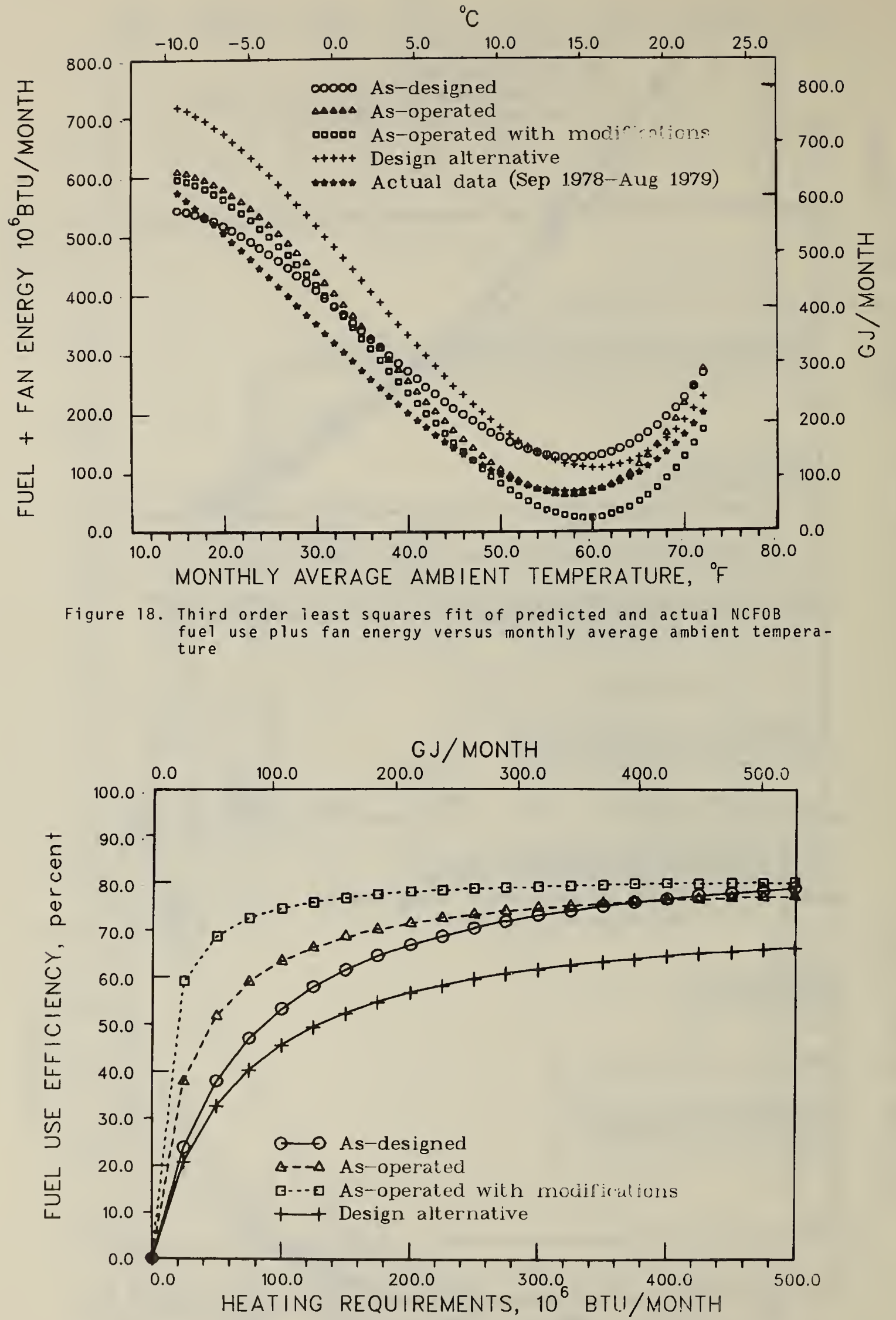

Figure 19. Fuel use efficiency versus heating requirements as predicted by simulation for the NCFOB (least squares fits) 


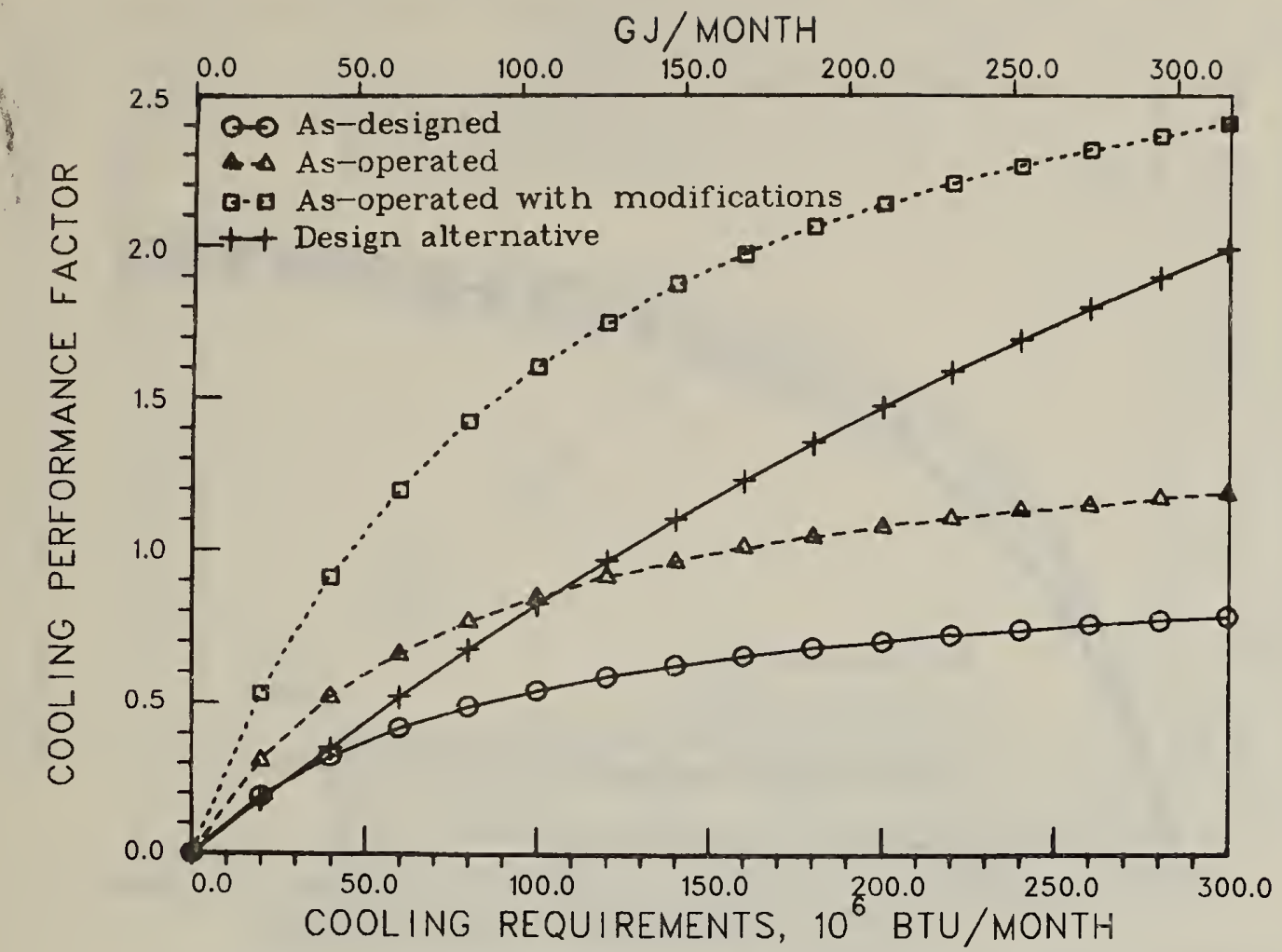

Figure 20. Cooling performance factor versus cooling requirements as predicted by simulations of the NCFOB (least squares fits)

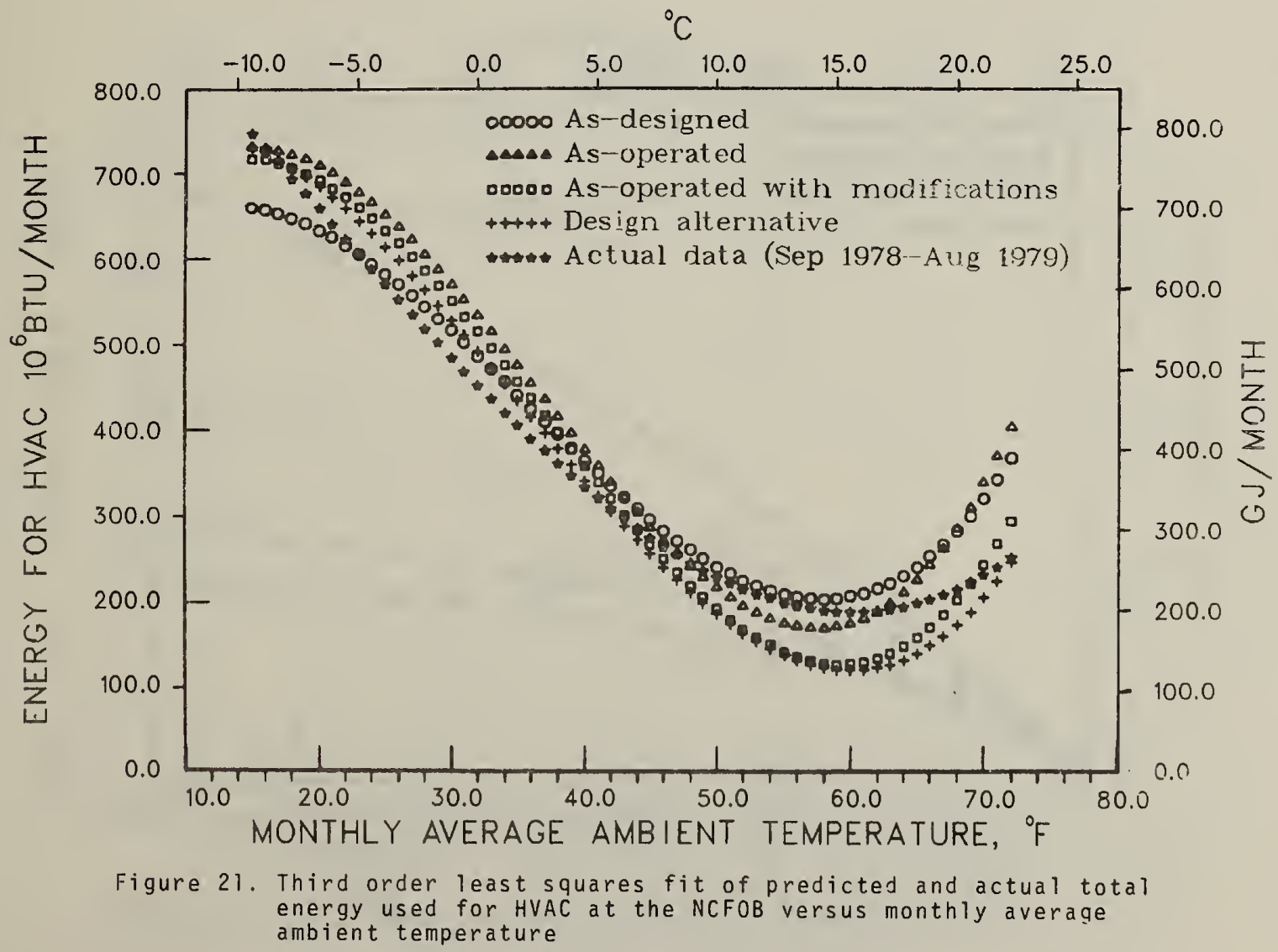




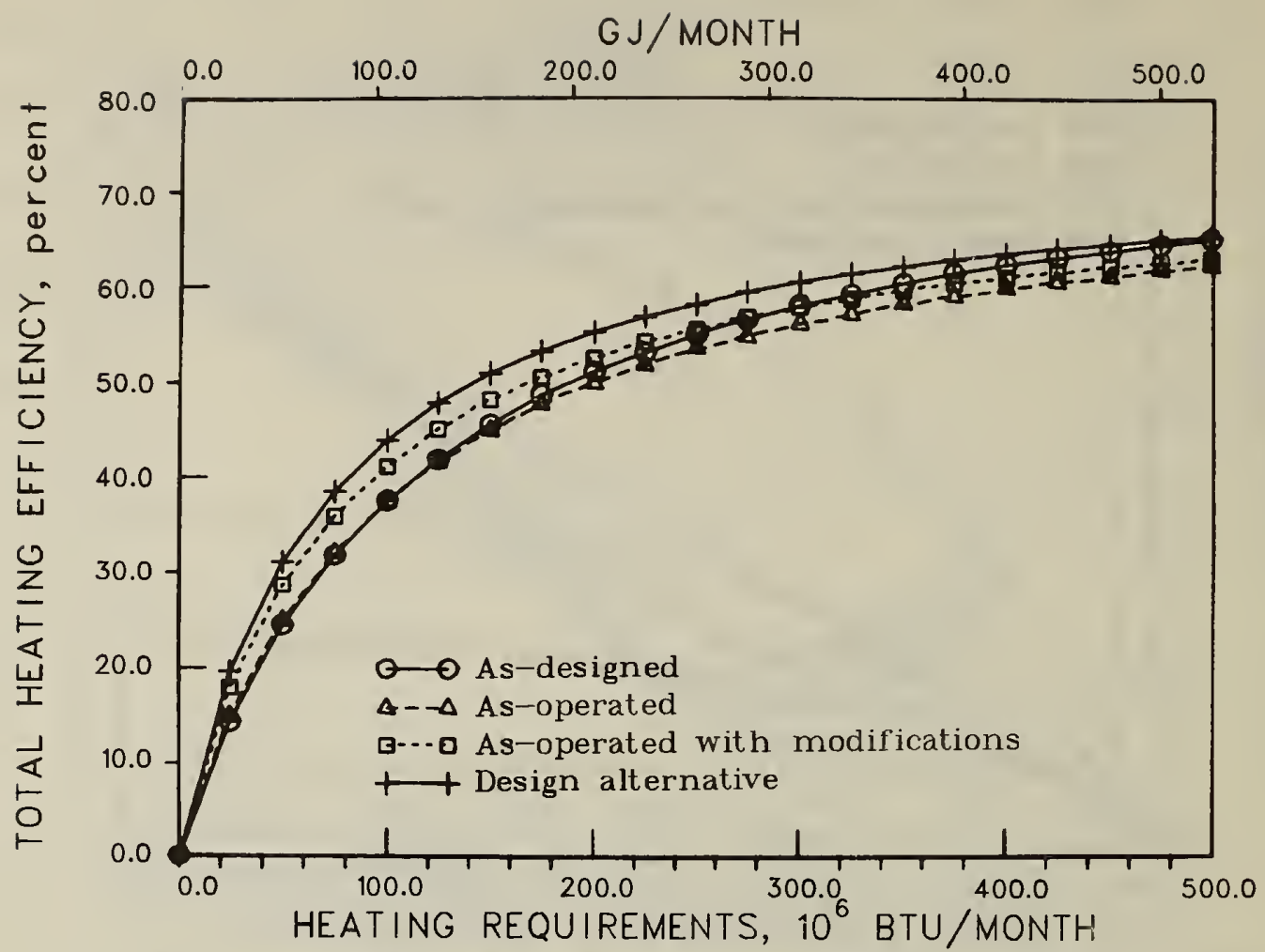

Figure 22. Total heating efficiency versus heating requirements as predicted by simulations of NCFOB (least squares fit)

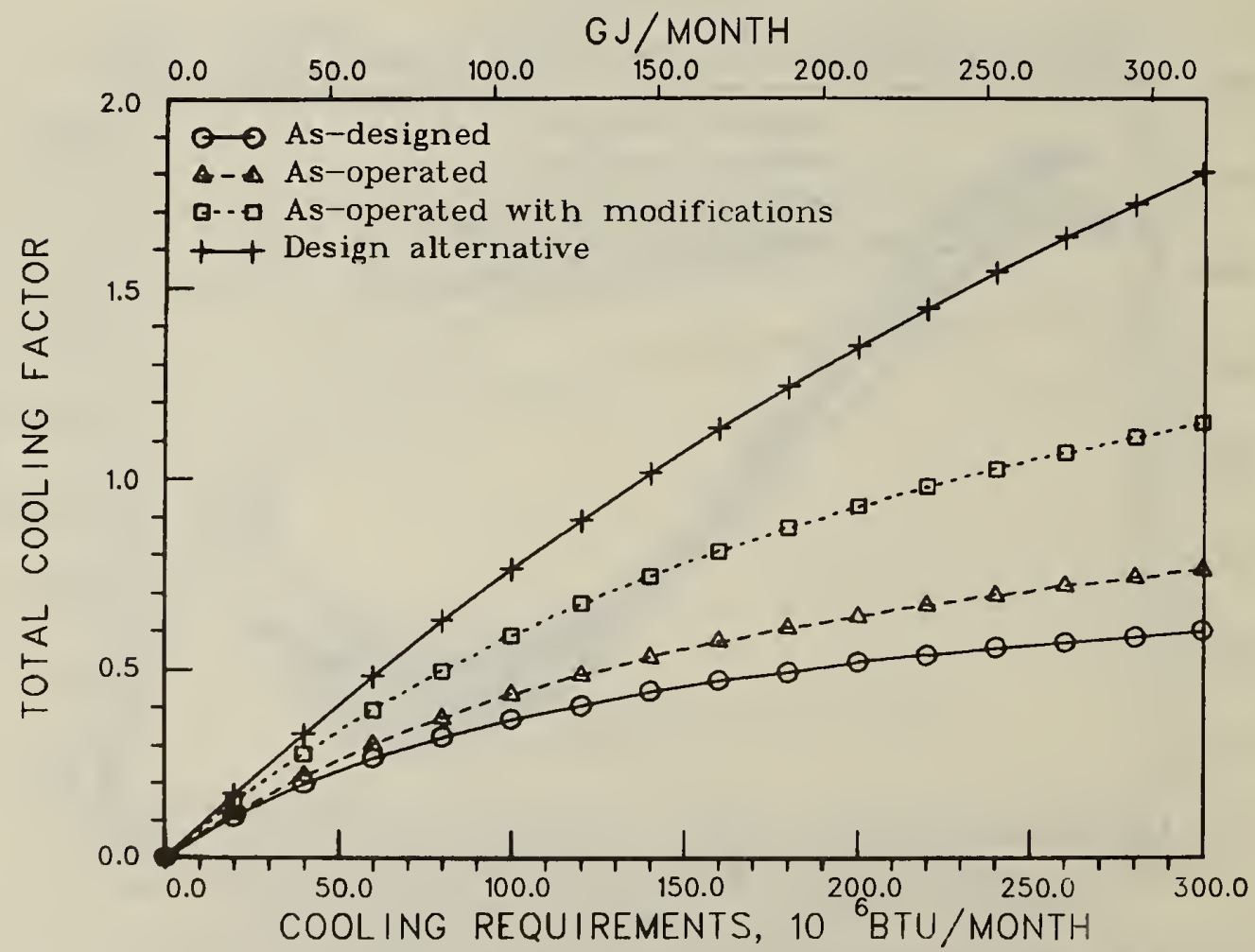

Figure 23. Total cooling factor versus cooling requirements as predicted by simulations of NCFOB (least squares $\mathrm{fit}$ ) 

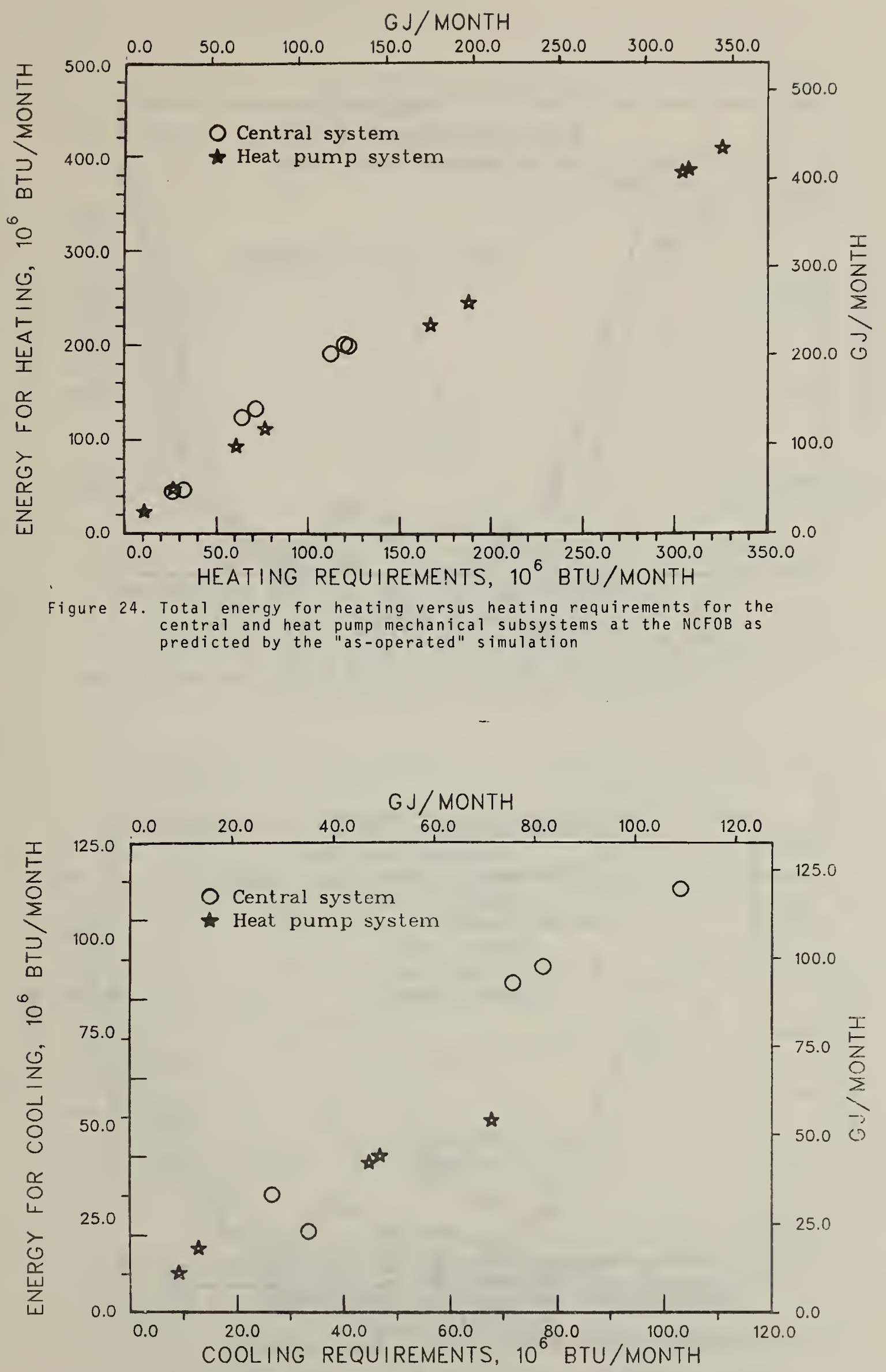

Figure 25. Total energy for cooling versus cooling requirements for the central and heat pump mechanical subsystems at the NCFOB as predicted by the "as-operated" simulation 


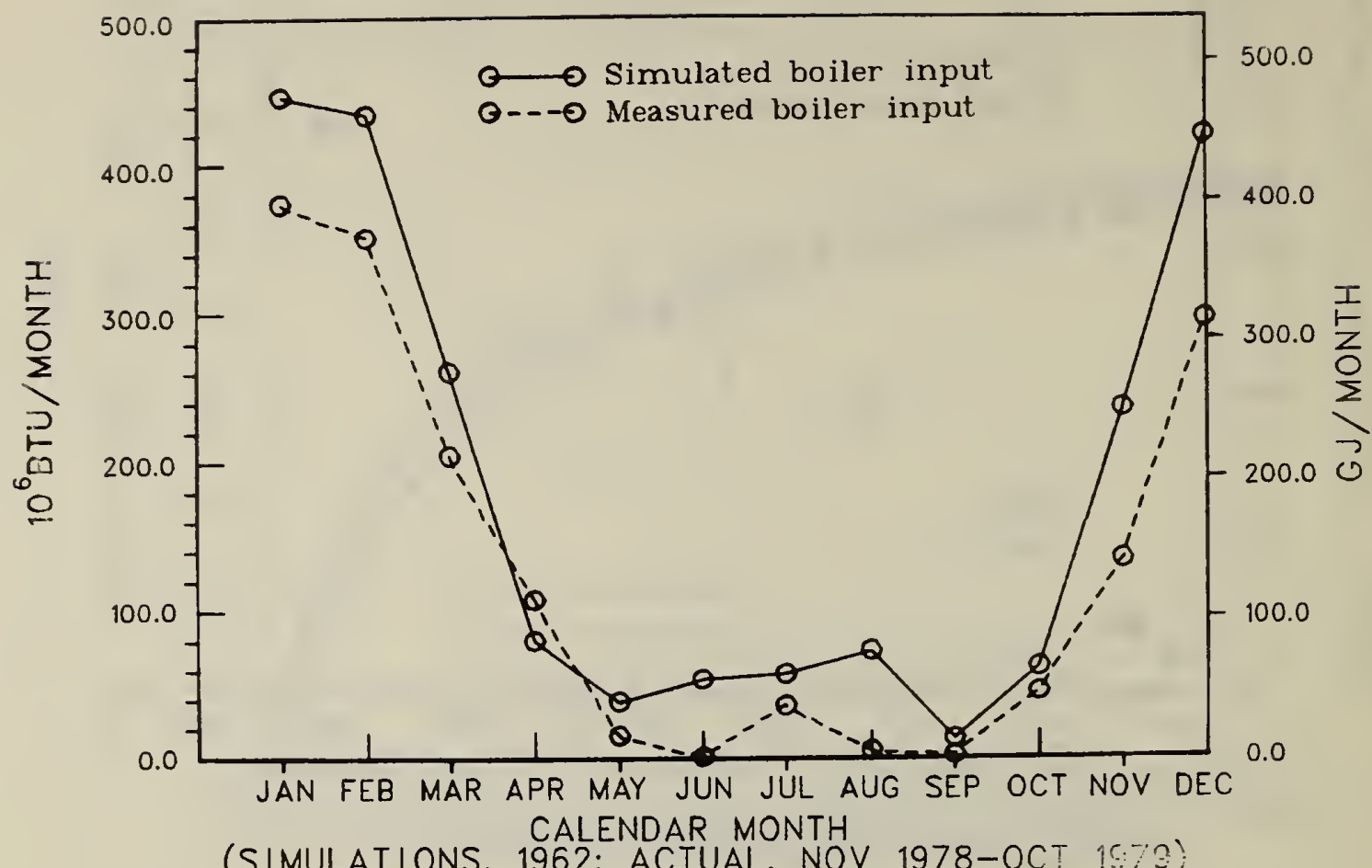

(SIMULATIONS, 1962; ACTUAL, NOV 1978-OCT 1973)

Figure 26. Comparison of actual and predicted boiler fuel input at the NCFOB using "as-operated" simulation data

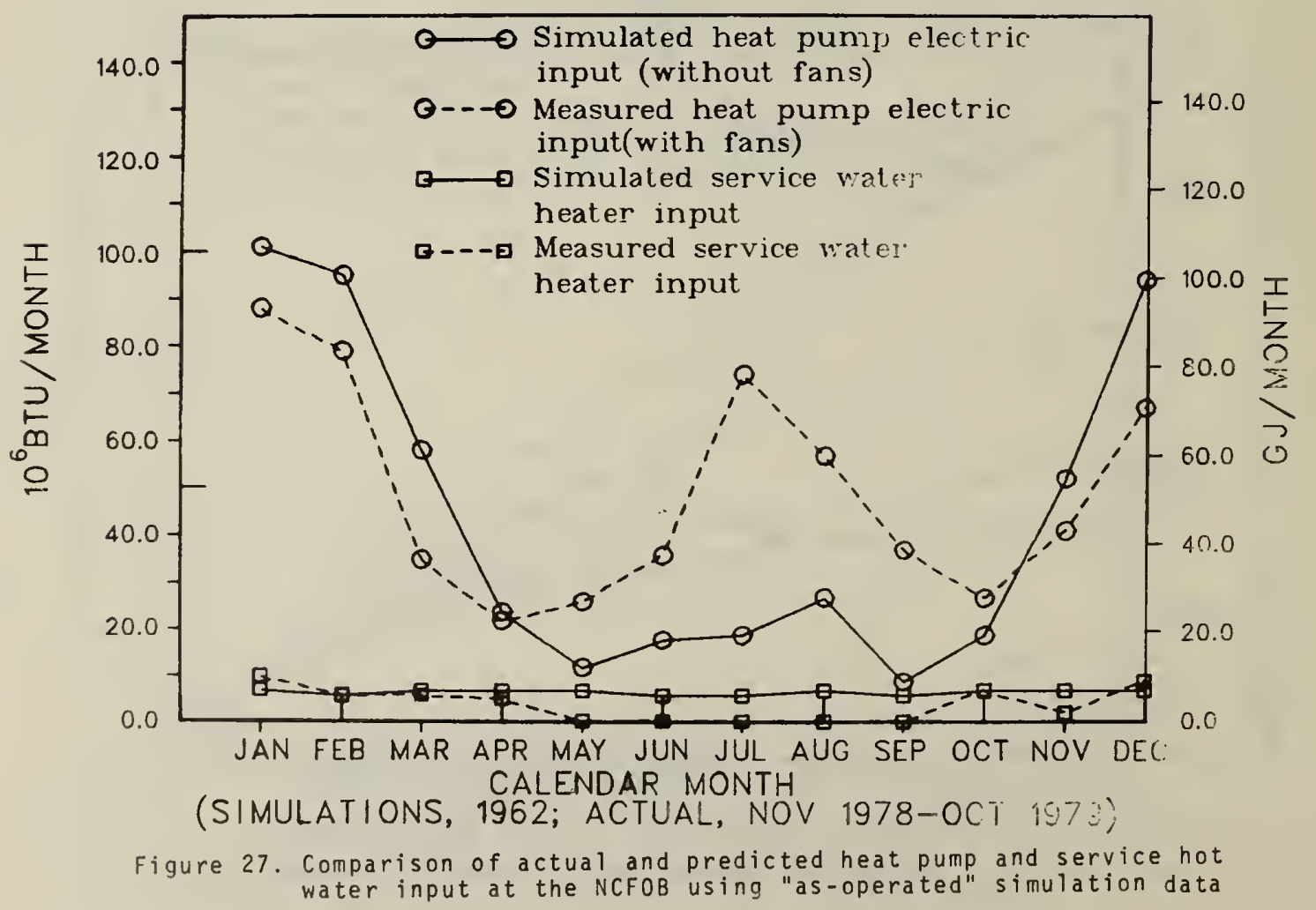




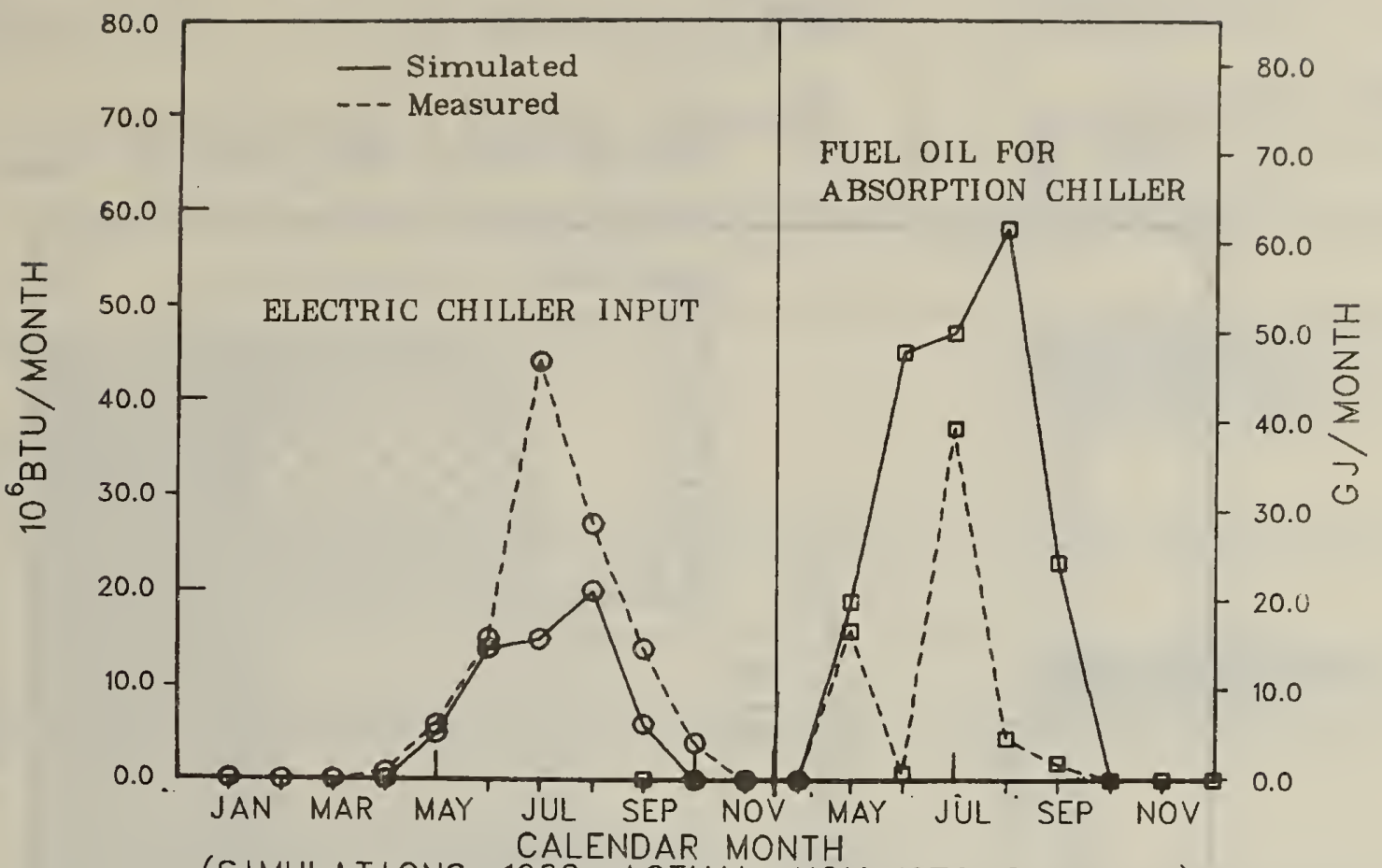

(SIMULATIONS, 1962; ACTUAL, NOV 1978-OCT 1079)

Figure 28. Comparison of actual and predicted energy to central chillers at the NCFOB using "as-operated" simulation data

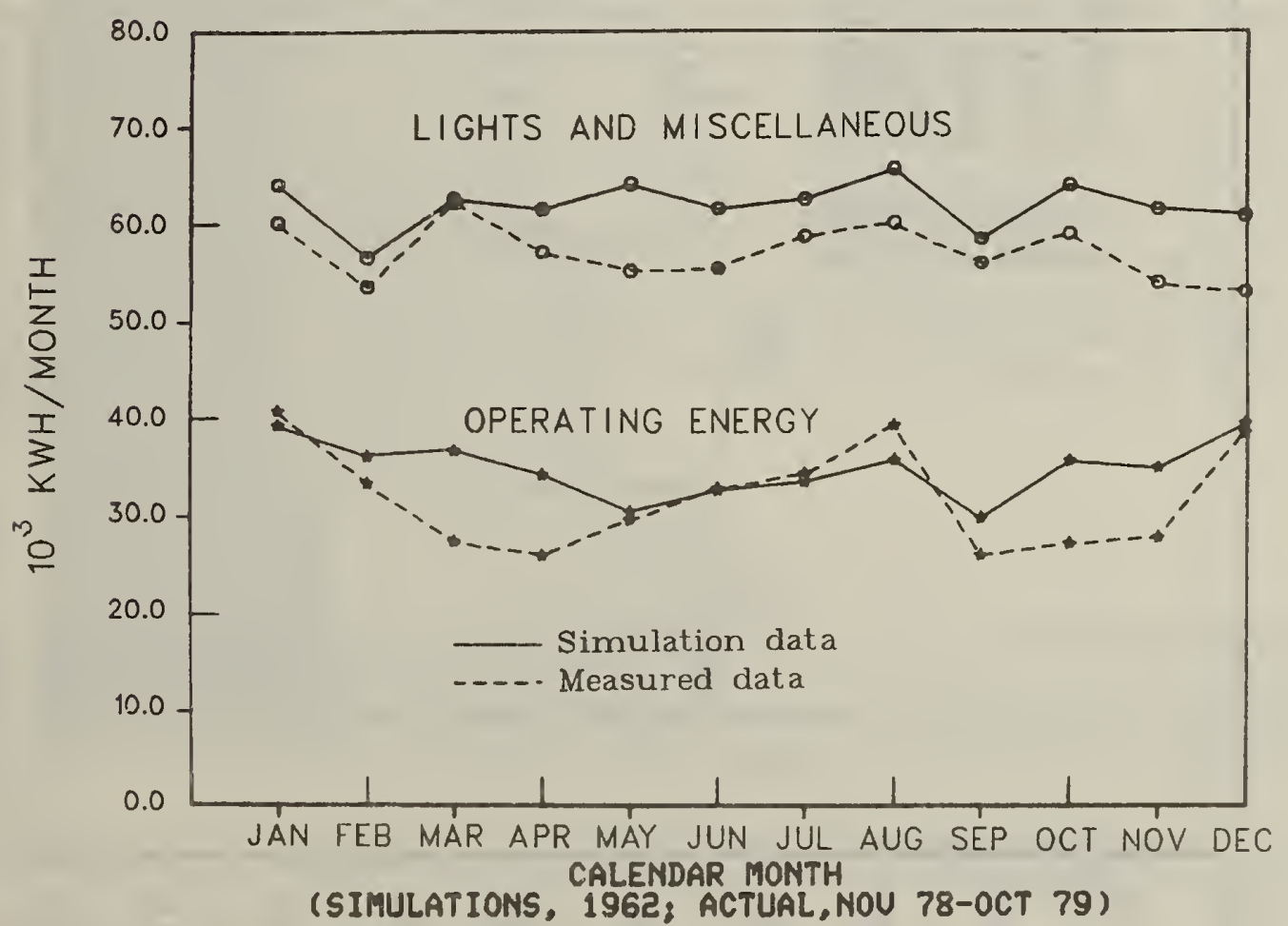

Figure 29. Comparison of actual and predicted lighting-miscellaneous and operating energy at the NCFOB using "as-operated" simulation data 


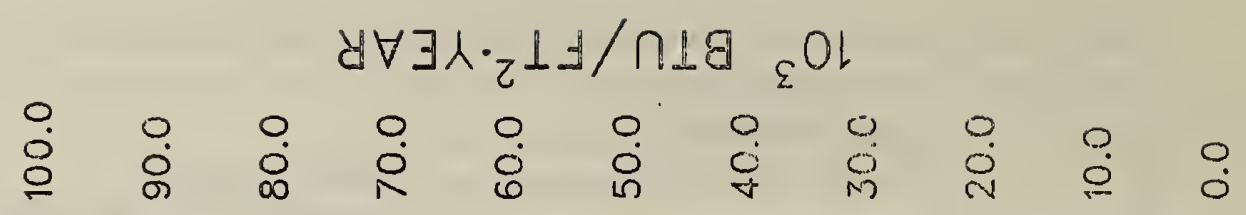

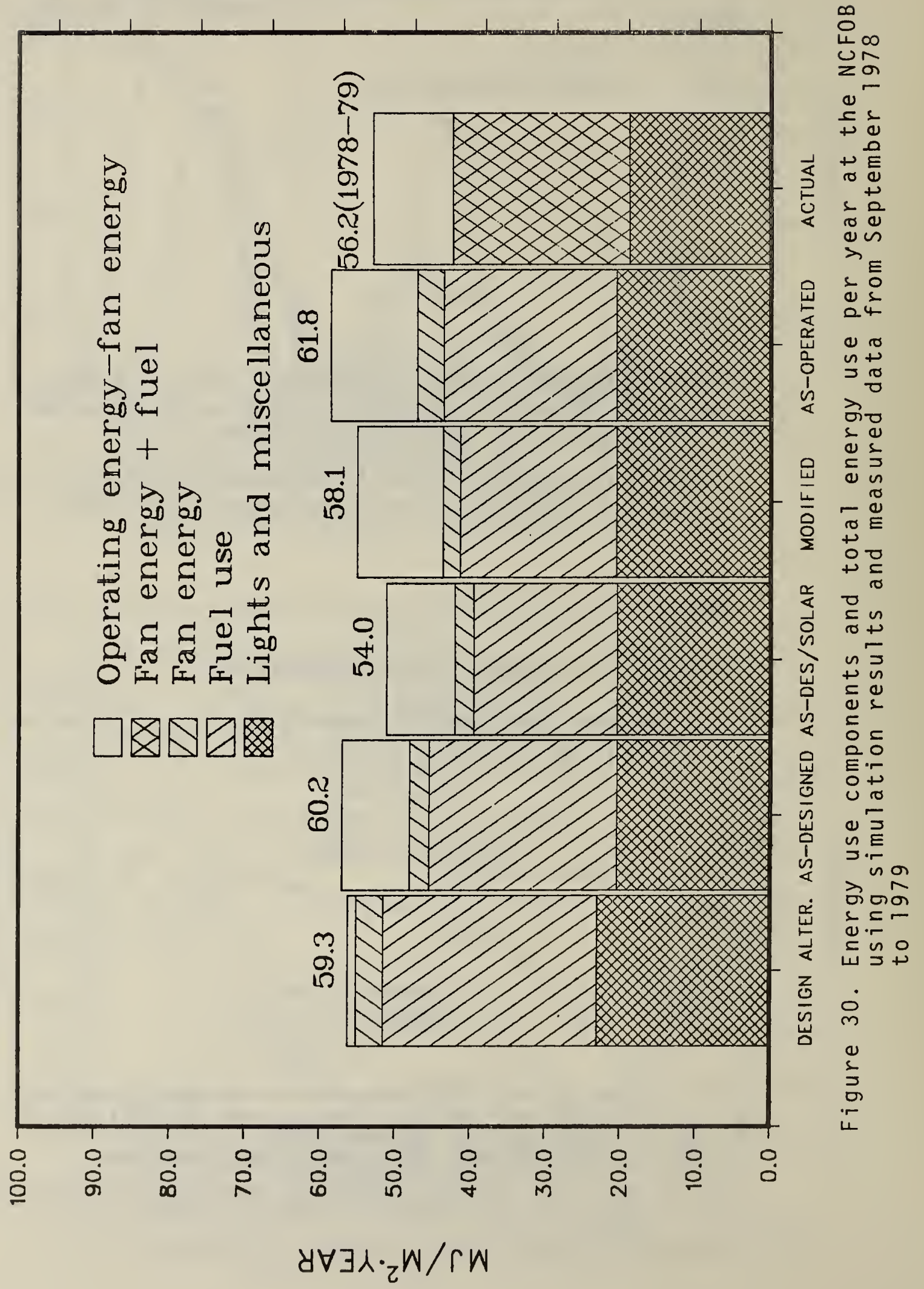


NBS. $114 A$ A $\{L-9-78\}$

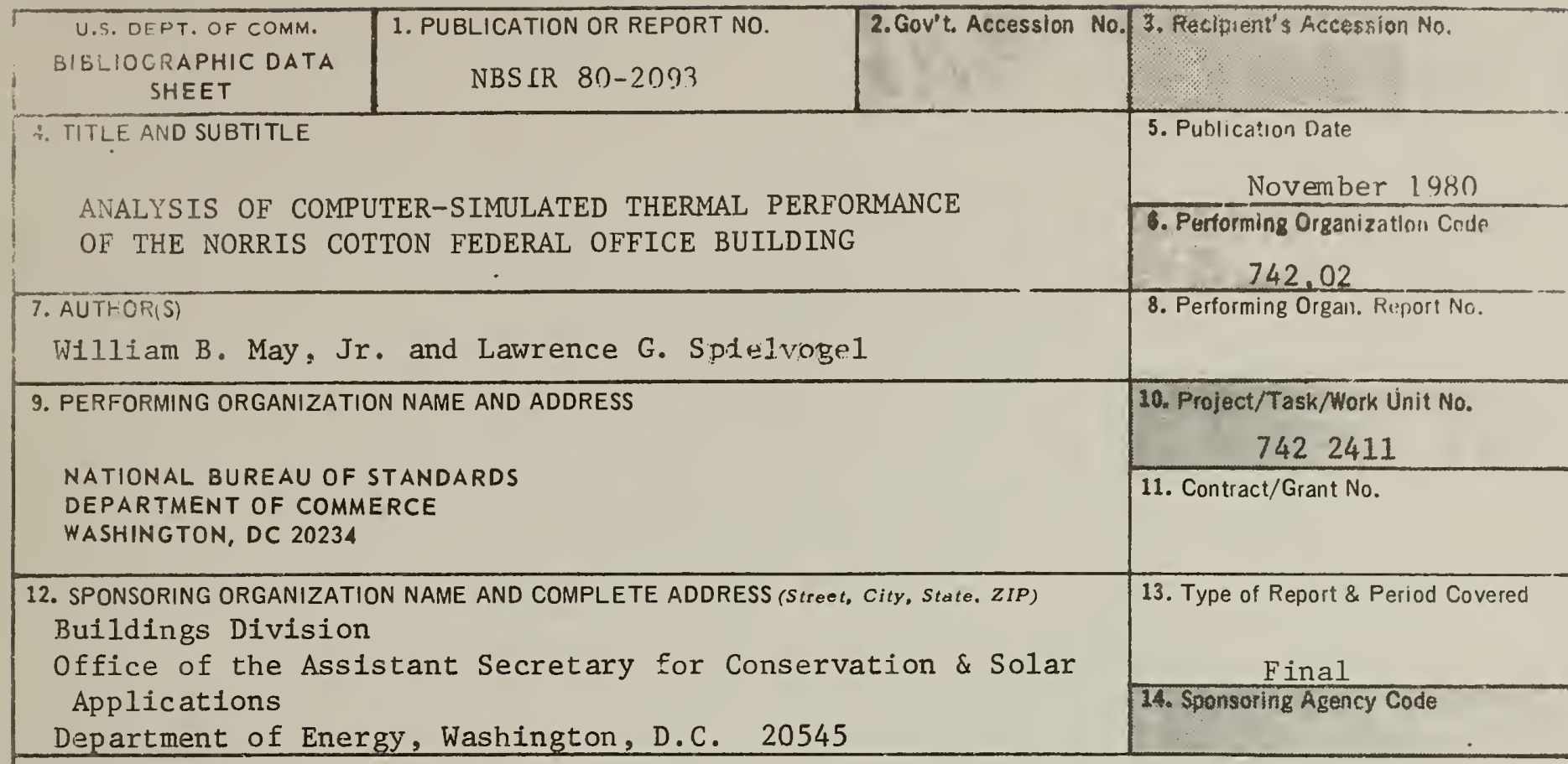

15. SUPPLEMENTARY NOTES

Document describes a computer program; SF-185, FIPS Software Summary, is attached.

16. ABSTRACT (A 200-word or less factual summary of most significant information. If document includes a significant bibliography or literature survey, mention it here.)

Five computer-based simulations of the Norris Cotton Federal Office Building (NCFOB) in Manchester, New Hampshire, were performed using the Ross Meriwether Energy Systems Analysis Program. The NCFOB is a medium-size office building, occupied in September, 1976, designed to serve as a demonstration of and feasibility test for energy-conserving building features. The simulations included two simulations in accordance with the original design--with and without a solar system; a simulation of the building as actually operated; a simulation of the building with modifications to actual operation; and a simulation of an alternative building design. Results of the five simulations are compared with each other and with actual measured data at several levels of detail, including total energy consumption, consumption by fuel type, and heating and cooling requirements. Good agreement between the simulation and actual data is demonstrated, and consequences of design features are discussed.

17. KEY WORDS (six to twelve entries; alphabotical ordor; capitalize only the first letter of the first key word unleos a proper nams; separated by semicolons)

Building models; building performance data; computer simulations, building; energy conservation in commercial buildings; heat pumps; validation of computer models, buildings

18. AVAILABILITY

For Official Distribution. Do iNot Release to NTIS

Order From Sup. of Doc., U.S. Government Printing Office, Wasinington, DC 20402, SD Stock No. SNO03-003-

X Order From National Technical Information Service (NTIS), Springfield, VA. 22161

\begin{tabular}{|l|c|}
\hline $\begin{array}{l}\text { 19. SECURITY CLASS } \\
\text { (THIS REPORT) }\end{array}$ & $\begin{array}{c}\text { 21. NO. OF } \\
\text { PRINTED PAGES } \\
\text { UNCLASSIFIED }\end{array}$ \\
\hline $\begin{array}{l}\text { 20. SECURITY CLASS } \\
\text { (THIS PAGE) }\end{array}$ & $\begin{array}{c}22 . \text { Price } \\
\text { UNCLASSIFIED }\end{array}$ \\
\hline
\end{tabular}



